THE RETAIL ABSORPTION OF SEARS AND TARGET'S FORMER STORE PORTFOLIO: EXAMINING THE SPATIAL CONSEQUENCES OF LONG-TERM VACANCIES IN SHOPPING CENTRES ACROSS CANADA

\author{
By \\ Jennifer Nhieu \\ Geographic Analysis, Ryerson University, 2018 \\ A major research paper presented \\ to Ryerson University \\ In partial fulfilment of the requirements \\ for the degree of Master of Spatial Analysis \\ in the program of Spatial Analysis
}

Toronto, Ontario, Canada, 2019

(C) Jennifer Nhieu, 2019 


\section{Author's Declaration for Electronic Submission of a Major Research Paper}

I hereby declare that I am the sole author of this MRP. This is a true copy of the MRP, including any required final revisions.

I authorize Ryerson University to lend this MRP to other institutions or individuals for the purpose of scholarly research.

I further authorize Ryerson University to reproduce this research paper by photocopying or by other means, in total or in part, at the request of other institutions or individuals for the purpose of scholarly research.

I understand that my MRP may be made electronically available to the public.

Jennifer Nhieu 


\title{
The Retail Absorption of Sears and Target's Former Store Portfolio: Examining the Spatial Consequences of Long-Term Vacancies in Shopping Centres across Canada
}

\author{
Jennifer Nhieu \\ Ryerson University \\ Master of Spatial Analysis \\ Spatial Analysis \\ Toronto, Ontario, Canada, 2019
}

\begin{abstract}
The study uses sociodemographic and shopping centre data to classify shopping centres across Canada with former Sears and Target properties by occupancy. This paper uses three methods: descriptive, statistical and spatial analysis to identify what endogenous and exogenous factors are strong or weak predictors of occupancy, as well as examine what spatial consequences are related to long-term vacancies in shopping centres. The results indicate population, income, the size of the shopping centre, the total estimated size of the site, and the configuration of the space to be important variables towards higher occupancy for shopping centres with former Sears and Target properties. Overall, the study was able to provide more groundwork for future studies on long-term vacancies in shopping centres.
\end{abstract}

Keywords: Sears, Target, Shopping Centres, Vacancy, Canada 


\section{Acknowledgements}

First, and foremost, I would like to express my most profound appreciation to Dr. Tony Hernandez, for his expertise, guidance, and patience throughout my academic career and the process of writing this paper. Without your help, this paper would not have been possible.

I would like to acknowledge my professors who have inspired and guided me throughout my academic career at Ryerson University. Thank you to Professor Stephan Swales, Dr. Shuguang Wang, Dr. Wayne Forsythe, Dr. Lu Wang and Dr. Joe Aversa.

I would also like to give a special thanks to all my parents and to my friends who supported me during this time. Thank you to my amazing friends Jody Chow, Saeed Shah, Selasi Dorkenoo, and Brian Truong. Their camaraderie and positivity were a significant contribution to what I have achieved in both my academic and professional career. 


\section{Table of Contents}

Author's Declaration ..............................................................................................................

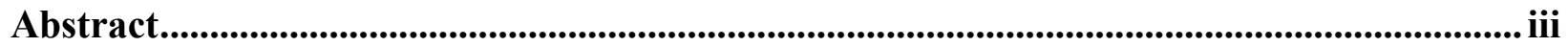

Acknowledgements ................................................................................................................................. iv

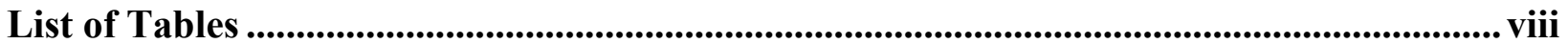

List of Figures............................................................................................................................................ ix

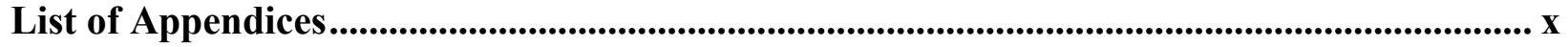

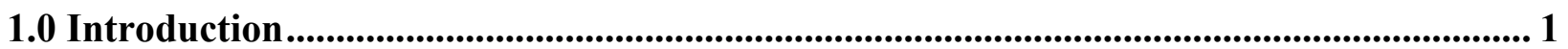

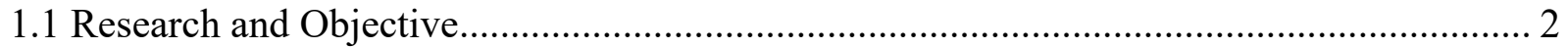

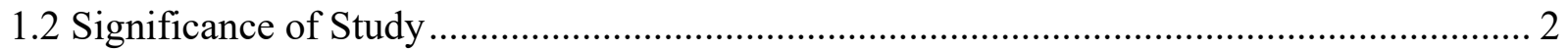

2.0 Theoretical Framework....................................................................................................... 2

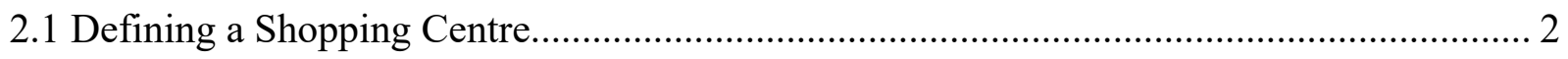

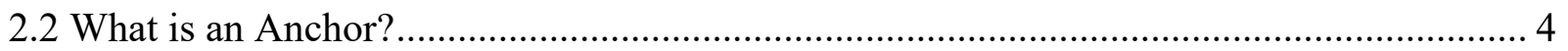

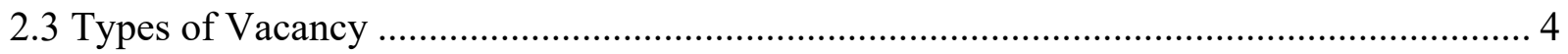

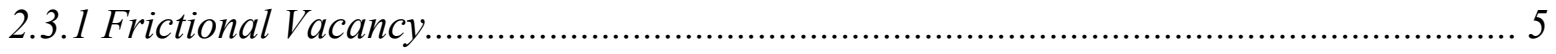

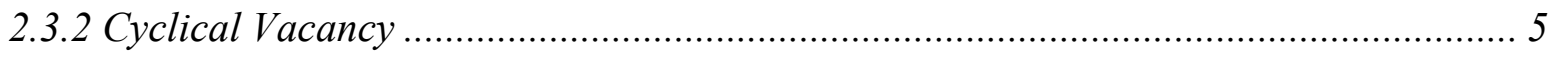

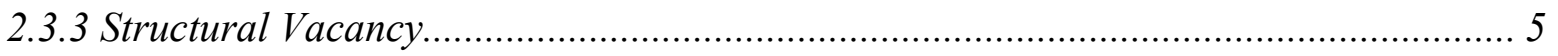

2.3.4 Vacant Stores and the Challenges Associated with Vacancy ...................................... 6

2.4 Retail Revolution in Shopping Centres........................................................................ 7

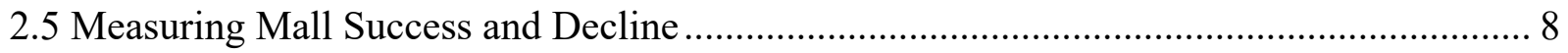

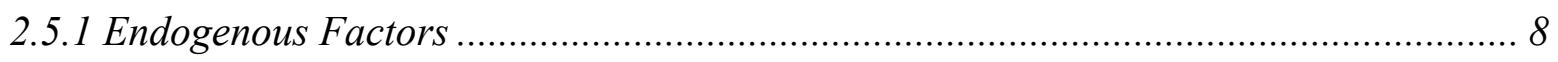

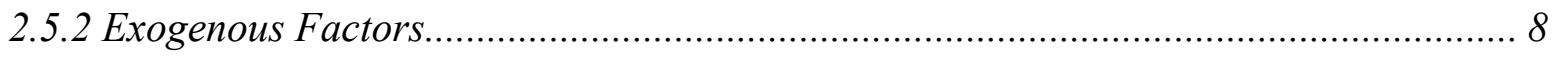

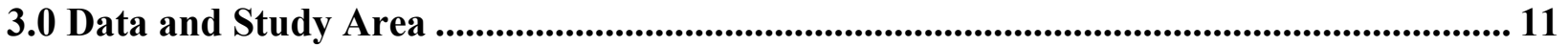

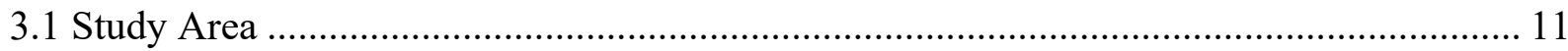

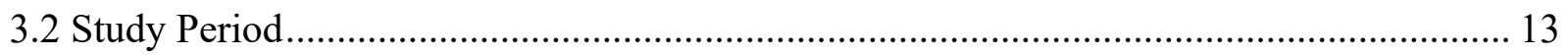

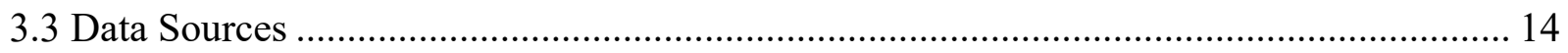

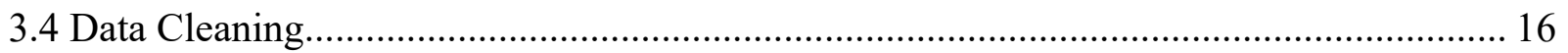

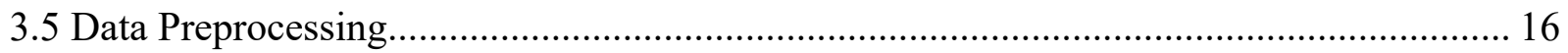

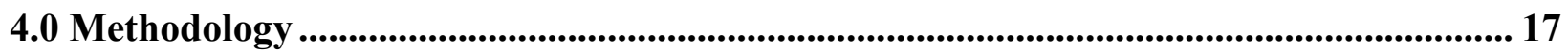

4.1 Measuring the Occupancy of Former Sears and Target Stores......................................... 17

4.1.1 Multicollinearity and Variable Standardization................................................... 17

4.2 The Status of Former Sears and Target Store Spaces in Shopping Centres ....................... 18

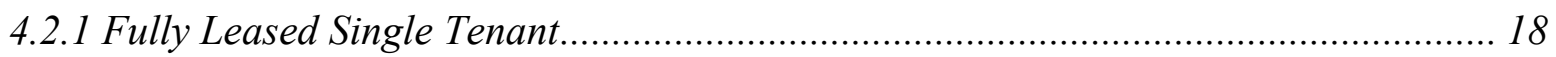

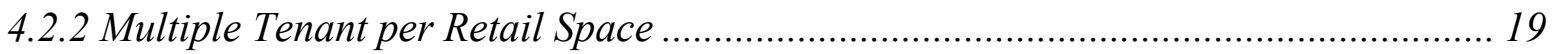

4.2.3 Vacant Sears and Target Stores in Shopping Centres ............................................. 20

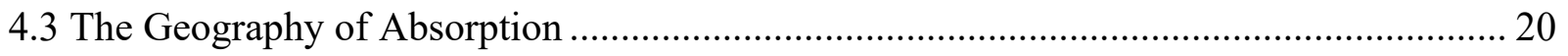

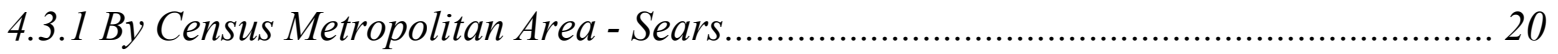

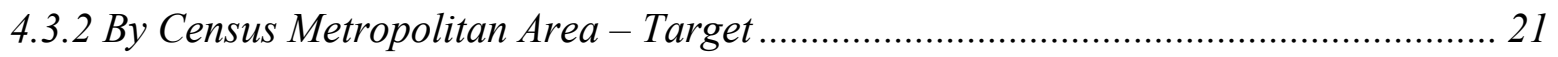




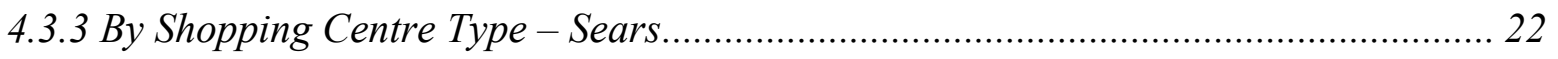

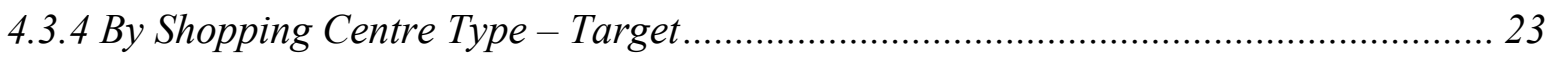

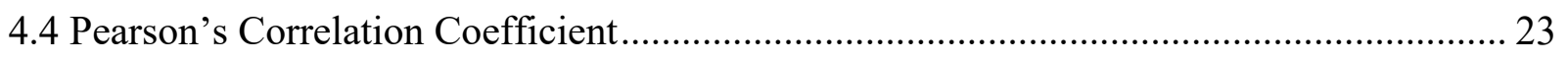

4.4.1 Pearson's Correlation Coefficient Sears Results - 15km Trade Area ……............... 24

4.4.2 Pearson's Correlation Coefficient Target Results - 15km Trade Area...................... 25

4.4.3 Pearson's Correlation Coefficient Results Discussion............................................ 25

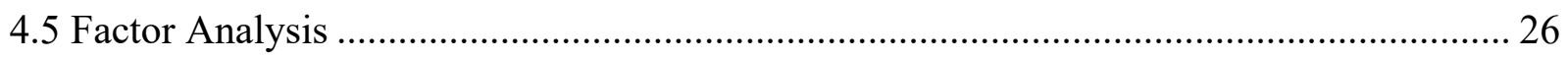

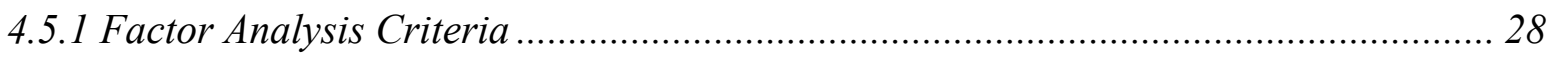

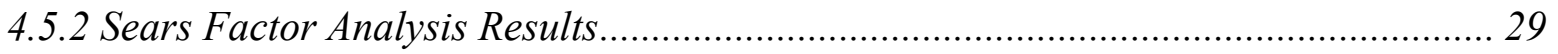

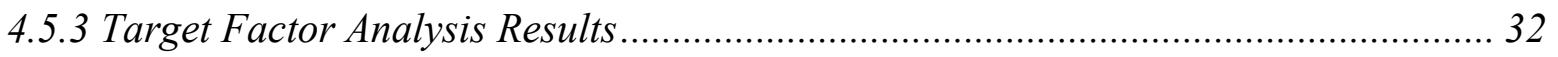

4.5.4 Factor Analysis Results - Sears and Target Comparison ....................................... 35

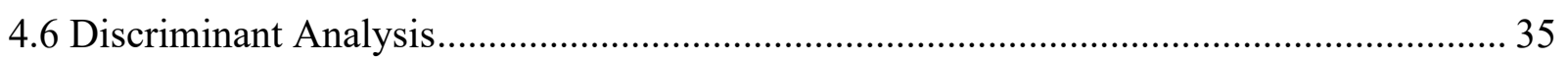

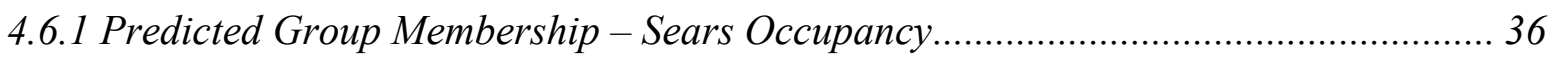

4.6.2 Test of Equality of Group Means - Sears Occupancy ............................................. 36

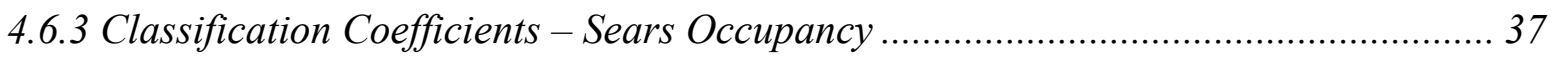

4.6.4 Predicted Group Membership - Target Occupancy ............................................. 37

4.6.5. Test of Equality of Group Means - Target Occupancy ............................................ 38

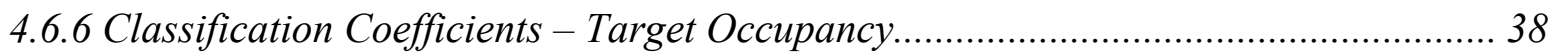

4.7 Discriminant Analysis Results Discussion ................................................................... 39

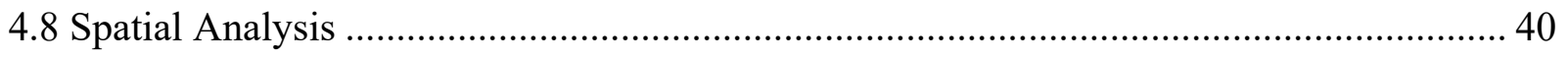

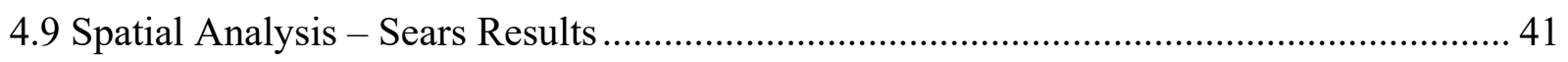

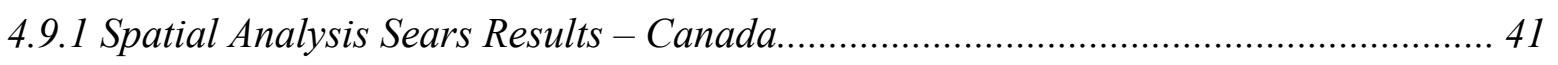

4.9.2 Spatial Analysis Sears Results - Vancouver, British Columbia ................................. 42

4.9.3 Spatial Analysis Sears Results - Edmonton, Alberta ................................................. 43

4.9.4 Spatial Analysis Sears Results - Calgary, Alberta ……......................................... 44

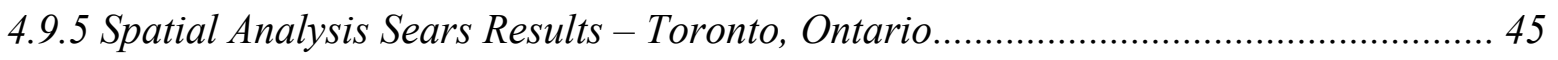

4.9.6 Spatial Analysis Sears Results - Ottawa, Ontario.................................................... 46

4.9.7 Spatial Analysis Sears Results - Montreal, Quebec ............................................... 47

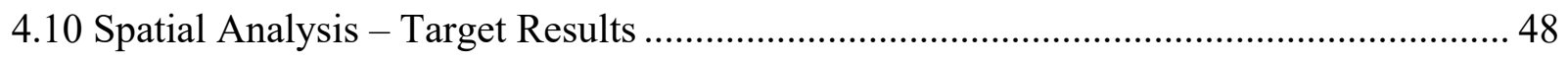

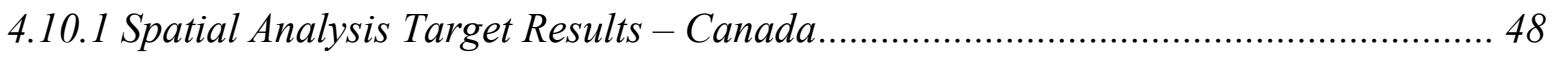

4.10.2 Spatial Analysis Target Results - Vancouver, British Columbia .............................. 49

4.10.3 Spatial Analysis Target Results - Edmonton, Alberta ........................................... 50

4.10.4 Spatial Analysis Target Results - Calgary, Alberta …………............................ 51

4.10.5 Spatial Analysis Target Results - Toronto, Ontario ............................................. 52

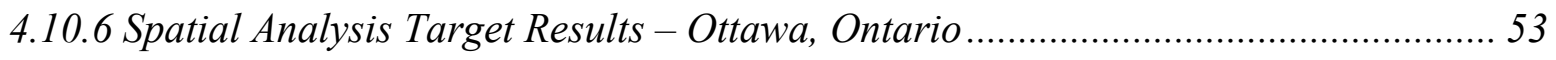

4.10.7 Spatial Analysis Target Results - Montreal, Quebec ............................................... 54

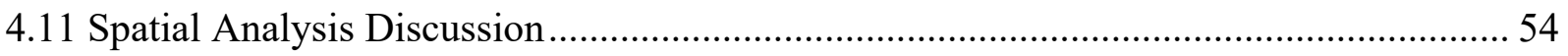




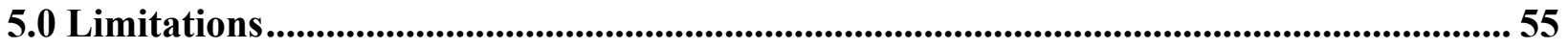

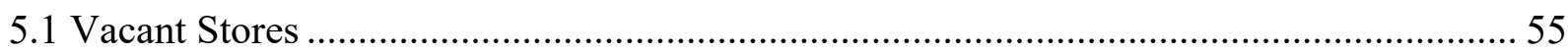

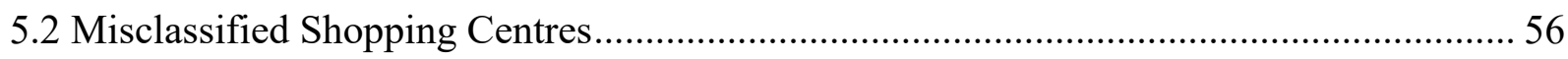

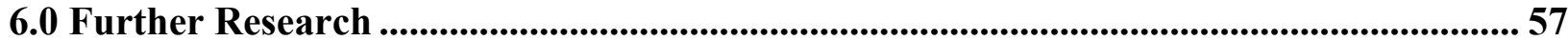

6.1 Exploratory Analysis of Additional Variables.............................................................. 57

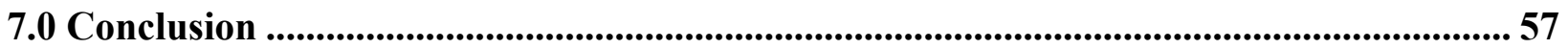

Appendix A: Descriptive Analysis Figures and Tables .........................................................60 60

Appendix B: Statistical Analysis Figures and Tables ....................................................66

Appendix C: Spatial Analysis Maps............................................................................................ 77

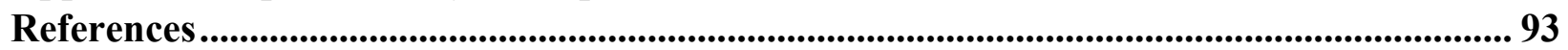




\section{List of Tables}

Table 1: Canada Shopping Centre Classification ................................................................ 3

Table 2: Traditional Enclosed Shopping Centre Classification .............................................. 3

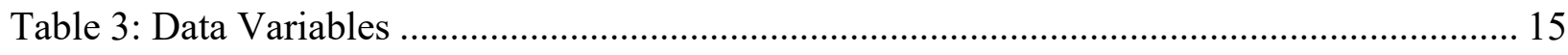

Table 4: Former Sears Store Space by Census Metropolitan Area.......................................... 21

Table 5: Former Target Store Space by Census Metropolitan Area ........................................ 22

Table 6: Former Sears Store Space by Shopping Centre Type.............................................. 22

Table 7: Former Target Store Space by Shopping Centre Type ............................................. 23

Table 8: Sear's Pearson's Correlation Coefficients ............................................................. 24

Table 9: Target's Pearson's Correlation Coefficients........................................................... 25

Table 10: Sear's KMO Statistics and Significance................................................................. 29

Table 11: Sear's Total Variance Explained ...................................................................... 30

Table 12: Sear's Rotated Component Matrix ....................................................................... 31

Table 13: Target's KMO Statistics and Significance ............................................................ 32

Table 14: Target's Total Variance Explained ................................................................. 33

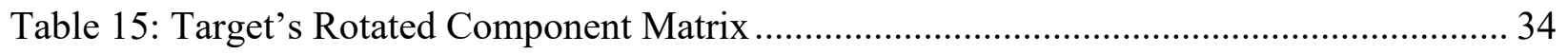

Table 16: Predicted Group Membership - Sears Occupancy ............................................... 36

Table 17: Significance and Discriminating Ability: Sears Occupancy ....................................... 36

Table 18: Standardized Canonical Discriminant Function Coefficients - Sears Occupancy ....... 37

Table 19: Predicted Group Membership - Target Occupancy ................................................ 38

Table 20: Significance and Discriminating Ability: Target Occupancy................................... 38

Table 21: Standardized Canonical Discriminant Function Coefficients - Target........................ 39

Table 22: Misclassified Shopping Centres ....................................................................... 56 


\section{List of Figures}

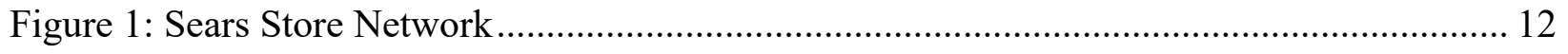

Figure 2: Target Store Network ......................................................................................... 13

Figure 3: Status of Former Sears and Target Stores .......................................................... 19

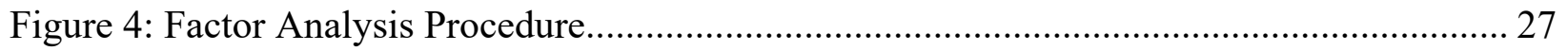

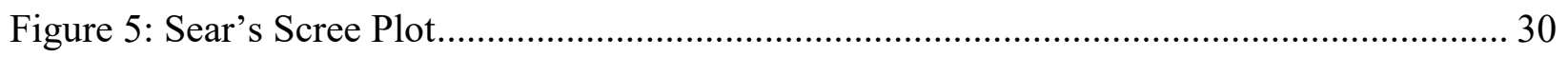

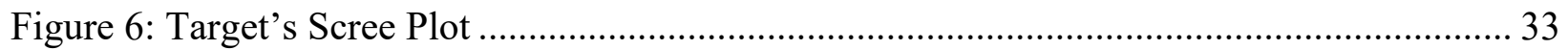

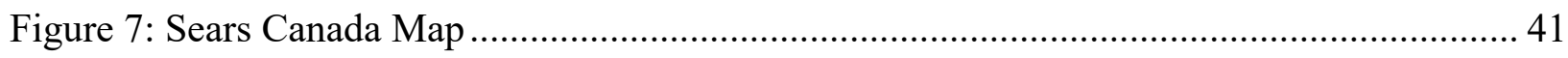

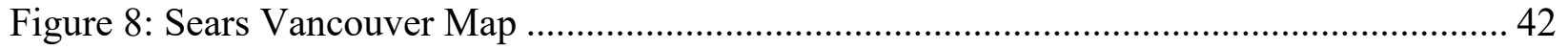

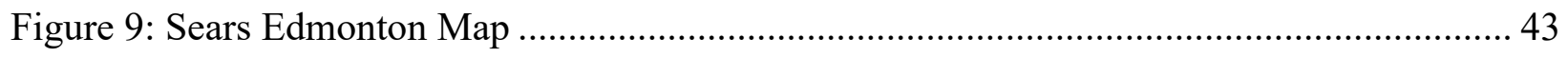

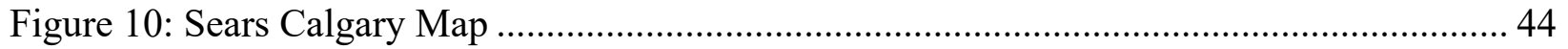

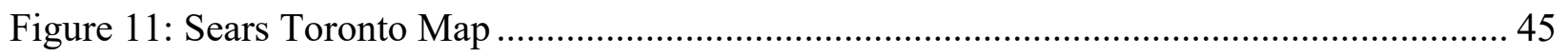

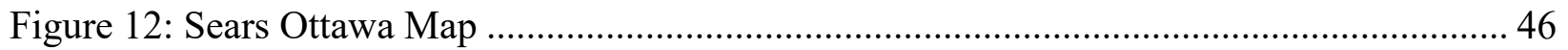

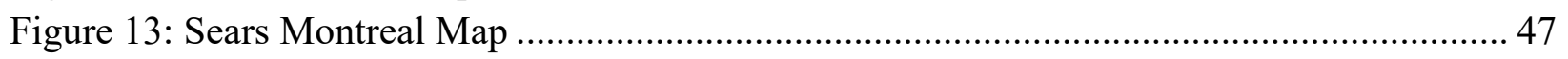

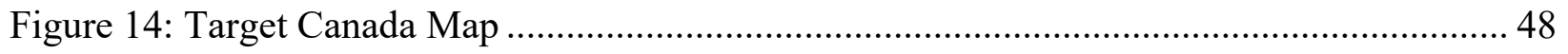

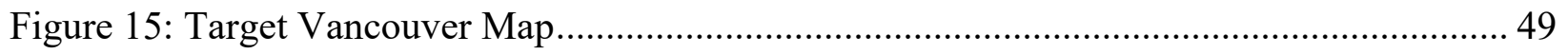

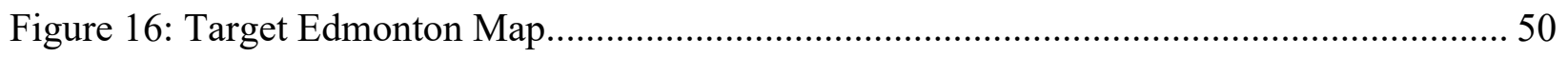

Figure 17: Target Calgary Map............................................................................................. 51

Figure 18: Target Toronto Map .............................................................................................. 52

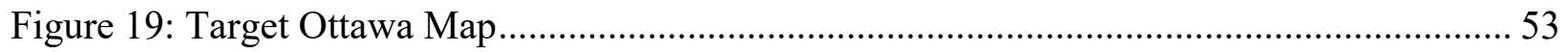

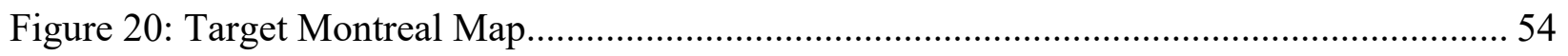




\section{List of Appendices}

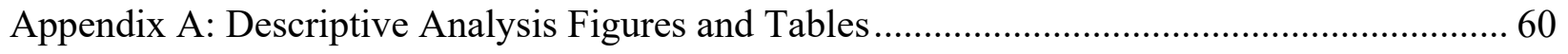

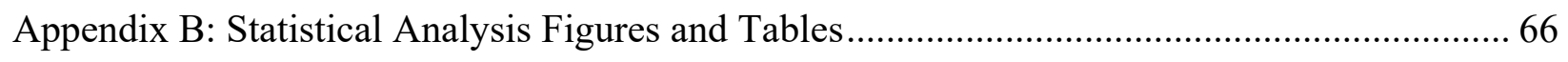

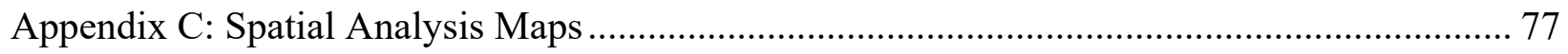




\subsection{Introduction}

The increase of retail company bankruptcies and store closures over the past few years are leading some to describe this phenomenon as the "retail apocalypse" (Peterson, 2017; Rushed, 2017; Kline, 2017). On January 15 th, 2015 , Target Canada Co., a subsidiary of Target Corporation and big-box retailer in the United States, announced their intention to close all 133 operating stores and abandon seven stores in development within two years of entering the Canadian marketplace (Evans, 2015; Emmons and Hernandez, 2017). Two years later, on January $14^{\text {th }}, 2018$, Sears Canada Inc., a subsidiary of the America-based department store chain closed all remaining stores in their 160 corporate store networks, including Sears, Sears Home, and Sears Outlet (Sears Canada Inc., 2016). In three years, Sears and Target contributed to the phenomenon when they closed all their operating stores leaving behind an estimated 35 million square feet of retail space in Canada (Sears Canada Inc. 2016; Emmons and Hernandez, 2017). Hundreds of shopping centres across the country lost either one or more anchor tenants as a result of these events.

In the United States, similar events have been occurring with Macy's, J.C Penney and Sears leaving behind an astounding 147 million square feet of retail space in 2017 (Heschmeyer, 2017). In recent years, large department stores have been responsible for hundreds of store closures across North America, predominately stores in shopping centres. These closures are drawing more media attention to topics such as the "death of shopping malls" in addition to the “retail apocalypse” (Corkery, 2017; Rushe, 2017; Sanburn, 2017). Despite retail property management companies continuing to report increasing net profits, increasing negative media attention has been placed on dead and dying malls (Retail Council of Canada, 2018). Some researchers claim these recent changes in retail trends are understudied, particularly at the store level (Tokosh, 2018). Since the 1960s, the main focus of study in Canadian retail geography literature has been on retail expansion, emerging shopping centre formats and foreign retailers (Tokosh, 2018). Existing research on this recent phenomenon are limited, and a concrete framework has yet to be developed for researchers to build on. However, due to rising interest in dead and dying malls, emerging shopping centre research is constructing theoretical themes that are used to predict a malls success or decline based on endogenous and exogenous variables related to the centre (Ferreira and Paiva, 2017; Tokosh, 2018). 


\subsection{Research and Objective}

This study will address this gap in the literature by examining the retail absorption process of Sears and Target. To better understand factors associated with the continued vacancies in the former spaces, as well as the spatial consequences of their closure. The following research questions will be investigated:

1. What endogenous and exogenous factors are strong or weak predictors of occupancy in shopping centres with former Sears and Target properties?

2. How do prolonged vacancies caused by former Sears and Target stores impact the shopping centre?

The objective of the study is to develop theories about associated factors and conduct an exploratory analysis of the spatial consequences of long-term vacancies in shopping centres. The statistical and spatial analysis will observe what has taken place to date, based on publicly available information from 2015 to 2019 . The absorption of Sears and Target is an on-going process with leasing and investment negotiations and redevelopment plans.

\subsection{Significance of Study}

Since 2018 , several successful leasing stories by various property management companies such as Cadillac Fairview, RioCan, and Cushman and Wakefield have been documented, however, as time progresses the window of frictional vacancy steadily closes and the likelihood of cyclical or structural vacancies increases. Therefore, identifying factors that are strong predictors of high occupancy is beneficial to the retail real estate industry. The information may be used to identify store locations in markets that are more susceptible to longterm vacancies and analyze their situation.

\subsection{Theoretical Framework}

\subsection{Defining a Shopping Centre}

The Canadian shopping centre landscape is continually evolving to reflect the trends within the retail industry. Over time, the shopping centre has established itself as part of a major 
structure in the North American retail landscape and have performed important functions as a result (Kowinski, 1985; Cohen, 2002; Lambert, 2008). In the last 50 years, many shopping centres formats have emerged. Therefore, defining the term "shopping centre" will provide conceptual clarity amongst the various types examined in this study. The International Council of Shopping Centers (ICSC) defines shopping centres as " a retail property that is planned, built, owned and managed as a single entity comprising commercial rental units (CRUs) and common area” (International Council of Shopping Centers, 2010). These shopping centres can be grouped into four categories (Table 1):

Table 1: Canada Shopping Centre Classification

\begin{tabular}{|l|l|l|l|l|}
\hline Type & Categories & GLA Range (Sq. Ft) & Description & Trade Area Size \\
\hline Traditional & Enclosed & $10,000-800,000+$ & Flanked by anchors & $<5 \mathrm{~km}$ to $30 \mathrm{~km}$ \\
\hline Traditional & Unenclosed & $10,000-800,000+$ & Open-air (e.g., Power Centres) & $<5 \mathrm{~km}$ to $30 \mathrm{~km}$ \\
\hline Specialty & Power Centre / Outlet & $50,000-1,000,000$ & Power Centre or Outlet & 8 to $50 \mathrm{~km}$ \\
\hline Hybrid & Hybrids & $250,000+$ & A mix of traditional and specialty & NA \\
\hline Retail Mixed-Use & Mixed-Use & $50,000+$ & Multi-component structure & NA \\
\hline
\end{tabular}

Source: Pitt and Musa, 2009; Yeates, Hernandez, and Murray, 2015

The ICSC (2017) provides a breakdown of Canada's shopping centre classification based on a variety of typical characteristics, such as concept, gross leasable area, and the number of anchors, the trade area size, and many other characteristics (Table 2).

Table 2: Traditional Enclosed Shopping Centre Classification

\begin{tabular}{|l|l|l|l|l|}
\hline Type & Categories & GLA Range (Sq. Ft) & Description & Trade Area Size \\
\hline Traditional & Super-regional & $800,000+$ & Flanked by at least 3 anchors & $10 \mathrm{~km}$ to $30 \mathrm{~km}$ \\
\hline Traditional & Regional & $300,000-799,999$ & Flanked by at least 2 anchors & $8 \mathrm{~km}$ to $20 \mathrm{~km}$ \\
\hline Traditional & Community & $100,000-400,000$ & Flanked by at least 1 anchor & $<10 \mathrm{~km}$ \\
\hline Traditional & Neighbourhood & $40,000-99,000$ & Flanked by supermarket & $<5 \mathrm{~km}$ \\
\hline Traditional & Convenience & $10,000-39,000$ & Convenience store & NA \\
\hline
\end{tabular}

Source: International Council of Shopping Centers, 2017

It is important to note, traditional format shopping centres are typically flanked by at least one anchor. These anchor(s) perform many roles in the shopping centre and many scholars argue their presence is vital to the success of a shopping centre (Konishi and Sandfort, 2003; Mejia and Eppli, 2003; Smith and Hay, 2005). 


\subsection{What is an Anchor?}

Traditional enclosed shopping centres are planned to have an inward orientation of retail stores connected by common walkways and are typically flanked by anchor stores on one or both sides with entrances leading to surrounding parking infrastructure or off-street surface parking outside the centre's perimeter (International Council of Shopping Centers, 2017). In the early to mid-1950s, Victor Grünbaum, an architect, developed the planned shopping centre format for the consumers to be able to make multi-purpose trips by clustering retail stores. This design assists in minimizing consumer travel costs as measured in distance and time (Konishi and Sandfort, 2003; Hardwick, 2004; Yaetes, Hernandez and Murray, 2015). The purpose of anchor stores is to increase consumer traffic to and within the shopping centre location (Konishi and Sandfort, 2003; Mejia and Eppli, 2003; Hardwick, 2004; Smith and Hay, 2005). In traditional shopping centres, these anchor stores are typically department stores, such as Sears or Hudson's Bay or big box general merchandisers, such as Wal-Mart or Target. Department stores and big-box general merchandiser sell goods in many different product categories, that encourages consumers to visit them (Konishi and Sandfort, 2003; Yaetes, Hernandez and Murray, 2015).

Furthermore, as anchor stores typically sell standard commodities (riskless, low-value goods), this allows the stores to offset markups from competition at the mall (Konishi and Sandfort, 2003). However, the departure of Target and Sears and the string of anchor tenant vacancies they have left behind, opens the question as to whether the need for large anchors may start to become a fixture of the past? Currently, many shopping centres have redeveloped the space into multiple units featuring new retail experiences or mixed-use developments, while many are still in different stages of vacancy.

\subsection{Types of Vacancy}

To analyze the challenges involved in turning a vacant space back to productive use, defining the term 'vacancy' provides a conceptual clarity among the types of vacancies experienced by the market. Rabianski (2002) categorizes vacancy into three main types: frictional, cyclical, and structural. 


\subsubsection{Frictional Vacancy}

Frictional vacancy is inherent to a well-functioning real estate market, and therefore, not a concern to shopping centre owners or landlords (Parli and Miller, 2017; Emmons and Hernandez, 2017). This type of vacancy involves having an excess supply of retail space that allows the market to work efficiently and facilities the ease of movement from one space to another. For example, a shopping centre may secure another retailer to occupy a former space; however, the tenant may not be able to open immediately or for several months. From the consumer perspective, this space would be considered vacant but not from the shopping centre perspective. Frictional vacancy is also a form of transitional vacancy, where there is a commitment to secure another tenant for the space at a later point in time. As such, this type of vacancy is an intrinsic part of the transition from one tenant to the next (Parli and Miller, 2017; Emmons and Hernandez, 2017).

\subsubsection{Cyclical Vacancy}

Cyclical vacancy occurs when demand for space declines as a result of a weakening economy and other financial factors in the area. Furthermore, as demand for space increases, cyclically vacant spaces will be gradually taken from the market (Rabianski, 2002; Emmons and Hernandez, 2017). Cyclical vacancy is problematic from a shopping centre perspective as the centre is reliant on economic recovery for the region surrounding the centre. This example suggests that the vacancy rate is correlated with economic growth, as an economic recovery would reduce vacancy over time (Emmons and Hernandez, 2017).

\subsubsection{Structural Vacancy}

Structural vacancy is the most problematic and challenging to owners and landlords (Emmons and Hernandez, 2017). It is space that is not in demand or appealing to potential tenants in its current configuration. The space may be too large to be reasonably used or requires redevelopment or reconfiguration (Remøy, 2010; Emmons and Hernandez, 2017). Sears and Target stores average 100,000 square feet per store, and very few retail chains in Canada can absorb and use this space productively. Also, some of these spaces were two levels, which posses' additional operational challenges (Emmons and Hernandez, 2017). Some of the former 
spaces were converted into residential units or redevelopment into multiple smaller retail units. This study will examine formers Sears and Target stores that have been redeveloped, renovated, re-sized or demolished to bring them back into productive retail or other uses.

\subsubsection{Vacant Stores and the Challenges Associated with Vacancy}

Sears and Target have several stores which are still totally vacant. Sears has 95 vacant stores $(65 \%)$ of 147 total stores in shopping centres at time of closure, while Target has 20 vacant stores (14\%) of 138 stores in shopping centres. It is important to note that, Sears is a year post-closure, while Target is four years post-closure. Therefore, shopping centres had more time to bring their former Target properties back into productive use. Some of these former stores are awaiting lease negotiations to finish and for the new retailer to move in. Moreover, some spaces are in the process of being reduced or reconfigured into multiple units, while some may likely sit empty until the opportunity to secure a new tenant arises.

From a research perspective, the classification of former Sears and Target spaces into these vacancy categories is challenging and often misleading due to assumptions made based on publicly available information. For example, according to Emmons and Hernandez (2017), the assumption that most of the former Sears and Target spaces not purchased during the real estate auction can be thought as a form of structural vacancy is misleading. The absorption of an estimated 35 million square feet is an extremely complex process. Factors such as existing lease obligations, legal restrictions, store development commitments, as well as the configuration, age, location and quality of the space create challenges in bringing the space back into productive use again (Emmons and Hernandez, 2017). Some shopping centres were proactive in the wake of Sears and Target's exit by quickly reconfiguring the original space into multiple tenant spaces. This reconfiguration can be classified as either a frictional or cyclical vacancy depending on market conditions, as the space was repurposed into a space which was desirable to new tenants. While some of the stores may appear to be structurally vacant is it unjust to make this assumption due to the lack of publicly available information on behind closed doors discussions. Therefore, this paper will only be able to provide partial insight into the absorption process and how the space is currently or may be used in the future. 


\subsection{Retail Revolution in Shopping Centres}

Canada's retail landscape is a product of complex structural changes because of logistical and technological innovations (Bonacich and Wilson, 2005; Hernandez, Helik, and Moore, 2006). Technological and logistical innovation was responsible for establishing major retail chains, such as Sears and Target. This change facilitated their rapid rise to dominance in retail landscapes across the globe (Aoyama and Ratick, 2017). The ability to offer competitive pricing while minimizing the costs associated with the middleman transformed the nature of retail competition from quality to quantity and affordability. For this reason, anchor store presence was highly desirable and was arguably necessary for the traditional shopping centres to generate traffic and sales to and within the centre (Miceli, Sirmans, and Stake, 1998; Fong, 2003). The loss of an anchor store can result in a decrease in the shopping centre's market size and reduce profit margins to the specialized retailers collocating with the anchor store (Konishi and Sandfort, 2003).

Scholars have theorized that the creation of entertainment experiences will play a significant role in providing shopping centres with a competitive advantage (Wilhelm and Mottner, 2005; Backstrom, 2006). Retail atmosphere research state the success of shopping centres was primarily dependent on having an entertaining experience that can offer the consumer sensory stimulation (smell, colours, music, etc.). However, recently, shopping centres have transitioned to technological and digital solutions to enhance the quality of shopping experiences. In Canada, shopping centres are increasingly integrating these solutions, specifically in the former Sears and Target spaces. For example, Square One, a super-regional shopping centre located in Mississauga, Ontario, lost both Sears and Target anchors. With over 200,000 square feet of retail space to fill, the owners decided to look towards more modern and innovated approaches of enhancing the shopping experience with the creation of their Food District and the addition of The Rec Room (Oxford Properties, 2019a; Oxford Properties, 2019b). These new additions provide consumers with interactive entertainment space and allnew dining experience with specialty food retailers. Both designed to increase the probability of attracting new patrons to the shopping centre. Other shopping centres have made similar changes to their former Sears and Target spaces. As such, it is important to discuss the factors that contribute to a shopping centre's success or decline. 


\subsection{Measuring Mall Success and Decline}

\subsubsection{Endogenous Factors}

Endogenous factors relate to the interior features of the shopping centre's structure and composition. The appeal of a shopping centre is built from the preferences of consumers (Drezner, 2006). As such, a shopping centre's ability to provide these consumer preferences to make the mall more appealing to the consumers is critical for success. For example, a robust retail mix is essential, as a diversity of merchandise can increase sales and customer traffic to the shopping centre. Multiple studies have demonstrated that multi-purpose or one-stop-shopping was the most crucial element to a shopping centre's success as economizing on time is a top priority for consumers; therefore, a robust retail mix is required (Reimers and Clulow, 2009; Yeates, Hernandez and Murray, 2015).

Additionally, renovations are necessary to stay competitive (Lowry, 1997; LeHew and Fairhurst, 2000; Tokosh, 2018). Renovations are necessary for the success of a shopping centre as it prolongs the lifespan of the centre. Lowry (1997) states that shopping centres have differing lifespans before renovation or redevelopment are required based on its mall hierarchy. For example, Lowry suggests a super-regional or regional shopping centre has a 30-year lifespan before renovations are needed (Lowry, 1997). However, recent studies demonstrate with the pace of retail innovation, and that lifespan is shortening to around 15-years (Chebat et al., 2014). Research efforts have been focused on investigating the impacts of the shortening of the retail life cycle to delay or bypass the decline phase. Renovations have been identified as an essential factor in improving a declining shopping centre situation (Bayus, 1994; Turley and Chebat, 2002). It has been theorized that shopping centres may not have use for larger tenants anymore. Recent retail trends are seeing a decrease in average retail square footage and the emergence of “mini department stores” such as Winners, Marshalls and Simons.

\subsubsection{Exogenous Factors}

A shopping centre's performance is also dependent on exogenous factors which exist outside of the shopping centre. Extensive retail location analysis has shown the importance of 
variables such as market size and household income to the success of a retailer. In the mid to late 1960s, notable researcher William Applebaum investigated locations for sales potential and predicted a business' likelihood to succeed long-term at given locations (Applebaum and Cohen, 1961; Applebaum, 1966). David Huff (1963) also developed a model that predicts customer flows to at a given site based on the customer's distance to that site, the store's attractiveness, and the distance and attractiveness of competing sites (ESRI, 2019). The applicability of the Huff model has continued to remain relevant in retail location analysis (Dramowicz, 2005; Miller 2008; Cui et al., 2012). Moving forward, advances in technology have enabled researchers to merge established theories in retail geography with the application of location analytics models (Ghosh and McLafferty, 1987).

Neighbourhood socioeconomics is also essential in retail location analysis as consumer demographics represent retail demand. To stay competitive, a shopping centre must alter or change its endogenous factors, as well as focus marketing efforts to target consumers within their trade area. To proceed with these changes, a market area analysis using demographic data is required. Furthermore, as a mall cannot move from its physical location, it must bear the consequences of any changes in the surrounding marketplace. For example, if the economic region surrounding the mall weakens, the shopping centre may experience a decrease in consumer traffic or high vacancy rates in the centre until the economy can recover. These consequences add to the pressures a shopping centre face (Tokosh, 2018).

With demographic shifts, changing consumer preferences, technological advances and other factors, traditional shopping centres formats are faced with more difficulties and competition now than they did in the past. The demographic shift towards a younger, tech-savvy and price-conscious consumer valuing a memorable retail experience forces traditional shopping centres to engage their shoppers differently. The introduction of new retail formats also offers a broad range of affordable products that are accessible through multiple distribution channels. This trend is changing the consumer's attitude towards technology, enhances consumer convenience and interaction, as well as increasing the business's visibility and reach to more potential consumers. With these changes, a heightened level of coordination between developers, leasing, retailers, and other associated parties will be needed to make the necessary changes in creating an attractive environment for these emerging consumers. 
Studies in retail geography have typically focused on retail expansion, particularly new stores entering the market. Existing mall research on long-term vacancies in shopping centres is also limited and has yet to develop a concrete framework for researchers to build upon, particularly at the store level. However, due to rising interest in dead and dying malls, emerging shopping centre research is beginning to construct theoretical themes that are used to predict a malls success or decline based on its sales and occupancy (Ferreira and Paiva, 2017; Tokosh, 2018). Also, some researchers were able to identify factors associated with a shopping centre's success and decline based on its sales and occupancy. However, there is a lack of research integrating spatial techniques into their statistical analysis, as well as examining the spatial consequences of the continued vacancies caused by department store closures in shopping centres.

In a recent study (2018) examining dying malls in the United States both factor and discriminant analysis was used to identify strong predictors of occupancy using endogenous and exogenous variables related to the mall (Tokosh, 2018). Specifically, Tokosh's study used an extensive retail database to classify American malls by occupancy and sales. The database provided 26 variables for 840 shopping centres across America. Some endogenous variables included leasable space, number of stores, store levels, date of the last renovation, while some exogenous variables included market area population, average household income, and mean age. He recognized that his shopping centre data did not cover all factors that contribute to a shopping centre's success or decline.

Furthermore, the researcher failed to account for multicollinearity. Multicollinearity occurs when there are "high correlations between two or more predictor variables" (Minitab Inc., 2013). In the study, all demographic variables (e.g., total population, average household income, number of households, and mean age) for three market sizes (e.g., 5, 10- and 20-mile radius) were used in the same analysis. When redundant information is present, the results in the analysis may be skewed. Additionally, the results indicated a lot of noise in the data due to the high Wilk's Lambda score. However, the canonical correlation value was under 0.6, indicating good to moderate group separation. 


\subsection{Data and Study Area}

\subsection{Study Area}

Planned shopping centres typically have one or more anchor store. Anchors are often categorized into a hierarchy based on the quality of the goods they sell (Shanmugam, 2013). These categories include upscale (e.g., Nordstrom and Holt Renfrew), mid-tier (e.g., Hudson's Bay), low-tier or discount anchors (e.g., Sears and Target) and more recently, non-anchors (e.g., Shoppers Drug Mart). As previously mentioned, the purpose of anchor stores is to increase consumer traffic to and within the shopping centre location. Therefore, it became a goal for developers in the early to mid-1950s to design malls to incorporate them. Furthermore, the larger the shopping centre, the more anchors the centre could hold. For example, super-regional centres usually have at least three anchor stores, and these mall formats are mostly located in largely populated areas such as census metropolitan areas.

Historically, when Sears entered the Canadian marketplace, they were barred from locating 25-miles from urban markets such as Toronto, Montreal, Halifax, Regina, and London by Simpsons until the 1970s, which hindered its initial expansion into the shopping centre format and into the Canadian marketplace. However, a few years before their merger, this 25 -mile restriction was lifted, allowing Sears to open their first store in Mississauga, Ontario. While the majority of Sears stores are located in urban markets, their presence in more suburban and exurban markets was due to this restriction (Figure 1). Between 2015 to 2016, Sears closed 13 stores before declaring bankruptcy. After their announcement, Sears closed an additional 57 stores in 2017 and 90 by the end of 2018. 


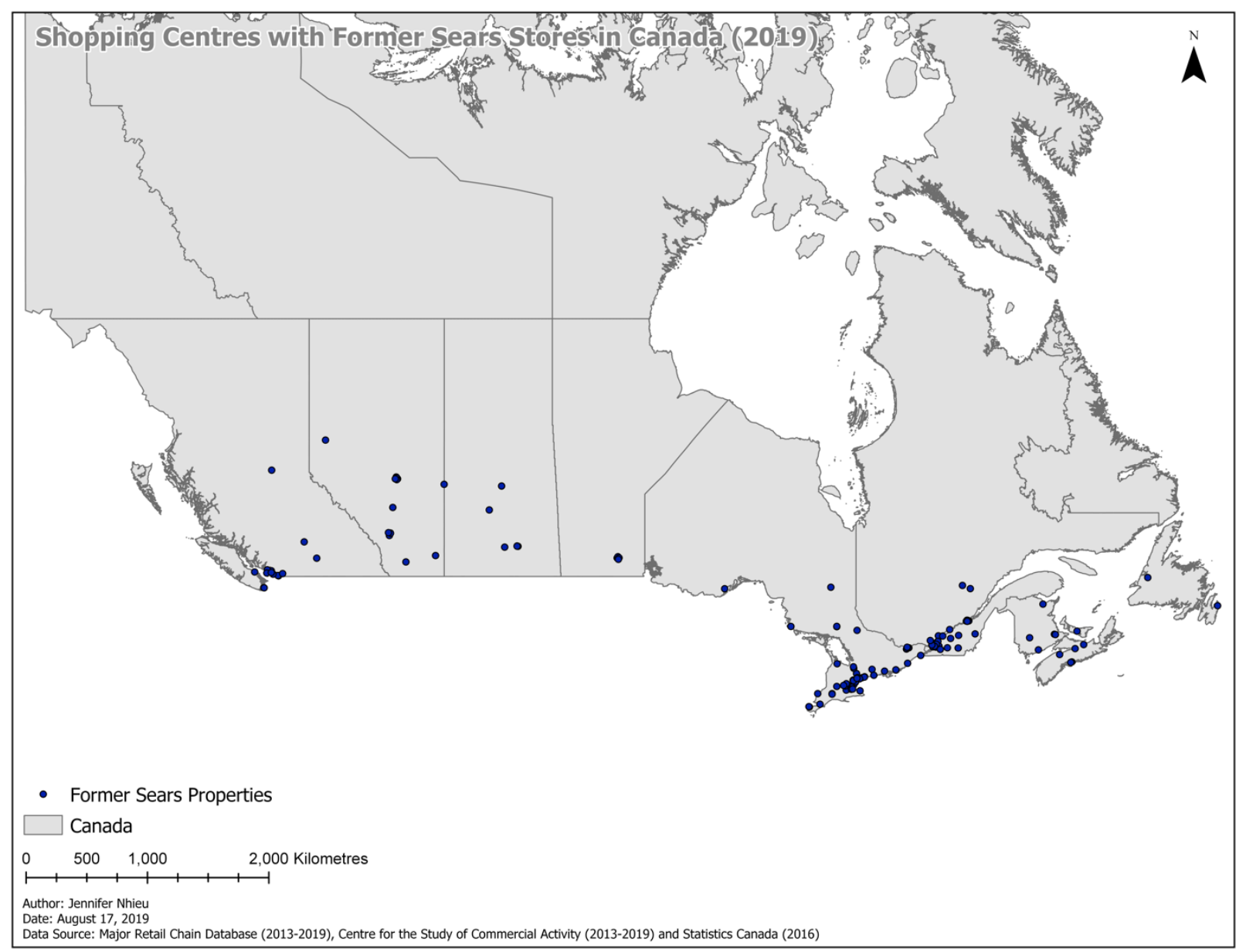

Figure 1: Sears Store Network

Source: Major Retail Chain Database (2013-2019), Centre for the Study of Commercial Activity (2019) and Statistics Canada (2016)

When Target entered into the Canadian marketplace through the acquisition of Zellers, a low-tier discount department store owned by the Hudson's Bay Company in 2011, Target acquired the leasehold of 220 stores and ended up selecting 189 stores of the stores (Emmons and Hernandez, 2017). Of the 189 stores, they opened 133 stores in less than two years totalling 14.25 million sq. ft. (Emmons and Hernandez, 2017). Their store portfolio spanned across Canada, with the first wave of stores opening in Ontario where they are primarily located, followed by Western and Central Canada and last few in Eastern Canada (Figure 2). 


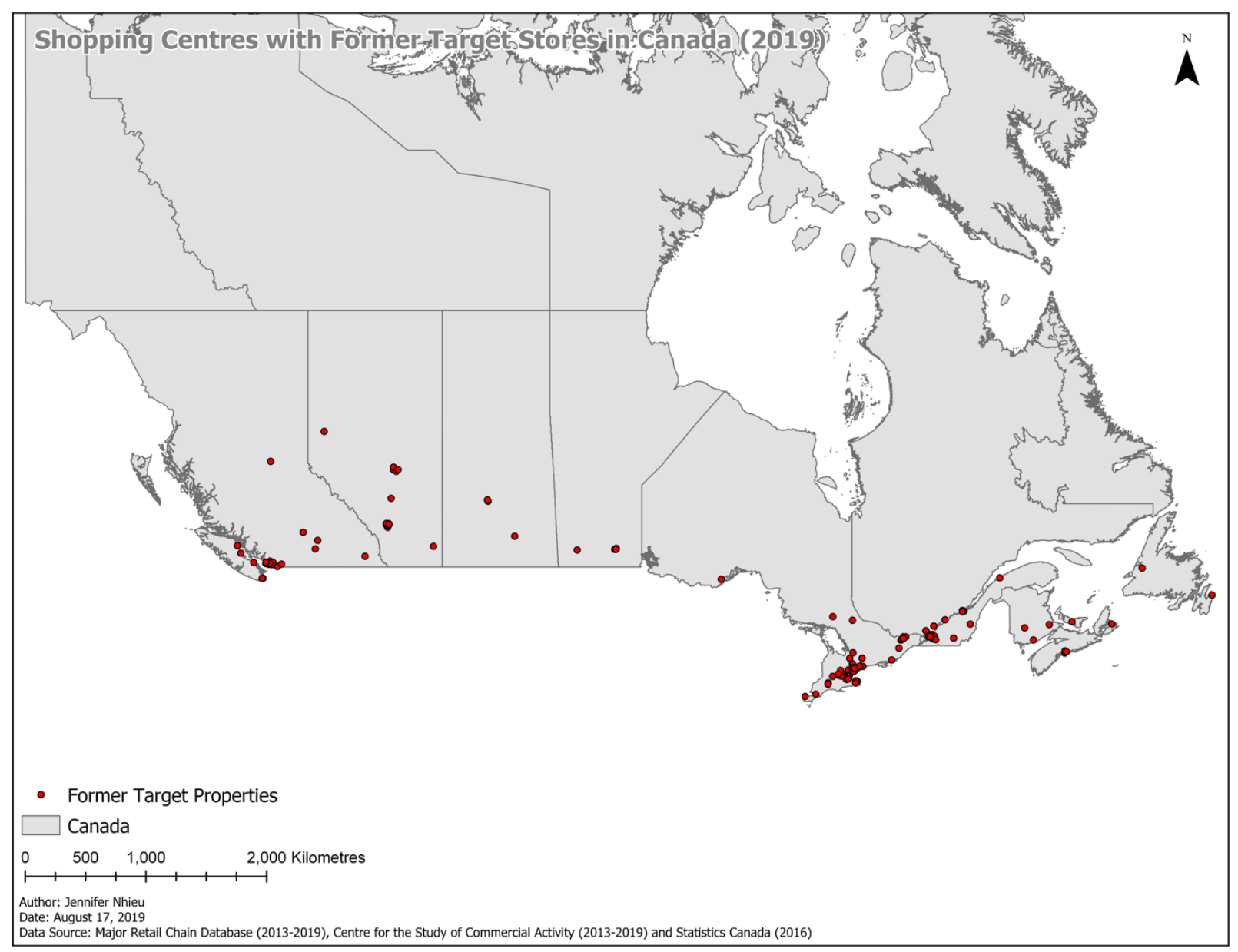

Figure 2: Target Store Network

Source: Major Retail Chain Database (2013-2019), Centre for the Study of Commercial Activity, (2019) and Statistics Canada, (2016)

To analyze the consequences of long-term vacancies of former Sears and Target spaces in Canadian shopping centres, the shopping centres were divided into three urbanity zones: urban, suburban, and exurban. Furthermore, dissemination area level data was the most appropriate geographic unit to examine the shopping centre's surrounding trade area. It provides the smallest unit on which demographic information can be obtained outside census metropolitan areas.

\subsection{Study Period}

Assessing the impacts of vacancy on shopping centres requires specialized data which consistently monitors the shopping centre and the space Sears and Target formerly occupied. This study examines the changes from when the retailer last occupied a shopping centre space to 
present day. For Sears, this time frame would be from 2015 to 2019, and 2013 to 2019 for Target.

\subsection{Data Sources}

To generate theories about the associated factors concerning store occupancy and analyze the spatial consequences of long-term vacancies in former Sears and Target stores, data from multiple sources is required. The Centre for the Study of Commercial Activity (CSCA) at Ryerson University has continued to monitor and produce research insights on Sears and Target's retail absorption progress since their closures. The CSCA has produced a report titled The Absorption of Target's Former Store Portfolio in Canada (2017) which provides valuable theories and documentation concerning Target's former store portfolio. As such, this study used the CSCA's Shopping Centre (SC) and Major Retail Chain (MRC) database, as well as additional secondary data from the centre related to Sears and Target stores. Also, Environics Analytics' Simply Analytics modelled data is used in the statistical analyses and in the spatial analysis to examine what factors are strong or weak predictors of occupancy in their former store portfolio. Table 3 lists all 27 variables explored or used in the analyses: 
Table 3: Data Variables

\begin{tabular}{|c|c|c|c|c|c|c|}
\hline Type & Variable & Variable Name & Year & Format & Description & Source \\
\hline Market Demand & MRKTD_TOT_HH18 & $\begin{array}{l}\text { Total Household Population } 12 \text { Years } \\
\text { or Over }\end{array}$ & 2018 & Count & Total Household Population 2018 & Environics \\
\hline Market Demand & MRKTD_TOT_POP18 & Total Population & 2018 & Count & Total Population 2018 & Environics \\
\hline Market Demand & MRKTD_POPCHANGE & Population Change 2016 to 2018 & $2016-$ & Percentage & Total Population 2016 to 2018 & Environics \\
\hline Market Demand & MRKTD_AVG_HH_INC18 & $\begin{array}{l}\text { Average Household Income (Constant } \\
\text { Year 2005 \$) }\end{array}$ & 2018 & Average & Average Household Income 2018 & Environics \\
\hline Market Supply & MRKTS_FORMER_SIZE & Size of Former Sears or Target Space & $\begin{array}{l}2013 \\
2018\end{array}$ & Sq. Ft. & $\begin{array}{l}\text { Target planned opening size in } 2013 \\
\text { and Sears's closing size in } 2018 .\end{array}$ & $\mathrm{CSCA}$ \\
\hline Market Supply & MRKTS_EST_SIZE_STORE & $\begin{array}{l}\text { Total Estimated Size of Current } \\
\text { Configuration }\end{array}$ & 2019 & Sq. Ft. & $\begin{array}{l}\text { Total estimated size of Sears or } \\
\text { Target store in its current } \\
\text { configuration }\end{array}$ & CSCA \\
\hline Market Supply & MRKTS_LEASED_SPACE & $\begin{array}{l}\text { Leased Space of Current } \\
\text { Configuration in the Market }\end{array}$ & 2019 & Sq. Ft. & & $\mathrm{CSCA}$ \\
\hline Market Supply & MRKTS_OCCP_RATE & Market Occupancy Rate & 2019 & Percentage & $\begin{array}{l}\text { Leased Space / Total Estimated } \\
\text { Size of its Current Configuration in } \\
\text { all shopping centres in } 15 \mathrm{~km} \text { trade } \\
\text { area. }\end{array}$ & $\mathrm{CSCA}$ \\
\hline Market Supply & MRKTS_OCCP_CATGRY & Market Occupancy Category & 2019 & Categorical & $\begin{array}{l}0=\text { vacant } \\
1=1-20 \% \text { occupancy } \\
2=21-40 \% \text { occupancy } \\
3=41-60 \% \text { occupancy } \\
4=61-80 \% \text { occupancy } \\
5=81-100 \% \text { occupancy }\end{array}$ & $\mathrm{CSCA}$ \\
\hline Market Supply & MRKTS_SC_SIZES & Market Total Shopping Centre Sq. Ft. & 2018 & Sq. Ft. & $\begin{array}{l}\text { Total shopping centre sq. f.t in } 15 \mathrm{~km} \\
\text { trade area. }\end{array}$ & CSCA \\
\hline Market Supply & MRKTS_SC_STORES & $\begin{array}{l}\text { Market Total of Shopping Centre } \\
\text { Stores }\end{array}$ & 2018 & Count & $\begin{array}{l}\text { Total number of stores in } 15 \mathrm{~km} \\
\text { shopping centre trade area }\end{array}$ & $\mathrm{CSCA}$ \\
\hline Market Supply & MRKTS_NEW_TENANTS & $\begin{array}{l}\text { Market Total of New Tenants in } \\
\text { Current Space }\end{array}$ & 2019 & Count & $\begin{array}{l}\text { Number of new tenants occupying } \\
\text { the current space. }\end{array}$ & $\mathrm{CSCA}$ \\
\hline PROPERTY & PRPRTY_SPACE_CHANGE & $\begin{array}{l}\text { Space Change in Current } \\
\text { Configuration }\end{array}$ & 2019 & Categorical & $\begin{array}{l}0=\text { vacant } \\
1=\text { in use }\end{array}$ & CSCA \\
\hline PPROPERTY & PRPRTY_CONFIG & Configuration of Current Space & 2019 & Categorical & $\begin{array}{l}1=\text { Single Tenant } \\
2=\text { large multiple use (less than } 5 \\
\text { tenants) } \\
3=\text { small multiple use (more than } 5 \\
\text { tenants) }\end{array}$ & CSCA \\
\hline PROPERTY & PRPRTY_S_AND_T_IN_SC & $\begin{array}{l}\text { Sears and Target in the same } \\
\text { Shopping Centre }\end{array}$ & 2019 & Categorical & $\begin{array}{l}0=\text { not in same SC } \\
1=\text { in same } \mathrm{SC}\end{array}$ & CSCA \\
\hline PROPERTY & PRRRTY_STORE_LEVELS & Store Levels in Former Space & 2019 & Count & & CSCA \\
\hline PROPERTY & PRPRTY_SC_HIERARHCY & Type Shopping Centre & 2018 & Categorical & $\begin{array}{l}5=\text { Super Regional } \\
4=\text { Regional } \\
3=\text { Power Centre } \\
2 \text { = Community } \\
1=\text { Other }\end{array}$ & CSCA \\
\hline PROPERTY & PRPRTY_URBANITY & Shopping Centre Urbanity & 2019 & Categorical & $\begin{array}{l}1=\text { Urban } \\
2=\text { Suburban } \\
3=\text { Exurban }\end{array}$ & $\mathrm{CSCA}$ \\
\hline SITE & SITE_SC_SIZE & Size of Shopping Centre & 2018 & Sq. Ft. & & $\mathrm{CSCA}$ \\
\hline SITE & SITE_SC_STORES & Number of Stores in Shopping Centre & 2018 & Count & & CSCA \\
\hline SITE & SITE_FORMER_SIZE & Size of Former Sears or Target Space & 2013 & Sq. Ft. & $\begin{array}{l}\text { Target planned opening size in } 2013 \\
\text { and Sears's closing size in } 2018 .\end{array}$ & CSCA \\
\hline SITE & SITE_EST_SIZE_STORE & $\begin{array}{l}\text { Total Estimated Size of Current } \\
\text { Configuration }\end{array}$ & 2019 & Sq. Ft. & & CSCA \\
\hline SITE & SITE_LEASED_SPACE & $\begin{array}{l}\text { Total Leased Space of Current } \\
\text { Configuration }\end{array}$ & 2019 & Sq. Ft. & & CSCA \\
\hline SITE & SITE_OCCP_RATE & $\begin{array}{l}\text { Occupancy Rate of the Store's } \\
\text { Current Configuration }\end{array}$ & 2019 & Percentage & Leased Space / Total Estimated Size & $\mathrm{CSCA}$ \\
\hline SITE & SITE_OCCP_CATGRY & Occupancy Category of Current Space & 2019 & Categorical & $\begin{array}{l}0=\text { vacant } \\
1=1-20 \% \text { occupancy } \\
2=21-40 \% \text { occupancy } \\
3=41-60 \% \text { occupancy } \\
4=61-80 \% \text { occupancy } \\
5=81-100 \% \text { occupancy }\end{array}$ & CSCA \\
\hline SITE & SITE_NEW_TENANTS & $\begin{array}{l}\text { Total Number of New Tenants in } \\
\text { Current Space }\end{array}$ & 2019 & Count & & CSCA \\
\hline SITE & SITE_PER_OCCUP_OF_SC & $\begin{array}{l}\text { Percentage of Occupied Space in } \\
\text { Shopping Centre }\end{array}$ & 2019 & Percentage & $\begin{array}{l}\text { Current Total Estimated Size / Size } \\
\text { of Shopping Centre }\end{array}$ & $\mathrm{CSCA}$ \\
\hline
\end{tabular}

Source: Environics Analytics (2016-2018), CSCA (2013-2019), Statistics Canada (2016-2018) 


\subsection{Data Cleaning}

Data integrity is the "overall completeness, accuracy and consistency of data," in other words; the data must be reliable and accurate throughout its entire lifecycle (Techopedia, 2018). Data integrity ensures the data can be recovered, that it is searchable, and can be traceable to its origin and connectable (Lord, 2017). Moreover, data integrity can be easily compromised in a variety of ways: human error, transfer errors, viruses, and compromised hardware (Lord, 2017). Therefore, data integrity must be ensured by error checking to minimize risk to the study.

The Sears and Target master files that were provided by the CSCA needed to be updated and expanded for this study. The Sears master file did not have any information on the space after its closure in 2018, and the Target master file stopped consistently monitoring the former spaces in 2016. Therefore, a significant amount of data required updating from the websites of developers, shopping centre owners, leasing, news outlets, and the legal appointed monitor of Sears and Target.

\subsection{Data Preprocessing}

The term primary, secondary, and tertiary is frequently used terminology within trade area analysis (Hernandez, Lea, and Bermingham, 2004). These terms are used to distinguish between the different levels of patronage within a trade area. The primary trade area captures most of the patronage, with the secondary and tertiary areas containing progressively fewer customers (Hernandez, Lea, and Bermingham, 2004). Furthermore, when comparing the spatial extents of differences in patronage, store networks will differ between stores types. In some studies, the spatial extent for comparing shopping centres will differ based on hierarchy. For example, a larger shopping centre will have a larger trade area, with super-regionals having the largest (10 to 30 kilometres), regional (8 to 20 kilometres) and community (less than 10 kilometres) (International Council of Shopping Centers, 2017).

As the study examines the impacts of long-term vacancies at the market and site level, the dissemination level data had to be aggregated into the various trade area sizes to be explored in the analysis. ArcGIS Pro was used to aggregate the data into various trade area buffers. 
Specifically, the paper will examine factors within a 5,10- and 15-kilometre circular radius. The radiuses were applied to all shopping centres regardless of its hierarchy or mall format.

\subsection{Methodology}

\subsection{Measuring the Occupancy of Former Sears and Target Stores}

The study was conducted in three stages, a descriptive analysis, a statistical analysis, and a spatial analysis. The CSCA continuously updates, monitors and conducts studies to forecast trends in the shopping centre industry across Canada. As previously mentioned, the CSCA provided data for the endogenous category (e.g., leasable area, total store size, etc.), while Environics Analytics provided modelled data for the exogenous category. The data for both categories were provided at different geographic units. The exogenous category contained data at the dissemination area level, while the endogenous category contained data at the site area level. Therefore, to run a successful model, all variables must be standardized into comparable units. As such, both endogenous and exogenous variables had to be standardized using SPSS (Statistical Package for the Social Sciences).

The success or decline of a shopping centre has been appraised using occupancy and sales as predictive variables (Bloch, Ridgway, and Dawson, 1994). Moreover, both these variables are still being referenced in modern studies (Konishi and Sandfort, 2003; Shanmugam, 2013; Tokosh, 2018). For this paper, the occupancy rate of former Sears and Target spaces was the key variable to identify retail space absorption. Occupancy relates to different types of retail vacancy; the absorption process and what factors contribute to bringing these spaces back into productive use. The occupancy variable is calculated by dividing the total leased space by the total estimated size of the former Sears or Target space. Occupancy measures the amount of space leased based on the latest configuration of the space; this variable may be influenced by redevelopment or reconfiguration of the space.

\subsubsection{Multicollinearity and Variable Standardization.}

The first challenge of using statistical methods such as Pearson's correlation, factor analysis, or discriminant analysis is multicollinearity. Multicollinearity is defined as a 
phenomenon when the independent variable selected for the analysis exhibits correlation (Chakrapani, Lea, Hernandez., 2006). When there is an occurrence of highly inter-correlated independent variables, this effect produces redundancy in the results. Furthermore, by multiple counting the effect, some variables may have a greater exertion on the coefficients and model results. Therefore, it is not recommended to use variables that have a high multicollinearity to each other (Shi and Conrad, 2009 and Statistics Solutions, 2017). The following is a widely used diagnostic for multicollinearity:

- If the correlation is above 0.8 , then severe multicollinearity may be present in the analysis.

Any variables that do not fit within the criteria of this indicator were considered for removal. When removing a variable, the idea that independent variables are correlated must be considered. The stronger the correlation, the more difficult it is the change one variable without effecting another variable. Therefore, it is often challenging for the model to predict the relationship between an independent variable and a dependent variable autonomously because independent variables tend to change in unison (Frost, 2019).

\subsection{The Status of Former Sears and Target Store Spaces in Shopping Centres}

As of July 2019, 52 (35\%) of the 147 Sears properties have at least one tenant, of which $36(24 \%)$ were fully leased, with either a single tenant or multiple tenants (Figure 3). The remaining 95 (65\%) Sears properties are vacant, awaiting leasing negotiations or redevelopment activities. For Target, $118(86 \%)$ of the 138 have at least one tenant, of which 81 (58\%) were fully leased, with either a single tenant or multiple tenants. The remaining 20 (14\%) Target properties are vacant.

\subsubsection{Fully Leased Single Tenant}

Approximately one-fourth of the former Sears properties have been fully leased by a single tenant (30 stores) (Figure 3). These tenants are primarily Winners, HomeSense, Ashley HomeStore, and Leon's. Target has fully leased two-fifths of its former properties to a single tenant. These tenants are primarily the Big Three (Wal-Mart, Canadian Tire, and Lowe's). 


\subsubsection{Multiple Tenant per Retail Space}

Another 12 of the former Sears stores and 61 of the former Target stores have been divided into two or more units where at least one unit is leased (Figure 3). In total, 8\% (12 stores) of former Sears stores are leased to multiple tenants and 37\% (61) of former Target stores. The average number of tenants per space is approximately 2.4 for Sears and 5.5 for Target. Based on the existing redevelopment of the former stores from single to multiple tenants, the data suggests it takes approximately 3 to 4 mid-size retailers to completely fill a Sears or Target.
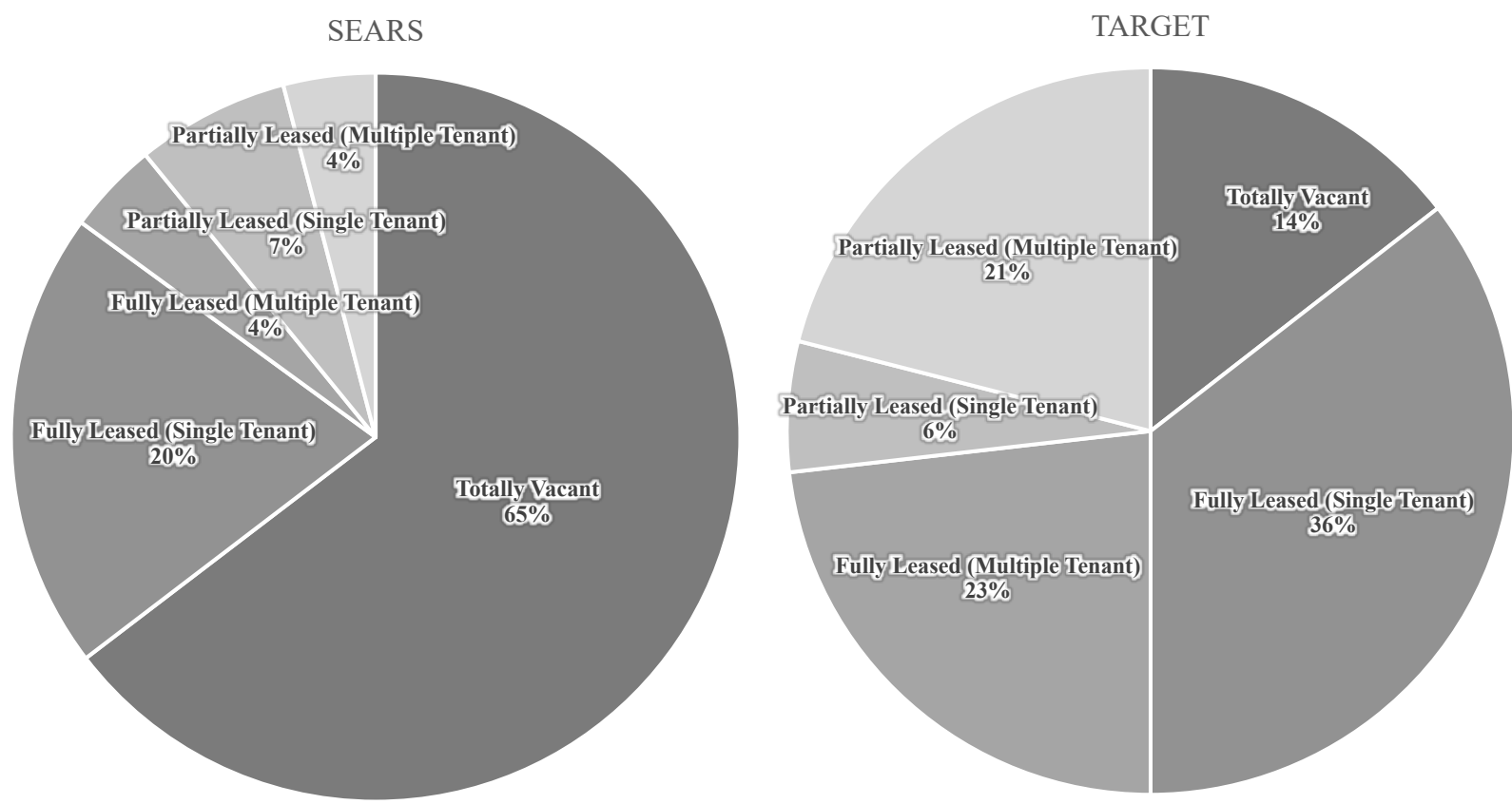

Figure 3: Status of Former Sears and Target Stores

Data Source: Centre for the Study of Commercial Activity (2019)

When redeveloping the former space into multiple units, the division of space would almost always lead to the downsizing of the total leasable space (Emmons and Hernandez, 2017). The result is a loss in retail space due to the construction of new walls and pathways which will take up space from the original footprint. The data reveals that $2 \%$ of Sears original footprint was lost in these multiple tenant reconfigurations, while Target lost $8 \%$. It is important to note that small increases and decreases may not always be reported in the site plans, and some stores are planned for reconfiguration in the future. 


\subsubsection{Vacant Sears and Target Stores in Shopping Centres}

More than half (95 stores) of the former Sears locations in shopping centres are still totally vacant (65\%), while Target has 20 (14\%) totally vacant former locations. As leasing negotiations are still ongoing, many shopping centres are still in the process of leasing, redeveloping, or reconfiguring the space. However, some spaces may sit vacant for the foreseeable future. Furthermore, a few shopping centres are proposing a re-zoning of the land to develop mixed-use communities, while others are planning to lease to non-retail uses or demolish the space.

\subsection{The Geography of Absorption}

\subsubsection{By Census Metropolitan Area - Sears}

Within the VETCOM markets (Vancouver, Edmonton, Toronto, Calgary, OttawaGatineau, Montreal), a year after Sears left the Canadian marketplace, Toronto, Edmonton and Montreal have the highest percentage of absorbed space respectively (Table 4). These markets and many others were only able to absorb less than a quarter of its leasable space, which demonstrates Canada's struggle to absorb the former Sears space. The Alberta market seems to be struggling the most, and a similar trend was seen with the Target absorption a year after their closure (Table 5). Another trend also seen with Target's absorption process is the census metropolitan areas (CMA) surrounding the Toronto CMA experiencing limited absorption of space, except for Hamilton and Oshawa. Markets including Ottawa-Gatineau, St. CatharinesNiagara, Kitchener-Cambridge-Waterloo, Halifax, Saskatoon, and St. John's have yet to lease any space as of 2019. In comparison, London and Moncton have managed to absorb half of the available Sears space as a result of high demand and low supply. 
Table 4: Former Sears Store Space by Census Metropolitan Area

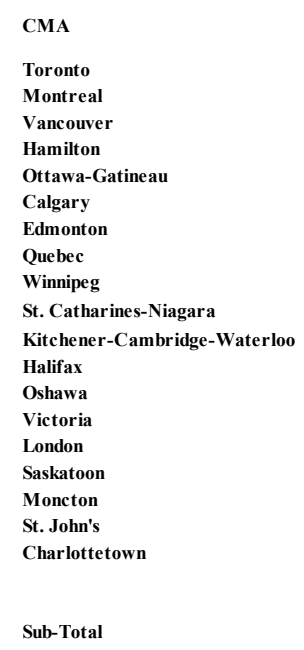

Total

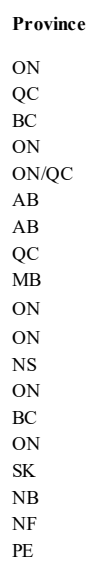

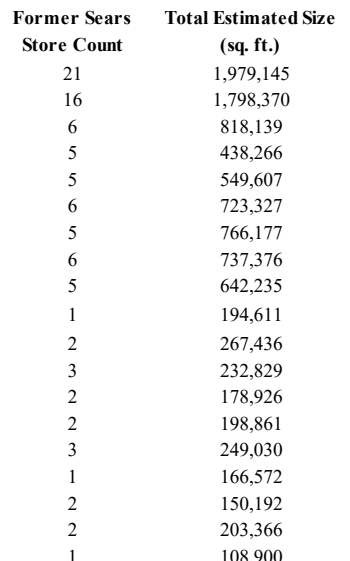

$15,902,181$

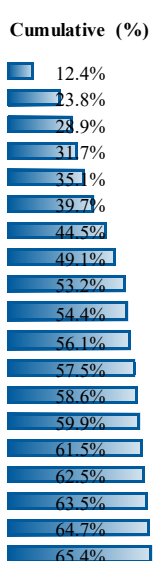

$65.4 \%$

$100.0 \%$

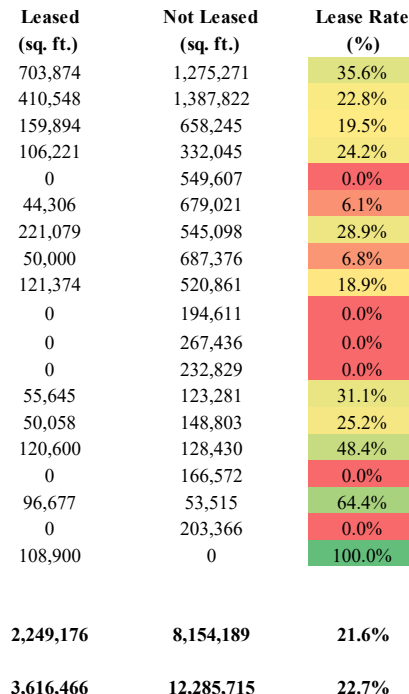

$22.7 \%$

Source: Centre for the Study of Commercial Activity (CSCA), 2019

\subsubsection{By Census Metropolitan Area - Target}

This year, the data reported a 0.95 million drop (-6\%) in square feet in total estimated size (e.g., 15.59 million in 2017 and 14.64 million in 2019) (Table 4). This loss in the gross leasable area is due to the splitting-up of space or redevelopment with smaller spaces. Within the VETCOM markets, Vancouver managed to absorb more than 50\% a year after Target left the marketplace as a result of high demand and low supply. In 2019, four years after Target left the market, Edmonton went from the lowest lease rate to the highest followed by Calgary, Vancouver, Montreal, Toronto and Ottawa-Gatineau.

In 2016, it was reported that the Alberta market was struggling to absorb space and was a victim of cyclical vacancy. However, the market managed to absorb more than $50 \%$ of the available Target space as of 2019 (Emmons and Hernandez, 2017; Johnson, 2015). In 2016, it was also observed that demands for space in Ottawa were initially strong as lease rates were running ahead of the province and setting national benchmarks.

However, a drop occurred from its peak of $84.1 \%$ in 2017 to $74 \%$ in 2019 due to the loss of leasable area in 2016. In 2016, Hamilton and Edmonton saw limited absorption of space, with $26.3 \%$ and $22.7 \%$ respectively. In three years, both CMAs had a rapid increase in lease rate, 
doubling in 2017 and continuing to increase in 2019. Due to large general merchandise, home improvement, grocery stores, and furniture and home furnishing retailers occupy the space.

Table 5: Former Target Store Space by Census Metropolitan Area

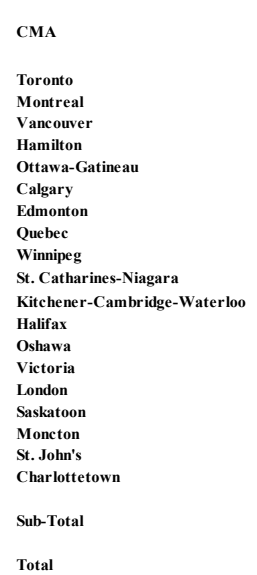

Province
ON
QC
BC
ON
ON/QC
AB
AB
QC
MB
ON
ON
NS
ON
BC
ON
SK
NB
NF
PE
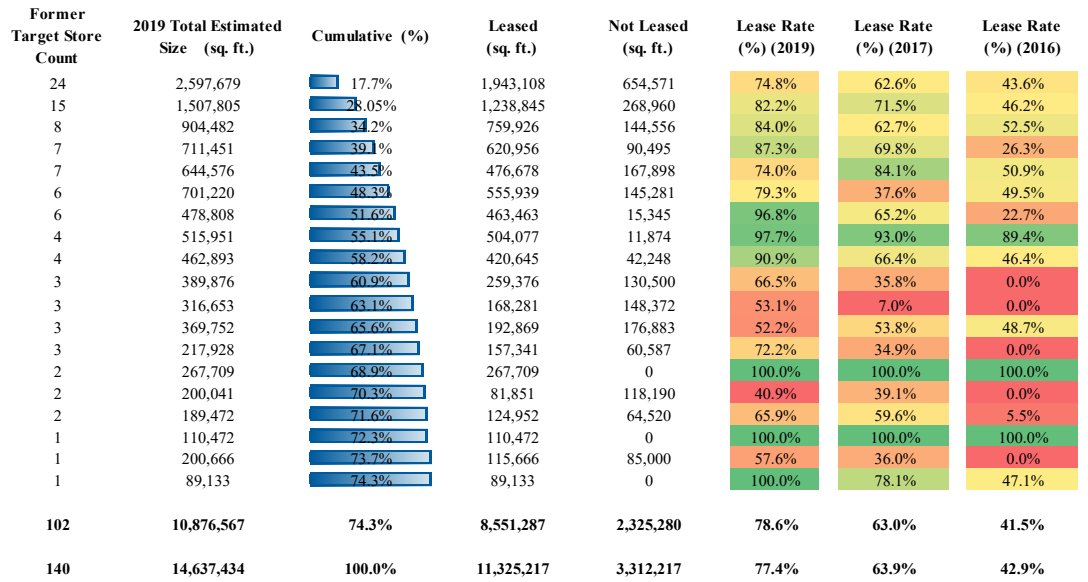

Source: Centre for the Study of Commercial Activity (CSCA), 2019

\subsubsection{By Shopping Centre Type - Sears}

Over half (104) of the 160 Sears locations were in super-regional and regional shopping centres (Table 6). Thirty-two stores were in super-regional shopping centres, with $13.7 \%$ of square feet leased and seventy-two stores in regional with $14.2 \%$ of square feet leased. Superregional and regional shopping centres are shown to have the lowest lease rate of the six shopping centre types Sears had occupied. Neighbourhood shopping centres and free-standing stores have the most success, leasing $100 \%$ and $79.2 \%$ of its total available space respectively. Power centres and community shopping centres have leased around $50 \%$ of its available space. Target and Sears have a little over 3 million square feet of leasable space to absorb, and their absorption rates vary by province and major market.

Table 6: Former Sears Store Space by Shopping Centre Type

\begin{tabular}{|c|c|c|c|c|c|c|c|}
\hline SC Type & $\begin{array}{c}\text { Number of } \\
\text { Stores }\end{array}$ & $\begin{array}{l}\text { Total Estimated } \\
\text { Size (sq. ft.) }\end{array}$ & $\begin{array}{l}\% \text { of Total } \\
\text { Stores }\end{array}$ & $\begin{array}{c}\% \text { of Estimated } \\
\text { Size }\end{array}$ & $\begin{array}{l}\text { Leased } \\
\text { (sq. ft.) }\end{array}$ & $\begin{array}{l}\text { Not Leased } \\
\text { (sq. ft.) }\end{array}$ & Lease Rate (\%) \\
\hline Super Regional & 32 & $5,273,390$ & $20.0 \%$ & $33.2 \%$ & 720,589 & $4,552,801$ & $13.7 \%$ \\
\hline Regional & 72 & $7,666,033$ & $45.0 \%$ & $48.2 \%$ & $1,091,144$ & $6,574,889$ & $14.2 \%$ \\
\hline Community & 17 & $1,183,976$ & $10.6 \%$ & $7.4 \%$ & 591,148 & 592,828 & $49.9 \%$ \\
\hline Neighbourhood & 2 & 97,400 & $1.3 \%$ & $0.6 \%$ & 97,400 & 0 & $100.0 \%$ \\
\hline Power Centre & 28 & $1,315,809$ & $17.5 \%$ & $8.3 \%$ & 826,585 & 489,224 & $62.8 \%$ \\
\hline Free-standing & 9 & 365,573 & $5.6 \%$ & $2.3 \%$ & 289,600 & 75,973 & $79.2 \%$ \\
\hline Total & 160 & $15,902,181$ & $100.0 \%$ & $100.0 \%$ & $3,616,466$ & $12,285,715$ & $22.7 \%$ \\
\hline
\end{tabular}

Source: Centre for the Study of Commercial Activity (CSCA), 2019 


\subsubsection{By Shopping Centre Type - Target}

Similarly, over half (80) of the 140 Target locations were also located in super-regional and regional shopping centres (Table 7). Twenty-three stores were in super-regional shopping centres with 70.5\% leased and fifty-seven in regional shopping centres with 59.7\% leased in 2019. Community shopping centres had the most success in leasing out their space, with close to $50 \%$ a year post-closure and completed leased in 2019. Following, super-regional and mixed-use developments were also successful in leasing out their space between 2016 to 2017. However, from 2017 to 2019, the absorption process slowed down as lease rates stayed the same for all shopping centre types except for community level.

Table 7: Former Target Store Space by Shopping Centre Type

\begin{tabular}{|c|c|c|c|c|c|c|c|c|c|}
\hline SC Type & $\begin{array}{c}\text { Number of } \\
\text { Stores }\end{array}$ & $\begin{array}{l}\text { Total Estimated } \\
\text { Size (sq. ft.) }\end{array}$ & $\begin{array}{c}\% \text { of Total } \\
\text { Stores }\end{array}$ & $\begin{array}{l}\% \text { of Estimated } \\
\text { Size }\end{array}$ & $\begin{array}{l}\text { Leased } \\
\text { (sq. ft.) }\end{array}$ & $\begin{array}{l}\text { Not Leased } \\
\text { (sq. ft.) }\end{array}$ & $\begin{array}{c}\text { Lease Rate (\%) } \\
\text { (2019) }\end{array}$ & $\begin{array}{c}\text { Lease Rate (\%) } \\
\text { (2017) }\end{array}$ & $\begin{array}{l}\text { Lease Rate (\%) } \\
\text { (2016) }\end{array}$ \\
\hline Community & 23 & $2,212,092$ & $16.4 \%$ & $15.1 \%$ & $1,704,115$ & 507,977 & $100.0 \%$ & $67.2 \%$ & $48.0 \%$ \\
\hline Mixed-Use & 4 & 485,981 & $2.9 \%$ & $3.3 \%$ & 426,981 & 59,000 & $70.2 \%$ & $70.2 \%$ & $70.2 \%$ \\
\hline Power Centre & 30 & $3,249,233$ & $21.4 \%$ & $22.2 \%$ & $2,384,822$ & 864,411 & $66.7 \%$ & $66.7 \%$ & $45.8 \%$ \\
\hline Regional & 57 & $5,761,828$ & $40.7 \%$ & $39.4 \%$ & $4,362,344$ & $1,399,484$ & $59.7 \%$ & $59.7 \%$ & $39.5 \%$ \\
\hline Super Regional & 23 & $2,584,882$ & $16.4 \%$ & $17.7 \%$ & $2,144,511$ & 440,371 & $70.5 \%$ & $70.5 \%$ & $40.3 \%$ \\
\hline Hybrid & 1 & 102,444 & $0.7 \%$ & $0.7 \%$ & 102,444 & 0 & $0.0 \%$ & $0.0 \%$ & $0.0 \%$ \\
\hline Not in SC & 2 & 240,974 & $1.4 \%$ & $1.6 \%$ & 200,000 & 40,974 & $39.5 \%$ & $39.5 \%$ & $39.5 \%$ \\
\hline Total & 140 & $14,637,434$ & $100.0 \%$ & $97.3 \%$ & $11,325,217$ & $3,312,217$ & $77.4 \%$ & $63.9 \%$ & $42.9 \%$ \\
\hline
\end{tabular}

Source: Centre for the Study of Commercial Activity (CSCA), 2019

While both retail companies had similar trends by market, Target and Sears also show apparent differences in patterns by shopping centre type. For example, a year post-closure, superregional and regional shopping centres had the highest lease rates for former Target spaces, but the lowest for Sears. Free-standing (i.e., not in a shopping centre) stores had the highest lease rate for Sears post-closure but were one of the lowest for Target. As previously mentioned, as time progresses the window of frictional vacancy steadily closes and the likelihood of cyclical or structural vacancies increases. As such, it is important to identify endogenous and exogenous factors that are strong predictors of occupancy for the former Sears and Target spaces.

\subsection{Pearson's Correlation Coefficient}

A Pearson's correlation coefficient was used to determine if a relationship exists between two continuous linear variables and the subsequent strength and direction of this relationship. To test a hypothesis on whether a statistically significant linear correlation exists between occupancy to the previously mentioned exogenous and endogenous independent variables in 5, 
10, and 15-kilometre trade areas using alpha 0.05. In the test, coefficients are returned with values between -1 and 0 , and 0 and 1 , with 0 being no correlation, and -1 and 1 being strong negative and strong positive correlations, respectively (Statistics Solutions, 2019). The ideal coefficient are values close to \pm 1 , which is a perfect correlation. Values between \pm 0.50 and 1 indicate a high degree of correlation. Values between \pm 0.30 and \pm 0.50 indicate a moderate degree of correlation. Values between 0 and \pm 0.30 indicate a low degree of correlation. Lastly, a coefficient value of 0 indicates that no relationship or correlation exists between the variables (Statistics Solutions, 2019). The exploratory Pearson's correlation for 5, 10, and 15-kilometre trade areas determined the 15-kilometre trade area yielded the best results. The 5 and 10kilometre trade areas resulted in most values with low coefficient values, and many were not significant at 0.05 or 0.01 . The data in this trade area size produced statistics where relationships existed between variables at 0.01 level with a high degree of correlation.

\subsubsection{Pearson's Correlation Coefficient Sears Results - 15km Trade Area}

Pearson's correlation coefficient for Sears determined a significant relationship at the 0.01 level exists between occupancy rate and variables including (Table 8):

\section{Table 8: Sear's Pearson's Correlation Coefficients}

\begin{tabular}{|l|c|c|c|c|c|c|c|c|c|c|c|}
\hline & $\begin{array}{c}\text { Occupancy } \\
\text { Rate } \\
\text { (Market) }\end{array}$ & $\begin{array}{c}\text { Leased } \\
\text { Space } \\
\text { (Market) }\end{array}$ & $\begin{array}{c}\text { New } \\
\text { Tenants } \\
\text { (Market) }\end{array}$ & $\begin{array}{c}\text { Space } \\
\text { Change } \\
\text { (Property) }\end{array}$ & $\begin{array}{c}\text { Configuration } \\
\text { (Property) }\end{array}$ & $\begin{array}{c}\text { Sears and } \\
\text { Target in SC } \\
\text { (Property) }\end{array}$ & $\begin{array}{c}\text { SC } \\
\text { Hierarchy } \\
\text { (Property) }\end{array}$ & $\begin{array}{c}\text { SC Size } \\
\text { (Site) }\end{array}$ & $\begin{array}{c}\text { SC } \\
\text { Stores } \\
\text { (Site) }\end{array}$ & $\begin{array}{c}\text { Former } \\
\text { Size } \\
\text { (Site) }\end{array}$ & $\begin{array}{c}\text { Leased } \\
\text { Space } \\
\text { (Site) }\end{array}$ \\
$\begin{array}{l}\text { Occupancy } \\
\text { Rate (Site) }\end{array}$ & $.610 * *$ & $.334 *$ & $.363 *$ & $\begin{array}{c}\text { New } \\
\text { Tenants } \\
\text { (Site) }\end{array}$ \\
\hline
\end{tabular}

** Correlation is significant at the 0.01 level (2-tailed)

The results indicate a significantly strong correlation $( \pm 0.50$ and 1$)$ exists between occupancy rate (site) and occupancy rate (market), space change, configuration, leased space (site), and new tenants (site). A significant moderate relationship ( \pm 0.30 and \pm 0.50$)$ exists between occupancy rate (site) and leased space (market), new tenants (market), shopping centre hierarchy, shopping centre size (site), shopping centre (site) and former size (site). Lastly, a significant low correlation ( 0 and \pm 0.30$)$ exists between occupancy rate (site) and Sears and Target occupying the same shopping centre. 


\subsubsection{Pearson's Correlation Coefficient Target Results - 15km Trade Area}

Pearson's correlation coefficient for Target determined a significant relationship at the 0.01 level exists between occupancy rate and variables including (Table 9):

Table 9: Target's Pearson's Correlation Coefficients

\begin{tabular}{|l|c|c|c|c|c|c|c|c|}
\hline & $\begin{array}{c}\text { Occupancy } \\
\text { Rate } \\
\text { (Market) }\end{array}$ & $\begin{array}{c}\text { Leased } \\
\text { Space } \\
\text { (Market) }\end{array}$ & $\begin{array}{c}\text { New } \\
\text { Tenants } \\
\text { (Market) }\end{array}$ & $\begin{array}{c}\text { Space } \\
\text { Change } \\
\text { (Property) }\end{array}$ & $\begin{array}{c}\text { Configuration } \\
\text { (Property) }\end{array}$ & $\begin{array}{c}\text { SC } \\
\text { Urbanity } \\
\text { (Property) }\end{array}$ & $\begin{array}{c}\text { Leased } \\
\text { Space } \\
\text { (Site) }\end{array}$ & $\begin{array}{c}\text { New } \\
\text { Tenants } \\
\text { (Site) }\end{array}$ \\
\hline $\begin{array}{l}\text { Occupancy Rate } \\
\text { (Site) }\end{array}$ & $.678^{* *}$ & $.221^{* *}$ & $.363^{* *}$ & $.870^{* *}$ & $.546^{* *}$ & $-.236^{* *}$ & $.887^{* *}$ & $.229^{* *}$ \\
\hline
\end{tabular}

** Correlation is significant at the 0.01 level (2-tailed)

The results indicate a significantly strong correlation $( \pm 0.50$ and 1$)$ exists between occupancy rate (site) and occupancy rate (market), space change, configuration, and leased space (site). A significant moderate relationship $( \pm 0.30$ and \pm 0.50$)$ exists between occupancy rate (site) and new tenants (market). Lastly, a significant low correlation ( 0 and \pm 0.30$)$ exists The results indicate a significantly strong correlation ( \pm 0.50 and 1$)$ exists between occupancy rate (site) and occupancy rate (market), space change, configuration, and leased space (site). A significant moderate relationship ( \pm 0.30 and \pm 0.50 ) exists between occupancy rate (site) and new tenants (market). Lastly, a significant low correlation ( 0 and \pm 0.30$)$ exists between occupancy rate (site) and leased space (market) and new tenants (site).

\subsubsection{Pearson's Correlation Coefficient Results Discussion}

The significant relationships ( 0.01 level) determined by Pearson's correlation had a mixture of market, property and site variables. The results for Sears and Target contained similar relationships, such as occupancy rate (site) correlating with leased space (market), new tenants (market), space change, configuration, and leased space (site). Therefore, it can be assumed, the spaces that had undergone re-configuration into multiple smaller units were more likely to be leased, resulting in a higher occupancy rate for these shopping centres. By reconfiguring the space into multiple tenants, more retailers that operate with smaller retail square footage will be able to lease the space. Furthermore, shopping centres sharing the same trade area were more likely to have leased their former space as well, as shopping centres close to each other are likely to have the same or similar market demand variables. 
In comparison, the data indicates that the size of the shopping centre has a significant negative moderate correlation with Sears. This outcome may be due to the low percentage of leased space in super-regional (13.7\%) and regional malls (14.2\%) with former Sears spaces (Table 6). Super-regional and regional malls are the two largest shopping centre types by hierarchy. As a result, this caused a negative correlation with the shopping centre size and type. The Target data did not present these variables with a negative correlation as super-regional and regional shopping centres with former Target spaces have a higher percentage of leased space (Table 6).

Urbanity also had a significant negative moderate to a low relationship with occupancy. This relationship may be due to the high number of former properties in urban markets and suburban markets compared to exurban markets. Sears has many former properties in urban and suburban markets, and shopping centres are struggling to lease the large amount of available space. However, in exurban markets such as Charlottetown or Moncton, there are less than three former properties altogether, therefore introducing the situation of low supply and high demand. Furthermore, many of the former Target properties across Canada have already been partially leased (86\%); therefore, urbanity would not have a strong correlation with occupancy in this case (Figure 3).

\subsection{Factor Analysis}

Factor analysis is a data reduction technique which allows the user to group variables that are highly correlated with one another into factors because it is assumed that all variables are influenced by underlying factors (Abdi and Williams, 2010). In other words, the technique emphasizes the variation and highlight strong patterns in the dataset to make data easy to visualize and understand (The Analysis Factor, 2017). Factor analysis can be performed on statistical packages such as the Statistical Package for the Social Sciences (SPSS). In SPSS, the technique follows a series of operations - extraction, interpretation, rotation and selection of factors (The Analysis Factor, 2017). Factor analysis approach to data reduction is a model of the measurement of a latent variable. A latent variable, also referred to as either a factor, underlying construct or an unobservable variable, which is a variable that cannot be measured with a single variable, such as mental health or soil health (The Analysis Factor, 2017). Instead, factor analysis 
is interpreted by the relationships it causes in a set of independent $(Y)$ variables (The Analysis Factor, 2017). The following is an example of the one-factor model. The latent variable $(F)$ is causing the responses to the four independent variables ( $Y$ ) (The Analysis Factor, 2017).

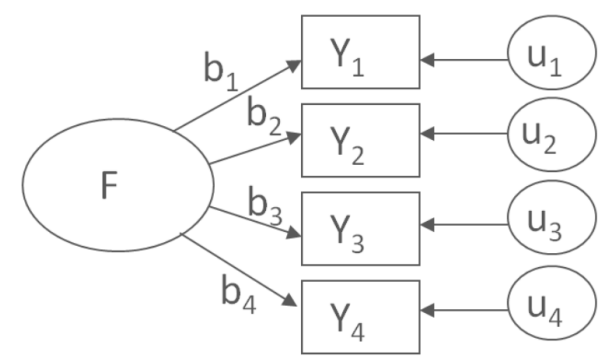

Figure 4: Factor Analysis Procedure Source: The Factor Analysis (2017)

Furthermore, in this model (Figure 4), exists a set of error terms. These terms are designated by $u$ and are variance in each $\mathrm{Y}$ that are unexplained by the factor (The Analysis Factor, 2017). The designation $\mathrm{u}$ exists because factor analysis only concerns itself with common sources of variation, hence its alternative name as "common" factor analysis (The Analysis Factor, 2017). Due to this preference, the rest of the variables, also called "error terms" or "unique sources," are less important or more difficult to identify (Suhur, 2005). Overall, the objective of factor analysis is to explain the correlation between the variables.

A factor analysis will be conducted to group together highly correlated variables into factors. The 27 variables from the database represent 246 shopping centres in Canada from different mall formats and hierarchy. After a set of factors have been determined, a discriminant analysis will be performed to identify strong or weak predictors of occupancy of former Sears and Target spaces.

There are several hypotheses:

H1: The factor analysis will group endogenous variables separately from exogenous variables. Internal elements, such as store size or percentage of space in the shopping centre, will explain similar factors related to the shopping centre. While external elements, such as population size or household income, will explain factors related to the market area. Therefore, endogenous and exogenous variables will be isolated from each other. 
H2: The factor analysis will group variables based on their variable type (market demand, market supply, site, and property). Market demand and supply type contain variables at a $15 \mathrm{~km}$ trade area radius, while site and property type contain variables about the characteristics of the shopping centre and former space.

\subsubsection{Factor Analysis Criteria}

The Kaiser-Meyer-Olkin (KMO) Statistic and Bartlett's test shows two tests, the KMO Measure of Sampling Adequacy and Bartlett's test of sphericity; both measures the suitability of the data to be used in factor analysis (IBM, 2019). The KMO measures "the sampling adequacy for each variable in the model and the complete model" (Statistics How To, 2018b). As such, the higher the KMO value (close to 1.0 and over 0.60 ), the more useful the results from the factor analysis (IBM, 2018). If the KMO is less than 0.50, factor analysis may not be suitable for the selected data (IBM, 2018). Furthermore, Bartlett's Test is designed to test that "variances are equal for all samples," this test is also referred to as homogeneity of variances (Statistics How To, 2018b). Therefore, the lower the significance value (less than 0.05), the more suitable the data are for structure detection (IBM, 2018).

The Kaiser criterion (1960), also referred to as the eigenvalue method, suggests retaining components with an eigenvalue greater than 1 . However, in some cases, the Kaiser criterion is not recommended as the sole criterion for estimating the number of factors, as it tends to overextract factors (The Analysis Factor, 2017). The scree test is an example of the Kaiser criterion as it retains "components or factors in the steep curve before the first point that starts the flat line trend" (Rajaretnam, 2015). The scree plot displays the eigenvalues on the y-axis and the number of components for the $\mathrm{x}$-axis. The ideal pattern in a scree plot is "a steep curve, followed by a bend and then a flat horizontal line" (Rajaretnam, 2015, pg. 259).

The percentage of variance column gives a ratio, expressed as a percentage, of the variance explained by each component to the total variance in all the variables. While the percentage of the cumulative column provides the percentage of variance explained by all components used in the model, the acceptable percentage of explained variance will depend on how the principal components are used, but typically the higher the variance explained, the better the model (IBM, 2018). 
After the number of factors has been determined, rotation must be performed to facilitate the interpretation. The purpose of the rotation is to retain factors that are statistically different from each other as possible. The orthogonal rotation method does this by applying a linear transformation to obtain a simpler factor loading factor, which eases the interpretation of the pattern. There are four main methods to rotate the initial loadings orthogonally. However, this study will focus on a popular and most commonly used scheme suggested by Henry Felix Kaiser called varimax rotation. The objective of this method is to maximize the squared factor loadings in each factor, so for each factor, high loadings will result in a few variables, and the rest will be near zero.

\subsubsection{Sears Factor Analysis Results}

The KMO statistic is a measure of sampling adequacy and at .755 (Table 10), indicating the data is suitable for factoring. Furthermore, Bartlett's Test shows a statistical significance of .000 , indicating that the data are suitable for structure detection.

Table 10: Sear's KMO Statistics and Significance

\begin{tabular}{|l|r|}
\hline KMO and Bartlett's Test & \\
\hline Kaiser-Meyer-Olkin Measure of Sampling Adequacy & .755 \\
\hline Bartlett's Test of Sphericity (Approx. Chi - Square) & 5446.604 \\
\hline df & 300 \\
\hline Sig. & .000 \\
\hline
\end{tabular}

A total of six components were extracted from the dataset. Figure 5 is a scree plot displaying the eigenvalues on the $y$-axis and the number of components on the x-axis. As previously mentioned, the Kaiser criterion suggests retaining components with an eigenvalue greater than 1, as an eigenvalue less than one would indicate the component explains less variance than a single variable would. Table 11 shows the total variance explained by the six components at $81.2 \%$. The table also indicates that the eigenvalues of each of the six components are greater than one. The rotated component matrix (Table 12) shows the factor loadings of the variables. Each component represents a theme related to the retail absorption process of Sears. 


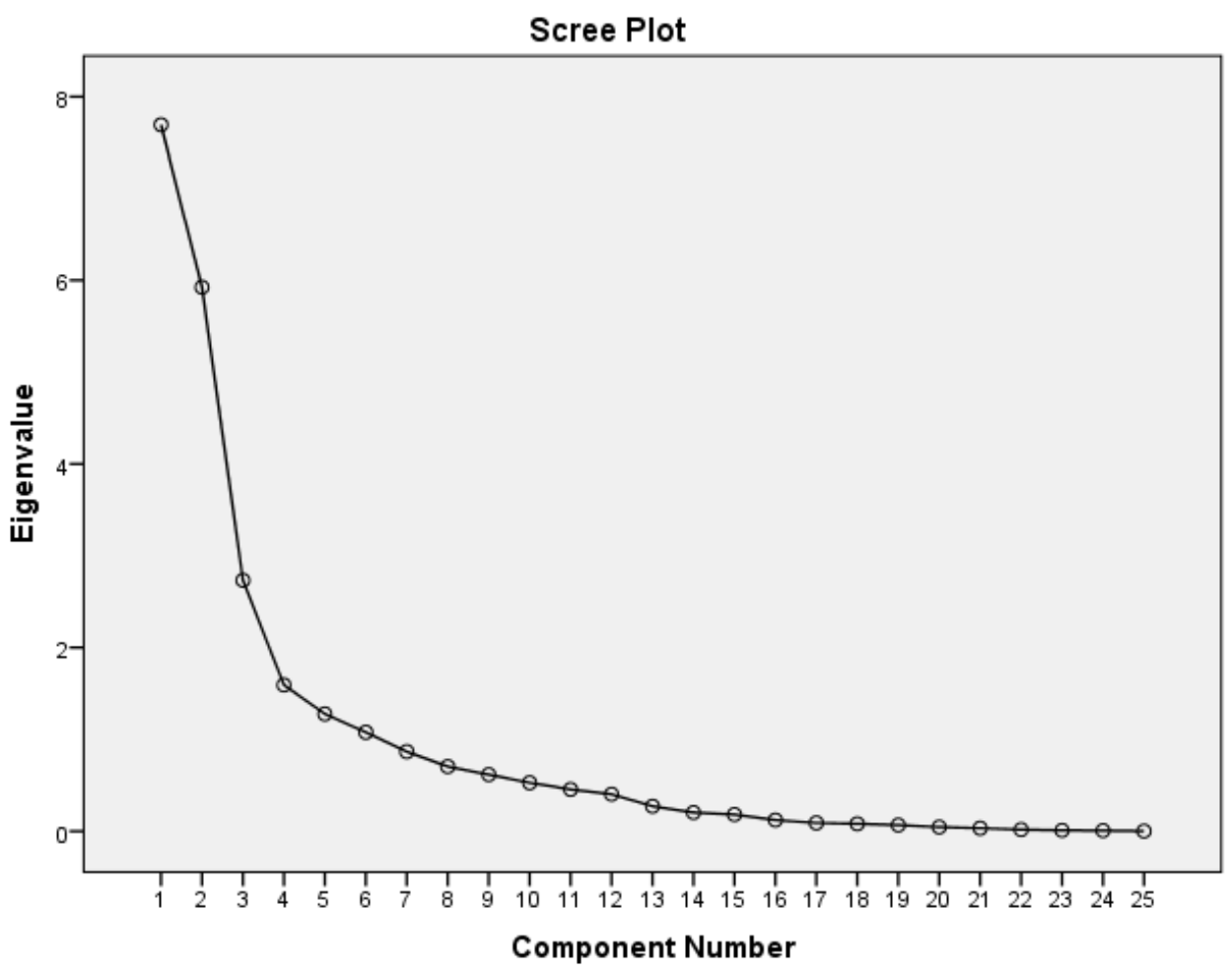

Figure 5: Sear's Scree Plot

Table 11: Sear's Total Variance Explained

\begin{tabular}{|c|c|c|c|c|c|c|}
\hline \multicolumn{7}{|c|}{ Total Variance Explained of Six Factors } \\
\hline \multicolumn{4}{|c|}{ Initial Eigenvalues } & \multicolumn{3}{|c|}{ Rotation Sum of Squared Loadings } \\
\hline Component & Total & $\%$ of Variance & Cumulative $\%$ & Total & $\%$ of Variance & Cumulative $\%$ \\
\hline 1 & 7.69 & 30.77 & 30.77 & 6.22 & 24.91 & 24.91 \\
\hline 2 & 5.92 & 23.69 & 54.47 & 5.15 & 20.60 & 45.52 \\
\hline 3 & 2.73 & 10.93 & 65.40 & 4.18 & 16.75 & 62.27 \\
\hline 4 & 1.59 & 6.37 & 71.77 & 2.10 & 8.42 & 70.69 \\
\hline 5 & 1.27 & 5.10 & 76.88 & 1.45 & 5.82 & 76.51 \\
\hline 6 & 1.07 & 4.31 & 81.19 & 1.16 & 4.67 & 81.19 \\
\hline
\end{tabular}


Table 12: Sear's Rotated Component Matrix

\begin{tabular}{|c|c|c|c|c|c|c|}
\hline \multicolumn{7}{|c|}{ Rotated Component Matrix } \\
\hline & Comp 1 & Comp 2 & Comp 3 & Comp 4 & Comp 5 & Comp 6 \\
\hline Total Household Population 12 Years or Over (Market Demand) & 0.864 & & & 0.204 & & \\
\hline Total Population (Market Demand) & 0.854 & & & 0.267 & & \\
\hline Population Change 2016 to 2018 (Market Demand) & 0.302 & & & 0.816 & & \\
\hline Average Household Income Constant Year 2005 (Market Demand) & 0.272 & & & 0.818 & & 0.194 \\
\hline Size of Former Sears or Target Space (Market Supply) & 0.949 & & & 0.185 & & \\
\hline Total Estimated Size of Current Configuration (Market Supply) & 0.948 & & 0.109 & 0.180 & & \\
\hline Leased Space (Market Supply) & 0.662 & 0.459 & 0.201 & & & -0.278 \\
\hline Occupancy Rate (Market Supply) & & 0.743 & & -0.148 & & -0.350 \\
\hline Size Shopping Centre (Market Supply) & 0.933 & & 0.177 & & & \\
\hline Number of Stores in Shopping Centre (Market Supply) & 0.924 & & 0.192 & & & \\
\hline Number of New Tenants (Market Supply) & 0.525 & 0.542 & 0.143 & 0.210 & & -0.190 \\
\hline Space Change in Former Space (Property) & & 0.916 & -0.278 & & & \\
\hline Current Configuration of Space (Property) & & 0.916 & -0.201 & & & 0.188 \\
\hline Sears and Target in same Shopping Centre (Property) & & & 0.573 & -0.264 & & -0.109 \\
\hline Store Levels (Property) & & & 0.107 & & & 0.829 \\
\hline Type of Shopping Centre (Property) & & -0.147 & 0.838 & & -0.205 & \\
\hline Shopping Centre Urbanity (Property) & -0.373 & & -0.118 & -0.601 & & 0.266 \\
\hline Size of Shopping Centre (Site) & 0.256 & & 0.804 & & -0.301 & \\
\hline Number of Stores in Shopping Centre (Site) & 0.192 & -0.124 & 0.873 & & -0.177 & \\
\hline Size of Former Sears or Target Space (Site) & 0.195 & -0.213 & 0.784 & 0.157 & 0.407 & \\
\hline Total Estimated Size of Current Configuration (Site) & 0.193 & -0.159 & 0.803 & 0.142 & 0.428 & 0.108 \\
\hline Leased Space (Site) & & 0.850 & & & 0.234 & \\
\hline Occupancy Rate (Site) & & 0.878 & -0.340 & & & \\
\hline Number of New Tenants in Former Spaces (Site) & & 0.874 & -0.181 & & & 0.183 \\
\hline Percentage of Occupied Space in Shopping Centre (Site) & & & -0.198 & & 0.911 & \\
\hline
\end{tabular}

Component 1 grouped number of households and population, as well as various market supply variables including the size of former Sears store, the total estimated size of former space, leased space, shopping centre square footage, and the number of stores in shopping centres. This component represents the market supply type variables.

Component 2 grouped occupancy rate (market supply), number of new tenants in former space (market supply), space change (property), configuration (property), leased space (site), occupancy rate (site), and number of new tenants in former space (site). This component represents variables related to occupancy and physical changes to the space.

Component 3 grouped Sears and Target in the same shopping centre (property), type of shopping centre (property), size of shopping centre (site), number of stores in shopping centre (site), size of former Sears space (site), and total estimated size of former space (site). This also component represents the physical size of the site and whether Sears and Target occupied the same shopping centre. 
Component 4 group population change, average household income, and shopping centre urbanity; this component represents demographic shifts and different urban zones. Component 5 and 6 both contain only one variable, percentage of occupied space in the shopping centre and store levels, respectively, the variables were statistically different from the other variables.

Each variable has a loading score over of 0.5 , which suggests a strong association between the variables and their respective component. While this may make interpretation of each component easier, the grouping of different variable types (i.e., market demand, market supply, property and site) creates an additional level of complexity during interpretation. Additionally, component 1, 2, 3 and 4 each comprised of at least three variables, and with the expectation of the number of new tenants (market supply), all variables loaded cleaning into their respective component, indicating strong collinearity exists between the grouped variables.

\subsubsection{Target Factor Analysis Results}

The KMO statistics is also at .755 (Table 13), indicating the data is suitable for factoring. Furthermore, Bartlett's Test shows a statistical significance of .000, indicating that the data are suitable for structure detection.

Table 13: Target's KMO Statistics and Significance

\begin{tabular}{|l|r|}
\hline KMO and Bartlett's Test & \\
\hline Kaiser-Meyer-Olkin Measure of Sampling Adequacy & .755 \\
\hline Bartlett's Test of Sphericity (Approx. Chi - Square) & 4340.185 \\
\hline df & 300 \\
\hline Sig. & .000 \\
\hline
\end{tabular}

A total of six components were extracted from the dataset. Figure 6 is a scree plot showing the eigenvalues and components. Table 14 shows the total variance explained by the six components at $78.6 \%$. The table indicates that the eigenvalues of each of the six components are greater than one. The rotated component matrix (Table 15) shows the factor loadings of the variables. Each component represents a theme related to the retail absorption process of Target. 


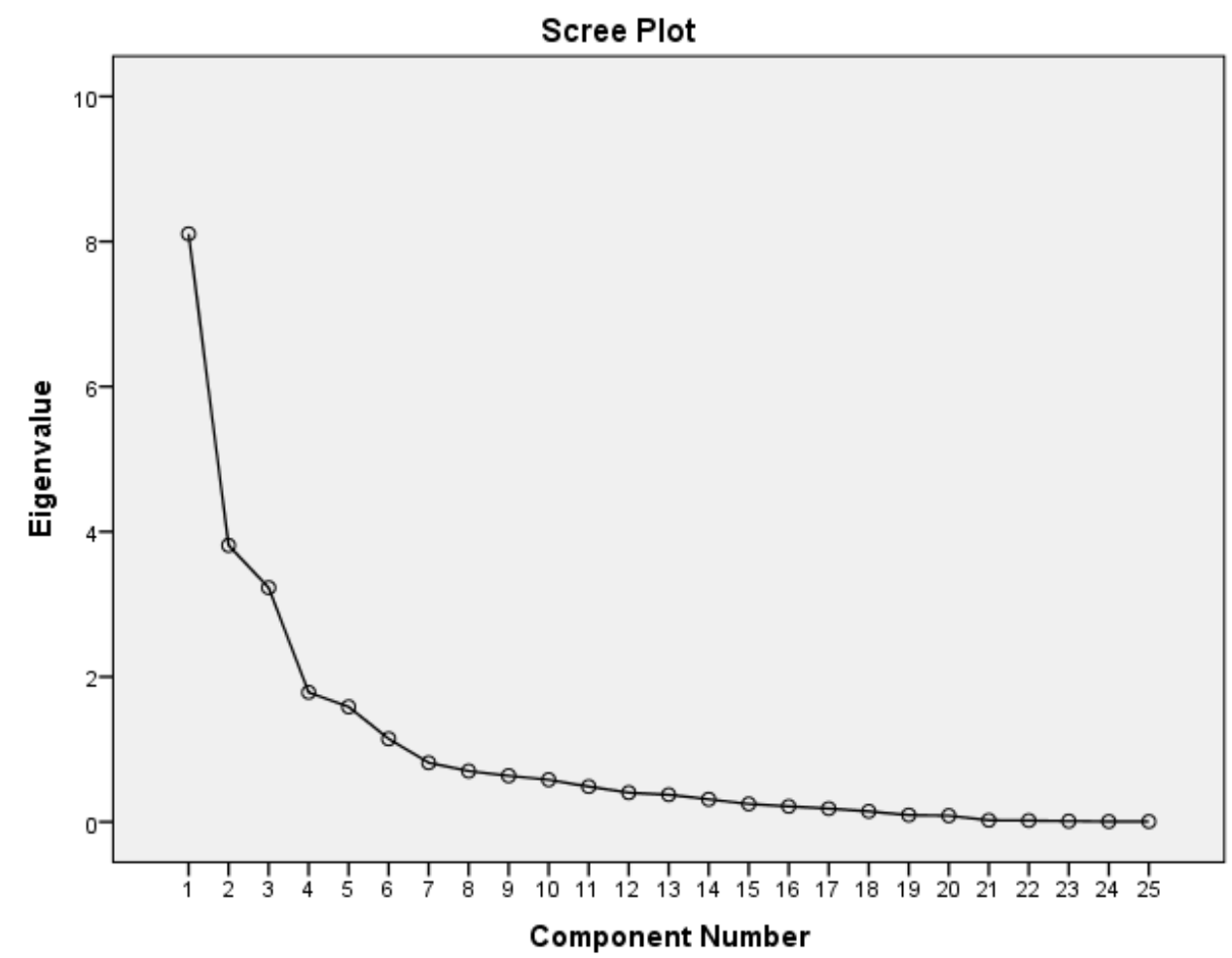

Figure 6: Target's Scree Plot

Table 14: Target's Total Variance Explained

\begin{tabular}{|c|c|c|c|c|c|c|}
\hline \multicolumn{7}{|c|}{ Total Variance Explained of Six Factors } \\
\hline \multicolumn{4}{|c|}{ Initial Eigenvalues } & \multicolumn{3}{|c|}{ Rotation Sum of Squared Loadings } \\
\hline Component & Total & $\%$ of Variance & Cumulative $\%$ & Total & $\%$ of Variance & Cumulative \% \\
\hline 1 & 8.10 & 32.42 & 32.424 & 6.97 & 27.90 & 27.90 \\
\hline 2 & 3.81 & 15.24 & 47.67 & 3.53 & 14.14 & 42.05 \\
\hline 3 & 3.22 & 12.91 & 60.58 & 3.49 & 13.97 & 56.02 \\
\hline 4 & 1.78 & 7.14 & 67.72 & 1.91 & 7.67 & 63.69 \\
\hline 5 & 1.58 & 6.34 & 74.06 & 1.91 & 7.64 & 71.34 \\
\hline 6 & 1.14 & 4.58 & 78.64 & 1.82 & 7.30 & 78.64 \\
\hline
\end{tabular}


Table 15: Target's Rotated Component Matrix

\begin{tabular}{|c|c|c|c|c|c|c|}
\hline \multicolumn{7}{|c|}{ Rotated Component Matrix } \\
\hline & Comp 1 & Comp 2 & Comp 3 & Comp 4 & Comp 5 & Comp 6 \\
\hline Total Household Population 12 Years or Over (Market Demand) & 0.923 & & & & & \\
\hline Total Population (Market Demand) & 0.931 & & & & & \\
\hline Population Change 2016 to 2018 (Market Demand) & 0.342 & & & 0.791 & & \\
\hline Average Household Income Constant Year 2005 (Market Demand) & 0.294 & -0.134 & & 0.809 & 0.107 & \\
\hline Size of Former Sears or Target Space (Market Supply) & 0.948 & & & 0.199 & & \\
\hline Total Estimated Size of Current Configuration (Market Supply) & 0.945 & & & 0.153 & 0.139 & \\
\hline Leased Space (Market Supply) & 0.938 & & 0.195 & & 0.120 & \\
\hline Occupancy Rate (Market Supply) & 0.124 & & 0.789 & & & \\
\hline Size Shopping Centre (Market Supply) & 0.819 & 0.328 & & 0.223 & & \\
\hline Number of Stores in Shopping Centre (Market Supply) & 0.826 & 0.360 & & 0.190 & & \\
\hline Number of New Tenants (Market Supply) & 0.746 & & & 0.217 & & 0.366 \\
\hline Space Change in Former Space (Property) & & & 0.892 & & & 0.245 \\
\hline Current Configuration of Space (Property) & & & 0.486 & & & 0.802 \\
\hline Sears and Target in same Shopping Centre (Property) & & 0.646 & & -0.403 & & \\
\hline Store Levels (Property) & 0.106 & 0.380 & & 0.414 & 0.416 & \\
\hline Type of Shopping Centre (Property) & & 0.717 & & & 0.129 & \\
\hline Shopping Centre Urbanity (Property) & -0.559 & -0.114 & -0.226 & -0.151 & -0.200 & \\
\hline Size of Shopping Centre (Site) & 0.144 & 0.854 & & 0.158 & 0.156 & \\
\hline Number of Stores in Shopping Centre (Site) & 0.197 & 0.865 & & & 0.107 & 0.136 \\
\hline Size of Former Sears or Target Space (Site) & 0.176 & 0.192 & & 0.149 & 0.768 & 0.207 \\
\hline Total Estimated Size of Current Configuration (Site) & 0.105 & & & & 0.899 & -0.149 \\
\hline Leased Space (Site) & 0.117 & & 0.885 & & 0.345 & \\
\hline Occupancy Rate (Site) & & & 0.957 & & & 0.128 \\
\hline Number of New Tenants in Former Spaces (Site) & & & & & & 0.920 \\
\hline Percentage of Occupied Space in Shopping Centre (Site) & & -0.801 & & & 0.234 & \\
\hline
\end{tabular}

Component 1 grouped number of households, population, size of former Target stores, total estimated size of former space (market supply), leased space (market supply), shopping centre sq. ft. (market supply), the number of stores in the shopping centre (market supply), number of new tenants in former space (market supply) and shopping centre urbanity (property) This component represents the market supply type variables and urbanity.

Component 2 grouped Sears and Target in the same shopping centre (property), type of shopping centre (property), size of the shopping centre (site), number of stores in the shopping centre (site) and percentage of occupied space in the shopping centre (site). This component represents variables relating to Sears and Target occupying the same shopping centre, as well as the physical size of the shopping centre.

Component 3 grouped occupancy rate (market), space change (property), leased space (site), and occupancy rate (site). This component represents variables relating to occupancy. Component 4 group population change and average household income; this component represents demographic shifts. 
Component 5 grouped store levels (property), size of former Target space (site), and total estimated size (site); this component represents the physical size of the store. Component 6 grouped configuration (property) and the number of new tenants in former space (site); this component represents the current configuration of the new tenants in the former Target spaces.

Each variable has a loading score of over 0.5 , which suggests a strong association between the variables and their respective component. As previously mentioned, while this may make interpretation of each component easier, the grouping of different variable types (i.e., market demand, market supply, property and site) creates an additional level of complexity during interpretation. Additionally, component 1,2, 3 and 5 each comprised of at least three variables, with all variables loaded into their respective component, indicating strong collinearity exists between the grouped variables. However, component 4 and 6 have less than three variables per component, indicating these variables were statistically different from the other variables.

\subsubsection{Factor Analysis Results - Sears and Target Comparison}

The factor analysis for Sears and Target both resulted in six factors, with common themes emerging from both results. These themes include market supply (e.g., the number of households, total population, etc.), shopping centre size characteristics, site characteristics, space change characteristics, sociodemographic shifts (average household income, population change, etc.), and configuration (e.g., single, small multiple, large multiple).

\subsection{Discriminant Analysis}

Discriminant analysis is "a statistical technique which allows the researcher to study the differences between two or more groups of objects with respect to several variables simultaneously" (Klecka, 1980; IBM, 2019). The technique builds a predictive model that is composed of a single or a set of discriminant function(s) based on linear combinations of predictor variables that may provide the best differentiation between the groups (IBM, 2019). For this study, a discriminant analysis will be used to identify factors that are strong predictors of occupancy in shopping centres across Canada. 


\subsubsection{Predicted Group Membership - Sears Occupancy}

Table 16 indicates the discriminant model classified 147 of the 147 Sears stores located in shopping centres. All 147 shopping centres and their respective occupancy category were classified correctly at $91.8 \%$. Table 17 indicates the model was significant .000 with $91.2 \%$ variance explained.

Table 16: Predicted Group Membership - Sears Occupancy

\begin{tabular}{|c|c|c|c|c|c|c|c|c|}
\hline \multicolumn{9}{|c|}{ Predicted Group Membership } \\
\hline \multicolumn{2}{|c|}{ Occupancy Category } & $\mathbf{0}$ & 1 & 2 & 3 & 4 & 5 & Total \\
\hline \multirow[t]{6}{*}{ Count } & $\mathbf{0}$ & 95 & 0 & 0 & 0 & 0 & 0 & 95 \\
\hline & 1 & 0 & 1 & 0 & 1 & 0 & 0 & 2 \\
\hline & 2 & 0 & 0 & 2 & 1 & 0 & 0 & 3 \\
\hline & 3 & 0 & 0 & 0 & 7 & 1 & 0 & 8 \\
\hline & 4 & 0 & 0 & 0 & 0 & 1 & 0 & 1 \\
\hline & 5 & 0 & 0 & 1 & 4 & 4 & 29 & 38 \\
\hline \multirow[t]{6}{*}{ Percentag } & $\mathbf{0}$ & 100 & 0 & 0 & 0 & 0 & 0 & 100 \\
\hline & 1 & 0 & 50 & 0 & 50 & 0 & 0 & 100 \\
\hline & 2 & 0 & 0 & 66.7 & 33.3 & 0 & 0 & 100 \\
\hline & 3 & 0 & 0 & 0 & 87.5 & 12.5 & 0 & 100 \\
\hline & 4 & 0 & 0 & 0 & 0 & 100 & 0 & 100 \\
\hline & 5 & 0 & 0 & 2.6 & 10.5 & 10.5 & 76.3 & 100 \\
\hline
\end{tabular}

\subsubsection{Test of Equality of Group Means - Sears Occupancy}

The Test of Equality of Group Means "measures each independent variable's potential before the model is created (IBM, 2018). The Wilks' Lambda, also referred to the U statistic, is another measure of a variable's potential as it tests for the equality of group centroids (IBM, 2018). Smaller values (less than 0.6 to 0.7 ) are preferred for Wilks' Lambda as it indicates that the groups differ. High values indicate that noise in the data exists. The Wilks' Lambda (Table 17) for all variables was less than one, and their significance of .000 indicates that the groups are significantly different on every variable. However, the canonical correlation was above 0.6, indicating poor group separation.

Table 17: Significance and Discriminating Ability: Sears Occupancy

\begin{tabular}{|l|c|c|c|c|}
\hline Function & Eigenvalue & \% of Variance & Cumulative \% & Canonical Correlation \\
\hline 1 & 12.728 & 91.2 & 91.2 & .963 \\
\hline Test of Function (s) & Wilks' Lambda & Chi-Square & df & Sig. \\
\hline 1 through 5 & .027 & 477.940 & 110 & .000 \\
\hline
\end{tabular}




\subsubsection{Classification Coefficients - Sears Occupancy}

The coefficients in Table 18 indicates the predictor power of each component. The table provides coefficients that can be used to calculate the discriminant score for each case. The scores are calculated to have a mean of zero and a standard deviation of one. These values range from .0 to 10 , and any value below 0.3 are considered weak predictor variables, which are highlighted in red.

Table 18: Standardized Canonical Discriminant Function Coefficients - Sears Occupancy

\begin{tabular}{|c|c|c|c|c|c|}
\hline & \multicolumn{5}{|c|}{ Functions } \\
\hline & $\mathbf{1}$ & 2 & 3 & 4 & 5 \\
\hline Total Household Population 12 Years or Over (Market Demand) & -.881 & .735 & .543 & -1.225 & 1.528 \\
\hline Total Population (Market Demand) & .793 & -.841 & -.381 & 1.733 & -1.295 \\
\hline Population Change 2016 to 2018 (Market Demand) & -.129 & .065 & -.259 & -.498 & .686 \\
\hline Average Household Income Constant Year 2005 (Market Demand) & -.041 & -.113 & .831 & -.166 & -.069 \\
\hline Size of Former Sears or Target Space (Market Supply) & .606 & -.617 & 6.322 & 3.899 & 2.317 \\
\hline Total Estimated Size of Current Configuration (Market Supply) & -.506 & -.059 & -6.316 & -2.672 & -2.624 \\
\hline Leased Space (Market Supply) & .332 & -.125 & .142 & -.089 & -.228 \\
\hline Size Shopping Centre (Market Supply) & 1.156 & 1.256 & -.734 & -3.466 & .524 \\
\hline Number of Stores in Shopping Centre (Market Supply) & -1.163 & -.471 & .779 & 1.926 & -.348 \\
\hline Number of New Tenants in Former Spaces (Market Supply) & -.092 & .065 & -.129 & .044 & .011 \\
\hline Current Configuration of Space (Property) & 1.512 & .820 & -.386 & .391 & .388 \\
\hline Sears and Target in same Shopping Centre (Property) & -.044 & .143 & .433 & .108 & -.132 \\
\hline Store Levels (Property) & -.082 & .619 & .482 & .048 & -.374 \\
\hline Type of Shopping Centre (Property) & -.271 & .180 & .282 & .132 & .628 \\
\hline Shopping Centre Urbanity (Property) & -.048 & .168 & .231 & -.050 & .726 \\
\hline Size of Shopping Centre (Site) & -.016 & -.552 & .326 & .797 & -.463 \\
\hline Number of Stores in Shopping Centre (Site) & -.079 & .296 & -.533 & -.428 & .447 \\
\hline Size of Former Sears or Target Space (Site) & -.440 & .367 & -.522 & 1.687 & .781 \\
\hline Total Estimated Size of Current Configuration (Site) & .168 & .231 & .162 & -1.908 & -.735 \\
\hline Leased Space (Site) & .494 & -.594 & .494 & -.276 & .140 \\
\hline Number of New Tenants in Former Spaces (Site) & -.773 & -.603 & .171 & -.241 & -.493 \\
\hline Percentage of Occupied Space in Shopping Centre (Site) & .035 & .083 & .215 & .505 & -.052 \\
\hline
\end{tabular}

Table 18 indicates the number of households (market demand), total population (market demand), the size of former Sears (market supply and site), the size of the shopping centre (market supply), and the number of stores in shopping centre (market supply), to be strong predictors variables.

\subsubsection{Predicted Group Membership - Target Occupancy}

Table 19 indicates the discriminant model classified 138 of the 138 Target stores located in shopping centres. All 138 shopping centres and their respective occupancy category were classified correctly at $96.4 \%$. Table 20 indicates the model was significant .000 with $93.5 \%$ variance explained. 
Table 19: Predicted Group Membership - Target Occupancy

\begin{tabular}{|r|r|r|r|r|r|r|r|r|r|}
\hline \multicolumn{7}{|c|}{ Pre dicted Group Me mbers hip } \\
\hline Occupancy Category & $\mathbf{0}$ & $\mathbf{1}$ & $\mathbf{2}$ & $\mathbf{3}$ & $\mathbf{4}$ & $\mathbf{5}$ & Total \\
\hline Count & $\mathbf{0}$ & 19 & 0 & 1 & 0 & 0 & 0 & 20 \\
\hline & $\mathbf{1}$ & 0 & 1 & 0 & 0 & 0 & 0 & 1 \\
\hline $\mathbf{2}$ & 0 & 0 & 3 & 1 & 0 & 0 & 4 \\
\hline $\mathbf{3}$ & 0 & 0 & 0 & 9 & 0 & 0 & 9 \\
\hline $\mathbf{4}$ & 0 & 0 & 0 & 0 & 7 & 0 & 7 \\
\hline $\mathbf{5}$ & 0 & 0 & 0 & 0 & 3 & 94 & 97 \\
\hline Percentage & $\mathbf{0}$ & 95.0 & 0 & 5.0 & 0 & 0 & 0 & 100 \\
\hline & $\mathbf{1}$ & 0 & 100 & 0 & 0 & 0 & 0 & 100 \\
\hline $\mathbf{2}$ & 0 & 0 & 75.0 & 25.0 & 0 & 0 & 100 \\
\hline $\mathbf{3}$ & 0 & 0 & 0 & 100 & 0 & 0 & 100 \\
\hline $\mathbf{4}$ & 0 & 0 & 0 & 0 & 100 & 0 & 100 \\
\hline $\mathbf{5}$ & 0 & 0 & 0 & 0 & 3.1 & 96.9 & 100 \\
\hline
\end{tabular}

4.6.5. Test of Equality of Group Means - Target Occupancy

The Wilks' Lambda (Table 20) for all variables was less than one, and their significance of .000 indicates that the groups are significantly different for every variable. However, the canonical correlation was above 0.6 , indicating poor group separation.

Table 20: Significance and Discriminating Ability: Target Occupancy

\begin{tabular}{|l|c|c|c|c|}
\hline Function & Eigenvalue & $\%$ of Variance & Cumulative \% & Canonical Correlation \\
\hline 1 & 18.598 & 93.5 & 93.5 & .974 \\
\hline Test of Function (s) & Wilks' Lambda & Chi-Square & df & Sig. \\
\hline 1 through 5 & .018 & 495.164 & 110 & .000 \\
\hline
\end{tabular}

\subsubsection{Classification Coefficients - Target Occupancy}

Table 21 indicates the predictor power of each component, with coefficients highlighted in red considered to be weak (below 0.3 ) predictor variables. 
Table 21: Standardized Canonical Discriminant Function Coefficients - Target

\begin{tabular}{|c|c|c|c|c|c|}
\hline & \multicolumn{5}{|c|}{ Functions } \\
\hline & 1 & 2 & 3 & 4 & 5 \\
\hline Total Household Population 12 Years or Over (Market Demand) & -1.927 & 1.583 & -.785 & 3.068 & -4.889 \\
\hline Total Population (Market Demand) & 1.707 & -1.061 & .421 & -2.688 & 5.694 \\
\hline Population Change 2016 to 2018 (Market Demand) & .114 & .342 & -.003 & -.299 & -.377 \\
\hline Average Household Income Constant Year 2005 (Market Demand) & -.180 & -.072 & .212 & .518 & .146 \\
\hline Size of Former Sears or Target Space (Market Supply) & -.386 & .312 & 1.091 & 2.747 & 3.773 \\
\hline Total Estimated Size of Current Configuration (Market Supply) & .885 & -.484 & -1.615 & -2.588 & -3.694 \\
\hline Leased Space (Market Supply) & -.071 & .189 & .715 & .081 & -.431 \\
\hline Size Shopping Centre (Market Supply) & -.307 & .176 & -.729 & -3.038 & 629 \\
\hline Number of Stores in Shopping Centre (Market Supply) & -.012 & -.054 & 1.491 & 3.197 & -.692 \\
\hline Number of New Tenants in Former Spaces (Market Supply) & -.206 & -.550 & -.577 & -.342 & -.211 \\
\hline Current Configuration of Space (Property) & .691 & 1.265 & -.042 & .186 & .141 \\
\hline Sears and Target in same Shopping Centre (Property) & .123 & .047 & -.385 & .580 & .014 \\
\hline Store Levels (Property) & .007 & -.056 & -.114 & .250 & -.139 \\
\hline Type of Shopping Centre (Property) & -.047 & .216 & .663 & -.025 & -.016 \\
\hline Shopping Centre Urbanity (Property) & -.120 & .366 & -.292 & .358 & .492 \\
\hline Size of Shopping Centre (Site) & .318 & .254 & 1.462 & .595 & -.015 \\
\hline Number of Stores in Shopping Centre (Site) & -.147 & -.223 & -1.656 & -1.380 & .298 \\
\hline Size of Former Sears or Target Space (Site) & -.275 & .039 & -.800 & -.056 & .072 \\
\hline Total Estimated Size of Current Configuration (Site) & -1.505 & .761 & .665 & .001 & .240 \\
\hline Leased Space (Site) & 2.038 & -.397 & .005 & -.089 & .081 \\
\hline Number of New Tenants in Former Spaces (Site) & -.127 & -.702 & .431 & .135 & -.223 \\
\hline Percentage of Occupied Space in Shopping Centre (Site) & .019 & .313 & .491 & -.049 & .166 \\
\hline
\end{tabular}

Table 21 indicates the number of households, total population, former size of Target, and total estimated size to be strong predictor variables for all components.

\subsection{Discriminant Analysis Results Discussion}

Limited studies on shopping centres employ factor and discriminant analysis to measure a shopping centre's occupancy. These studies are usually used to measure a mall's attractiveness using endogenous variables such as sales and retail square footage. This study's discriminant analysis resulted in five dimensions each for Sears and Target, which are themed based on their variable type. The discriminant analysis classified $91.8 \%$ of Sears and $96.4 \%$ of Target shopping centres by occupancy correctly. Therefore, there is sufficient evidence to reject hypothesis H1 and fail to reject hypothesis H2. This means the dataset is sufficient in predicting occupancy based on different variable types than only endogenous and exogenous factors.

The analysis for Sears determined the total population, the number of households, the size of the shopping centre (market), the number of stores in the shopping centre (market), and the size of the former Sears (market) to be strong predictors of occupancy. These results are consistent with multiple studies suggesting shopping centre size and population are related to the centre's potential success. Larger shopping centres with a large market to draw from can 
accommodate a wide variety of retailers and a higher gross leasable area. Also, the size of the former Sears store may have influenced what the owners or developers were able to do with the space. In relation, the configuration was also a strong predictor, as multiple tenant configuration may be more appealing to tenants who primarily operate with smaller retail square footage.

The analysis for Target determined the total population, the number of households, the size of the former Target store, and the total estimated size of the current space to be strong predictors of occupancy. Unlike the results for Sears, the results for Target found the size of the store to be a stronger predictor than the size of the shopping centre and the number of stores in the shopping centre. While the latter variables are still moderately strong at predicting occupancy, as previously mentioned, a large amount of partially leased (86\%) former Target properties across Canada would not make this variable a strong predictor.

Both studies determined the population size to be a strong predictor of occupancy, as larger markets can accommodate larger shopping centres and a variety of retailers. The average household income variable was surprisingly not a strong indicator of occupancy. This finding is not consistent with existing literature suggesting the socioeconomic status of a shopping centre's surrounding area to be a huge influence on their success (Jones and Hernandez, 2003). As previously mentioned, the median age of maintainer was an early exploratory variable in the study. However, when used in multiple statistical analyses, the variable was determined to have a weak relationship with occupancy. This is consistent with studies suggesting the consumer's age has little influence on a shopping centre's success. While other studies have theorized teens and seniors make up the largest consumer group, as they have ancillary time that the other age groups do not possess, and such studies typically do not account for spending power. It is important to note that consumer age studies related to shopping centre research are outdated. Instead, current ages studies prefer to examine changing retail trends based on generational consumer preferences.

\subsection{Spatial Analysis}

The results of the discriminant model were mapped to visualize the discriminant groups by the shopping centre. The discriminant groups differentiated different shopping centres by 
their occupancy rate predicted by the chosen variables in the analysis, with 5 indicating very high to 0 identifying vacant stores.

\subsection{Spatial Analysis - Sears Results}

The discriminant model classified 147 of 147 of the Sears stores located in shopping centres, with $91.8 \%$ of grouped cases correctly classified at a significance of .000 with $91.2 \%$ variance explained (Table 17).

\subsubsection{Spatial Analysis Sears Results - Canada}

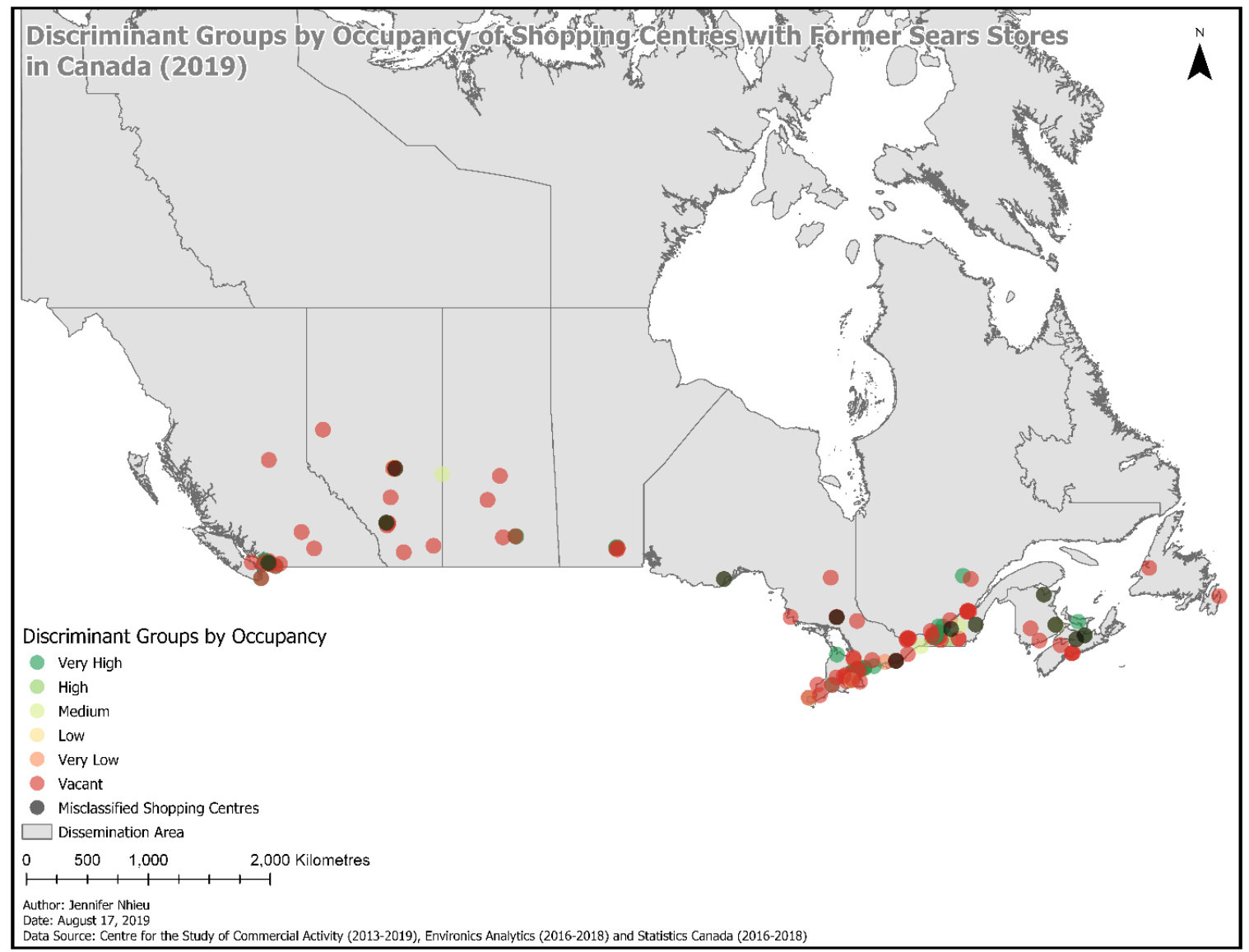

Figure 7: Sears Canada Map

Source: Centre for the Study of Commercial Activity (2013-2019), Environics Analytics (2016-2018) and Statistics Canada (2016-2018)

The discriminant model classified shopping centres in CMAs such as Vancouver, Toronto, and Montreal, which are part of the VETCOM markets, with high occupancy (Figure 7). However, other VETCOM markets such as Edmonton, Calgary and Ottawa are experiencing 
low occupancy and vacancy in their former Sears spaces. Moving gradually away from the CMAs, the spatial pattern presents mostly vacant and some low occupancy shopping centres in exurban areas. Furthermore, the grey dots represent misclassified shopping centres. It is important to identify shopping centres that have been misclassified, as the misclassification means that the centre does not have the prototypical characteristics related to occupancy (i.e., population, average household income, shopping centre size, etc.). The discriminant model misclassified 12 shopping centres, which are located in some VETCOM markets such as Vancouver, Edmonton, Calgary, and some exurban areas.

\subsubsection{Spatial Analysis Sears Results - Vancouver, British Columbia}

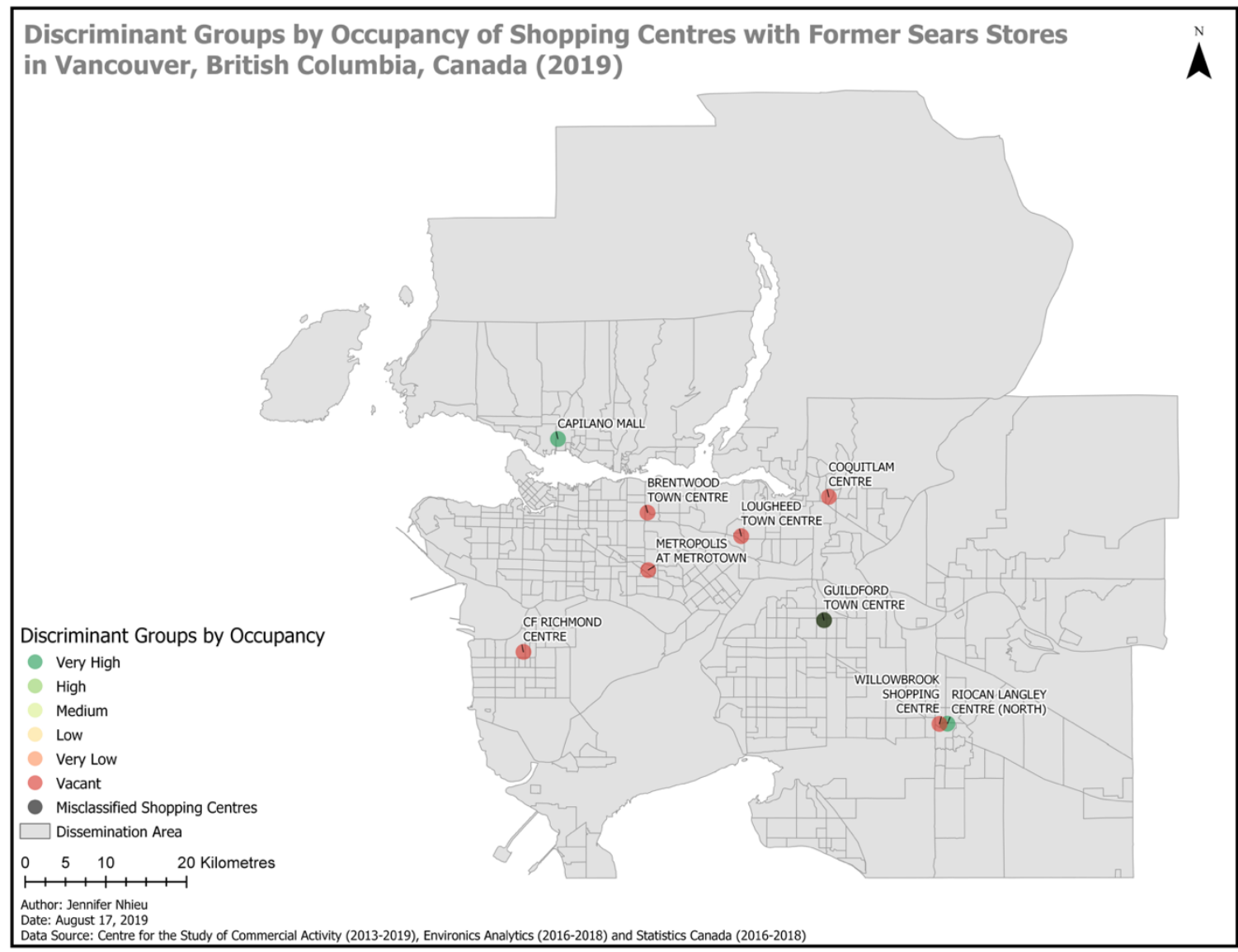

Figure 8: Sears Vancouver Map

Source: Centre for the Study of Commercial Activity (2013-2019), Environics Analytics (2016-2018) and Statistics Canada (2016-2018)

Three shopping centres in the Vancouver market were classified with a very high occupancy: Capilano Mall, Guildford Town Centre, and RioCan Langley Centre (North), with 
Guildford Town Centre, misclassified as high (Figure 8). These shopping centres have markets with an average population of 926,328 and an average household income of over $\$ 91,000$, which is above average compared with other shopping centres with former Sears spaces in the market. The shopping centres with high occupancy were a mix of super-regional and regional malls that did not lease to both Sears and Target. The shopping centres that were classified as vacant did not have the same market conditions. However, similar property and site conditions exist between the shopping centres that had high occupancy and those that are currently vacant, such as having the same shopping centre type and urbanity as well as having a similar number of stores. Sears is a year post-closure, and the Vancouver market is only 19.2\% leased (Table 4) as such, there is still the opportunity to secure new tenants.

\subsubsection{Spatial Analysis Sears Results - Edmonton, Alberta}

Discriminant Groups by Occupancy of Shopping Centres with Former Sears Stores in Edmonton, Alberta, Canada (2019)

Discriminant Groups by Occupancy

Very High

High

Medium

Low

Very Low

Vacant

- Misclassified Shopping Centres

$\square$ Dissemination Area

$0,10,20,40$ Kilometres

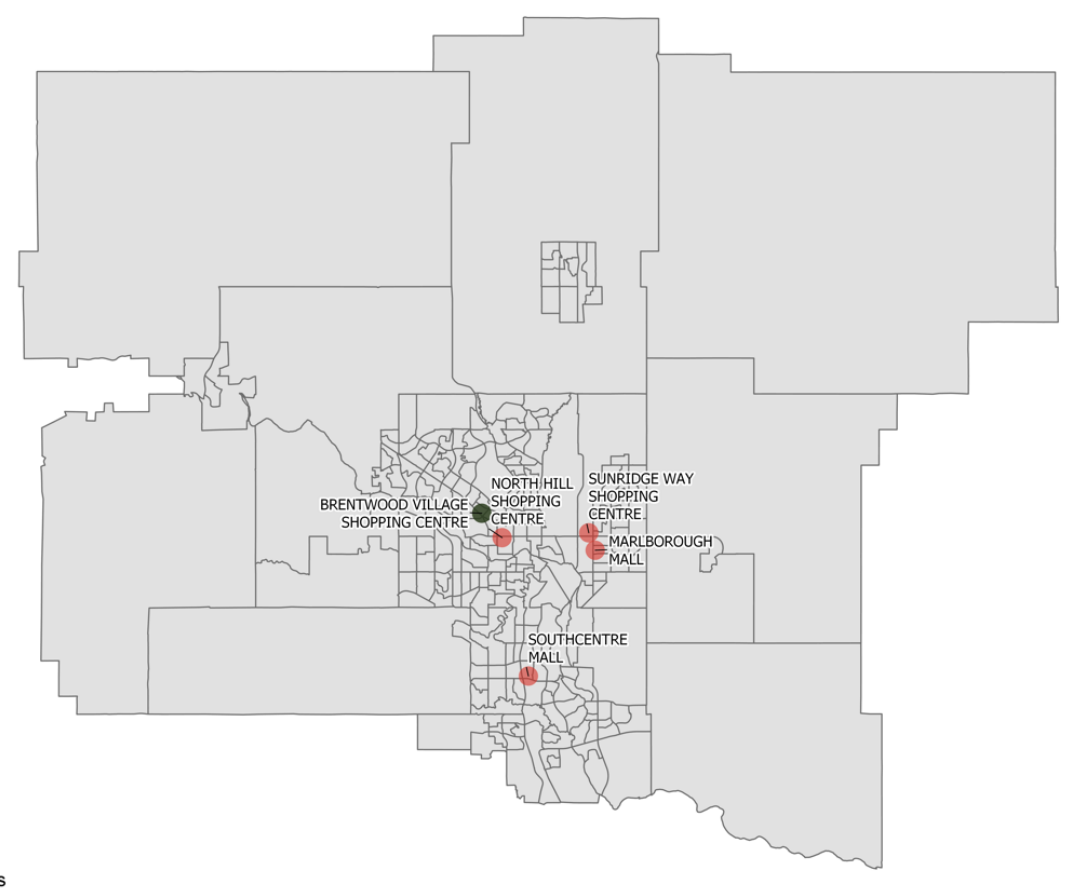

Author: Jennifer Nhieu

Date: August 17, 2019
Data Source: Centre for the Study of Commercial Activity (2013-2019), Environics Analytics (2016-2018) and Statistics Canada (2016-2018)

Figure 9: Sears Edmonton Map

Source: Centre for the Study of Commercial Activity (2013-2019), Environics Analytics (2016-2018) and Statistics Canada (2016-2018) 
The discriminant model misclassified Brentwood Village Shopping Centre to have a high occupancy rate, but its actual group membership is very high (Figure 9). The shopping centre's market has a total population of 1,001,375 and an average household home of $\$ 117,288$, which is above averaged compared with other shopping centres with former Sears spaces in the market. Brentwood Village is a community shopping centre, making it the smallest in the market. As the smallest shopping centre, it also had a low gross leasable area and a small number of stores. The size of the former Sears space in the shopping centre was also below average, at 40,043 sq. $\mathrm{ft}$. at closing, the space would be easier to lease compared to the average 100,000 sq. $\mathrm{ft}$. Sears space. Furthermore, Brentwood Village is managed by RioCan, Canada's largest real estate investment trust, who claimed they "their exposure to Sears is far lower, and we have been preparing for just this situation at many locations for some time now" (RioCan, 2017).

\subsubsection{Spatial Analysis Sears Results - Calgary, Alberta}

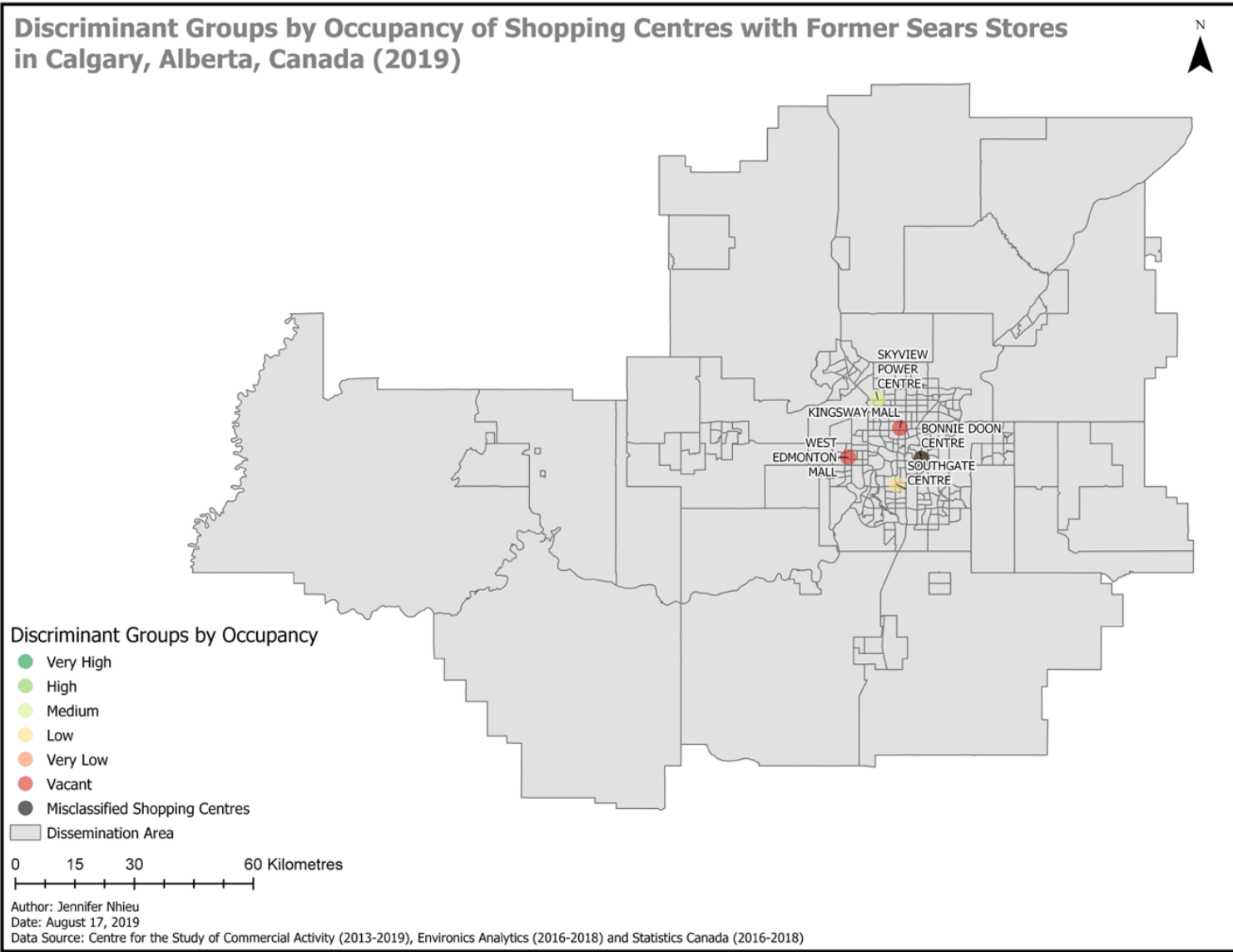

Figure 10: Sears Calgary Map

Source: Centre for the Study of Commercial Activity (2013-2019), Environics Analytics (2016-2018) and Statistics Canada (2016-2018) 
The discriminant model misclassified Bonnie Doon Centre to have low occupancy, but its actual group membership is very high (Figure 10), making it the shopping centre with the highest occupancy in Edmonton. Bonnie Doon is a regional shopping centre with a total population of 992,051 and an average household income of $\$ 93,054$, which is above average compared with the other shopping centres with former Sear's spaces in the market. The mall is owned by Morguard Investment Ltd., a Toronto based company who proposed to re-zone the land into a mixed-use transit-orientated development and announced its new tenant less than a year after Sears' closure. The senior vice-president of development, Margaret Knowles, said the company "wants to turn it from sad to ecstatic" (CBC News, 2018).

\subsubsection{Spatial Analysis Sears Results - Toronto, Ontario}

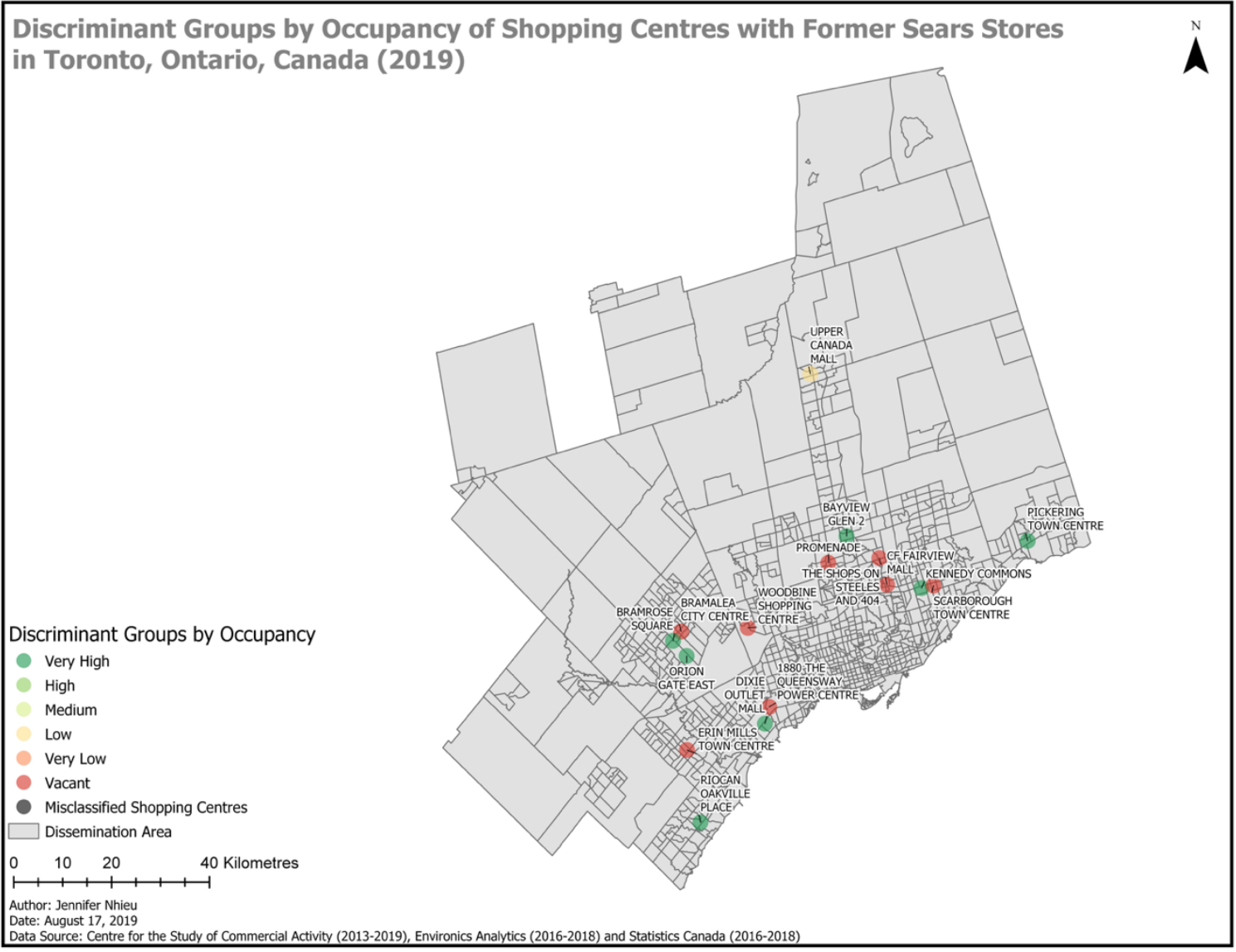

Figure 11: Sears Toronto Map

Source: Centre for the Study of Commercial Activity (2013-2019), Environics Analytics (2016-2018) and Statistics Canada (2016-2018) 
Seven shopping centres in the Toronto market were classified with a very high occupancy: Bramrose Square, Dixie Outlet Mall, RioCan Oakville Place, Pickering Town Centre, Kennedy Commons, Bayview Glen 2, and Orion Gate East (Figure 11). These shopping centres have markets with an average population of 1,323,845 and an average household income range of $\$ 91,000$ to $\$ 124,000$. The shopping centres with high occupancy were a mix of superregional regional, community, power centre and factory outlets. The common characteristics between these shopping centres are that they are located in either urban or suburban markets, and six of the seven centres did not lease to both Sears and Target.

\subsubsection{Spatial Analysis Sears Results - Ottawa, Ontario}

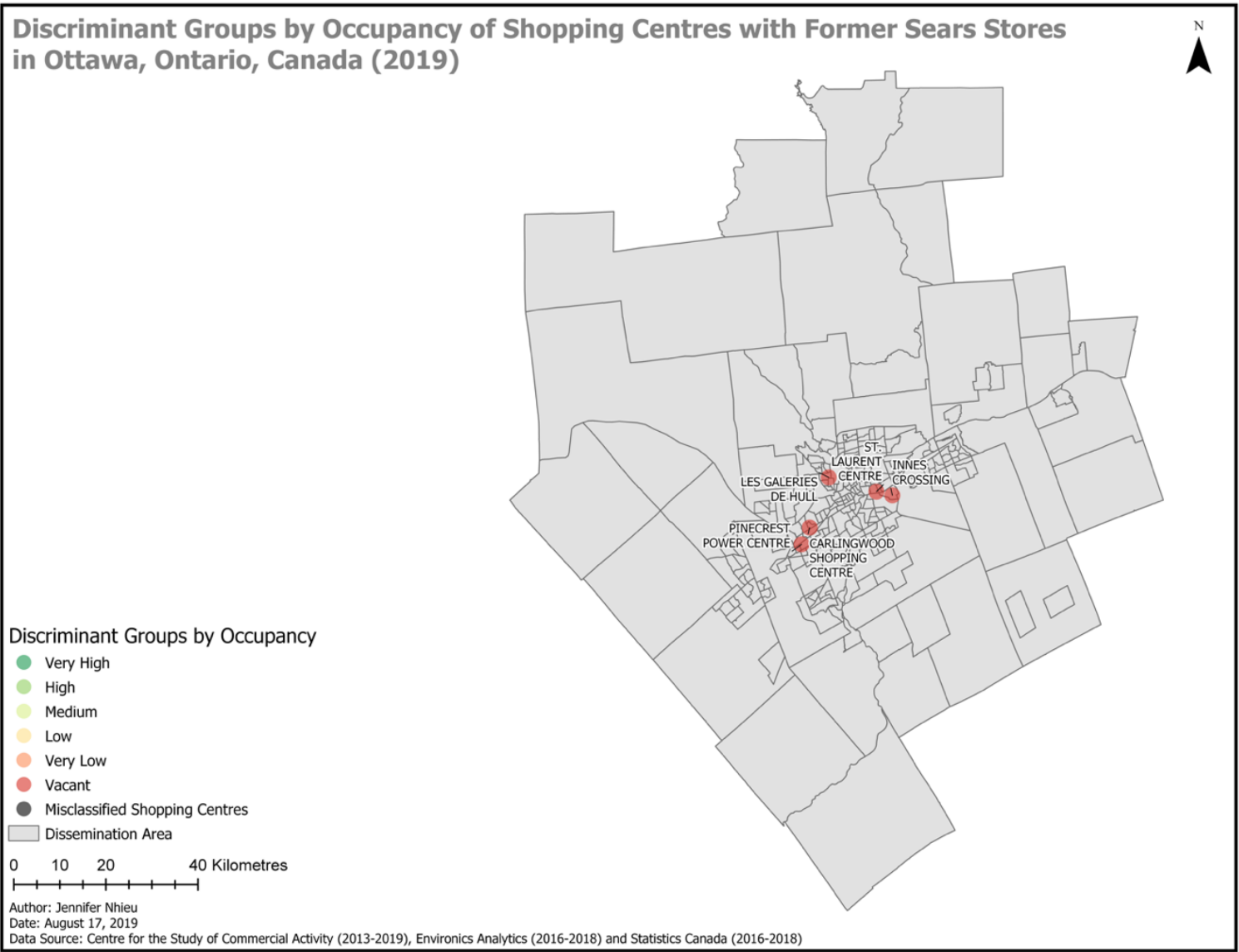

Figure 12: Sears Ottawa Map

Source: Centre for the Study of Commercial Activity (2013-2019), Environics Analytics (2016-2018) and Statistics Canada (2016-2018) 
The discriminant model classified all shopping centres in the Ottawa market as vacant (Figure 12). These results were expected as none of the shopping centres in Ottawa have leased any of their former Sears spaces (Table 4).

\subsubsection{Spatial Analysis Sears Results - Montreal, Quebec}

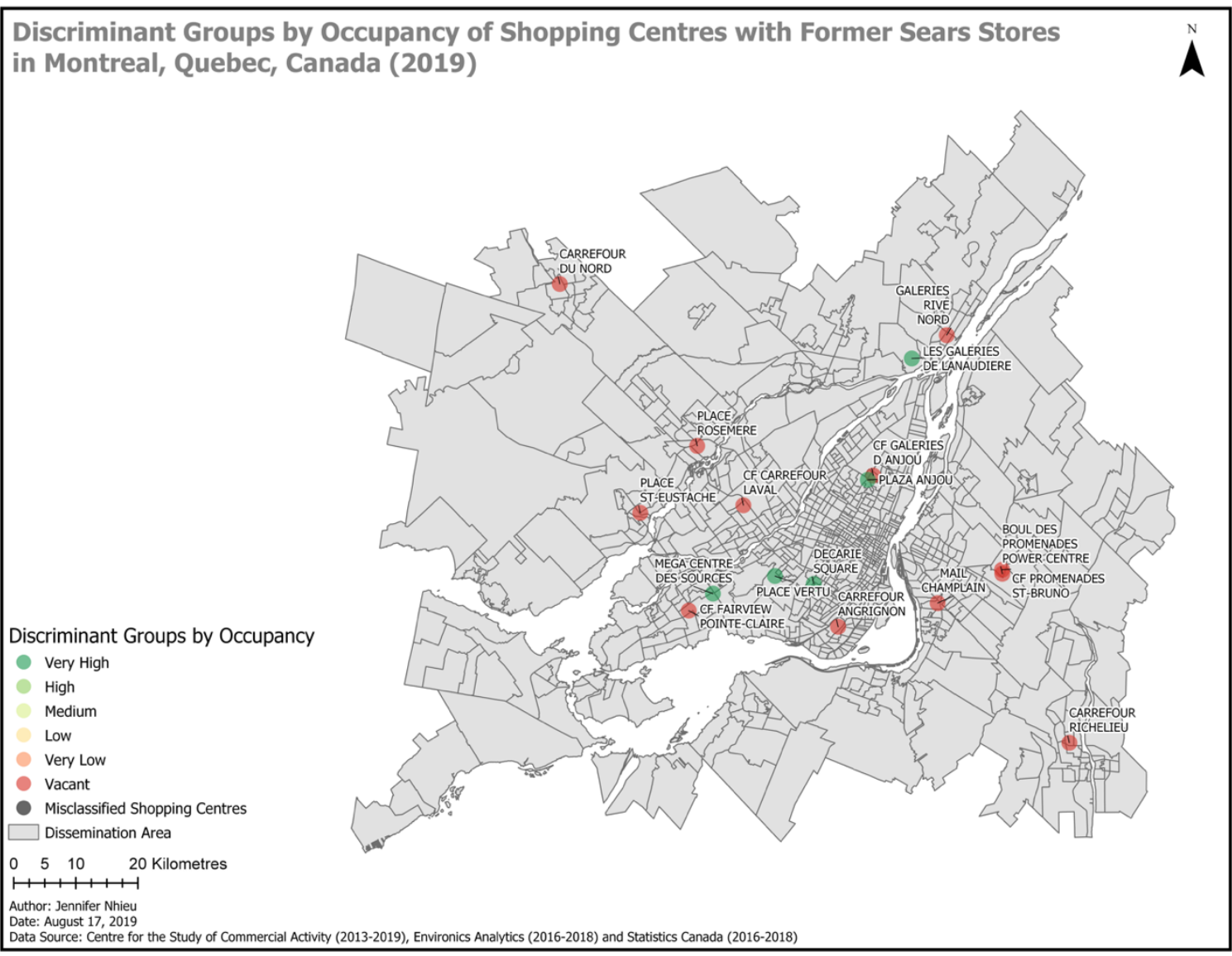

Figure 13: Sears Montreal Map

Source: Centre for the Study of Commercial Activity (2013-2019), Environics Analytics (2016-2018) and Statistics Canada (2016-2018)

Five shopping centres in the Montréal market were classified as high occupancy: Mega Centre des Sources, Place Vertu, Decarie Square, Place Anjou and Les Galeries de Lanaudiere (Figure 13). These shopping centres have markets with an average total population of 1,628,290 and an average household income range of $\$ 67,000$ to $\$ 79,000$. While the population is higher than average, as they are located in urban areas, the average household income range is below average compared with other shopping centres in the market. The shopping centres are a mix of super-regional, power centre, community and neighbourhood level. Most of the shopping centres 
were smaller compared to others located in suburban Montreal and as a result, had a lower number of stores. Some common characteristics are that they were mostly located in urban markets with some in the suburbs, the shopping centre leased to new tenants as a single-tenant configuration, and only one of the five centres leased to both Sears and Target.

\subsection{Spatial Analysis - Target Results}

The discriminant model classified 138 of 138 of the Target stores located in shopping centres, with $96.4 \%$ of grouped cases correctly classified at a significance of .000 with $93.5 \%$ variance explained (Table 22).

\subsubsection{Spatial Analysis Target Results - Canada}

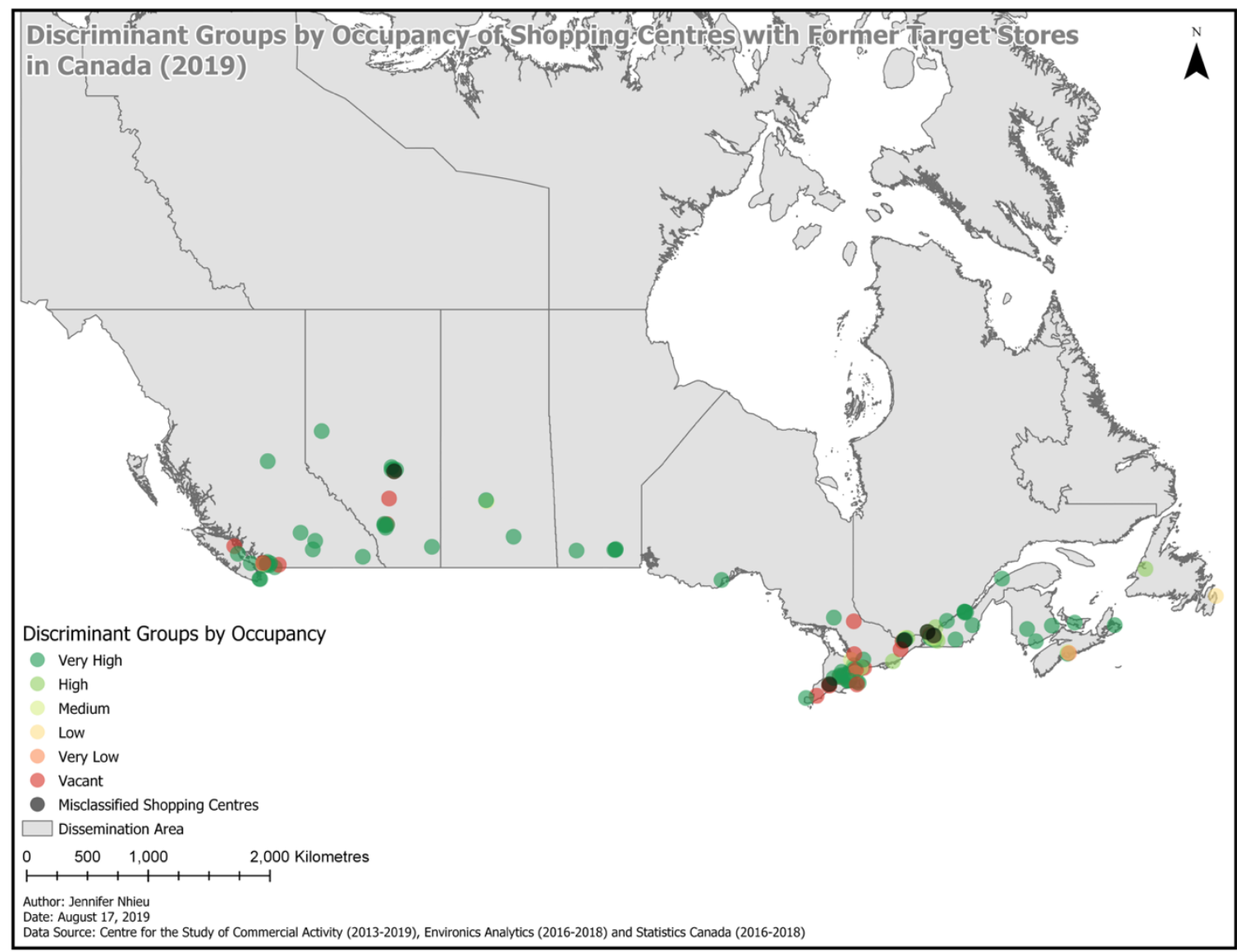

Figure 14: Target Canada Map

Source: Centre for the Study of Commercial Activity (2013-2019), Environics Analytics (2016-2018) and Statistics Canada (2016-2018) 
The discriminant model classified many shopping centres as high to very high across Canada, except for areas surrounding the Toronto and Vancouver CMA (Figure 14). As previously mentioned, shopping centres had more time and opportunity to work itself in bringing their former Target properties back into productive use. Therefore, many former spaces have already been completely leased. The model misclassified five shopping centres which were mainly located in Calgary, Ottawa and Montreal, three of six VETCOM markets.

\subsubsection{Spatial Analysis Target Results - Vancouver, British Columbia}

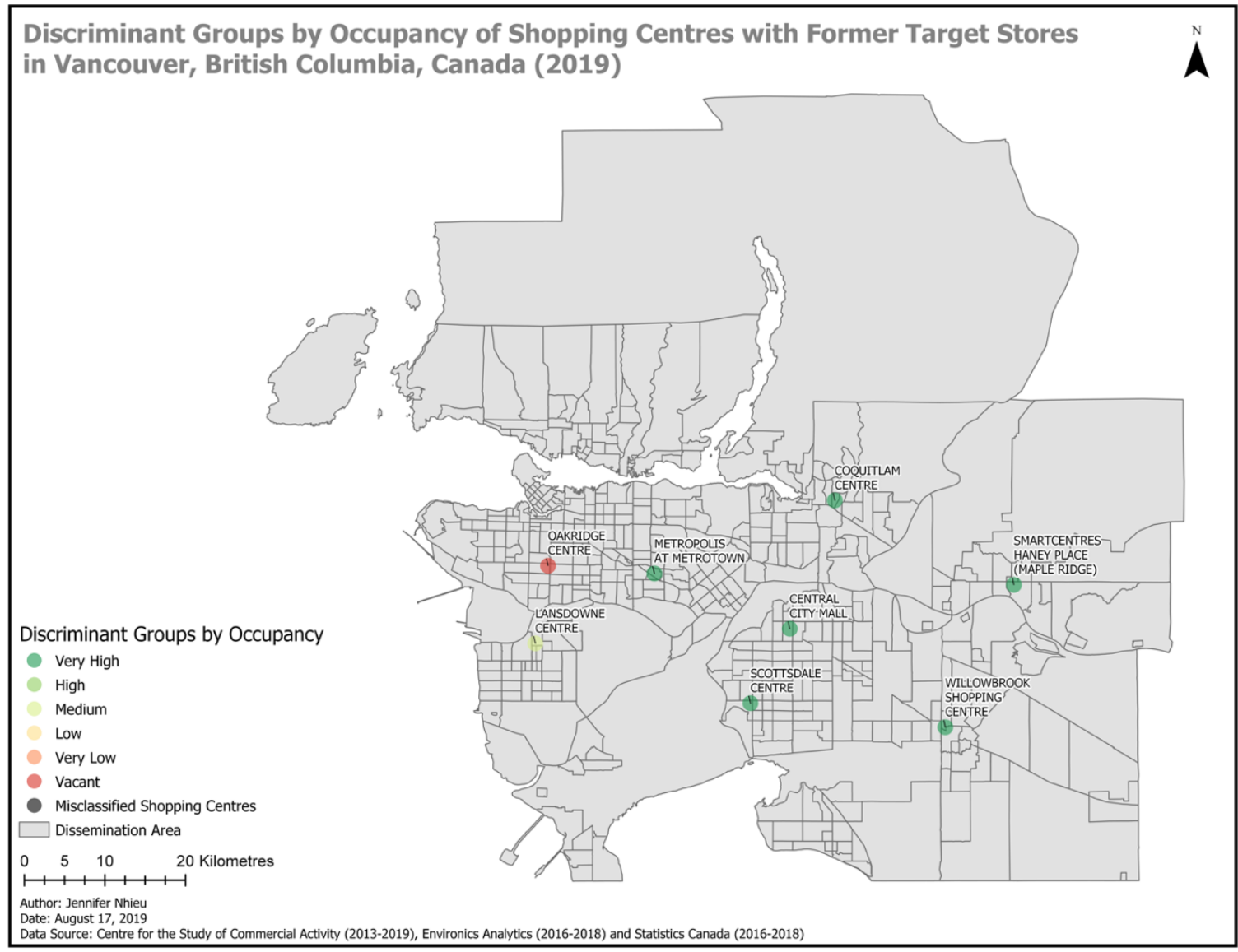

Figure 15: Target Vancouver Map Source: Centre for the Study of Commercial Activity (2013-2019), Environics Analytics (2016-2018) and Statistics Canada (2016-2018)

Six shopping centres in the Vancouver market were classified as very high occupancy: Metropolis at Metrotown, Coquitlam Centre, Central City Mall, Scottsdale Centre, Willowbrook Shopping Centre, and Smart Centres Hanley Place (Maple Ridge) (Figure 15). These shopping centres represent the majority of the Vancouver market with former Target stores. Together, they 
have an average total population of 912, 663 and an average household income ranging from $\$ 88,000$ to $\$ 96,000$. These shopping centres vary significantly in type and characteristics.

\subsubsection{Spatial Analysis Target Results - Edmonton, Alberta}

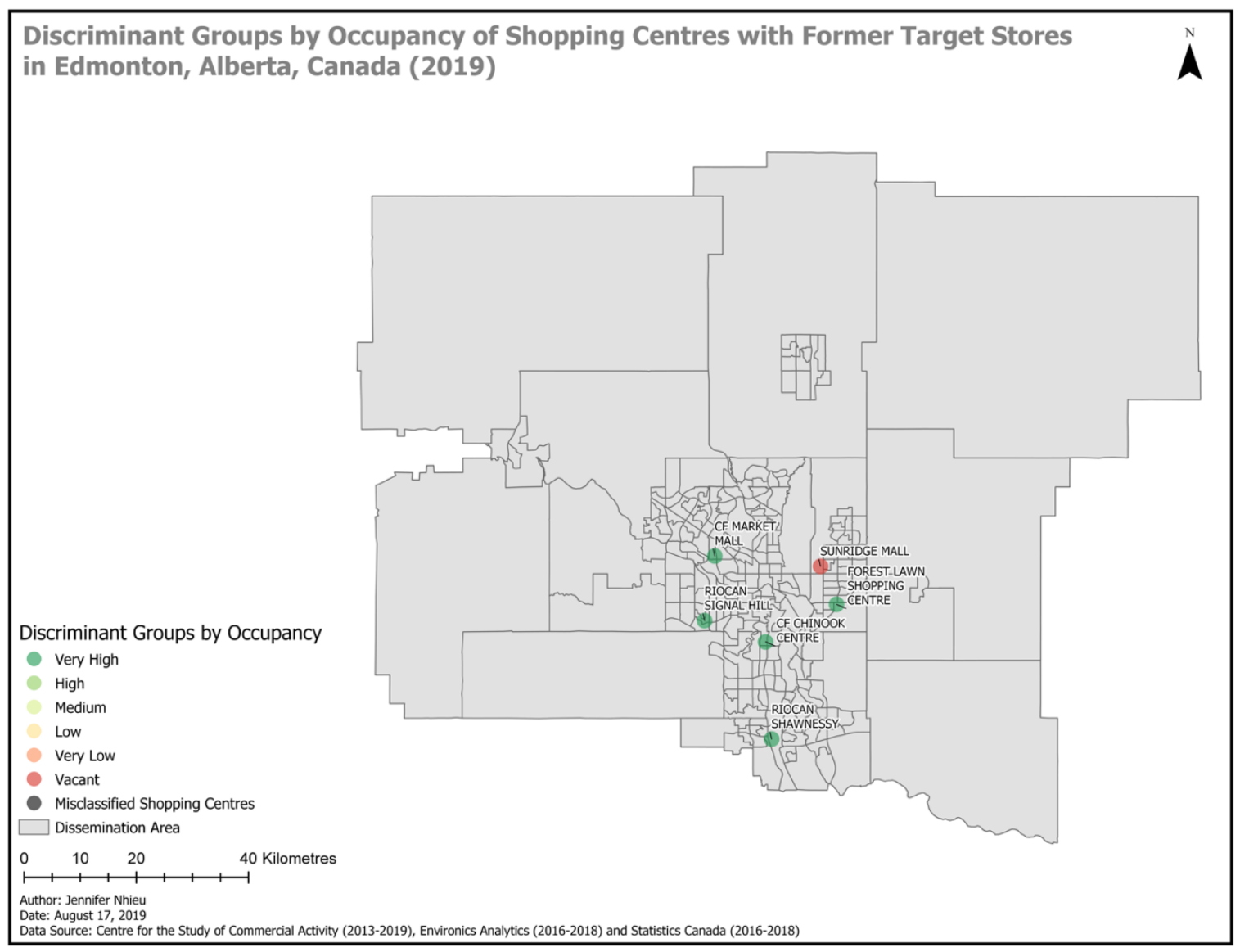

Figure 16: Target Edmonton Map

Source: Centre for the Study of Commercial Activity (2013-2019), Environics Analytics (2016-2018) and Statistics Canada (2016-2018)

Five shopping centres in the Edmonton market were classified as high occupancy: CF Market Mall, RioCan Signal Hill, CF Chinook Centre, RioCan Shawnessy and Forest Lawn Shopping Centre (Figure 16). These shopping centres represent the majority of the Vancouver market with former Target stores. Together, they have an average total population of 786,394 and an average household income ranging from $\$ 110,00$ to $\$ 138,000$. The shopping centres are a mix of super-regional, power centre, and community level. The common characteristics between these shopping centres are that they were mostly located in urban or suburban markets, the new tenants leased as a single-tenant configuration, and only one of the five centres leased to both 
Sears and Target. Four of the five shopping centres are also developed and owned by Cadillac Fairview and RioCan, which are some of Canada's largest property management companies.

\subsubsection{Spatial Analysis Target Results - Calgary, Alberta}

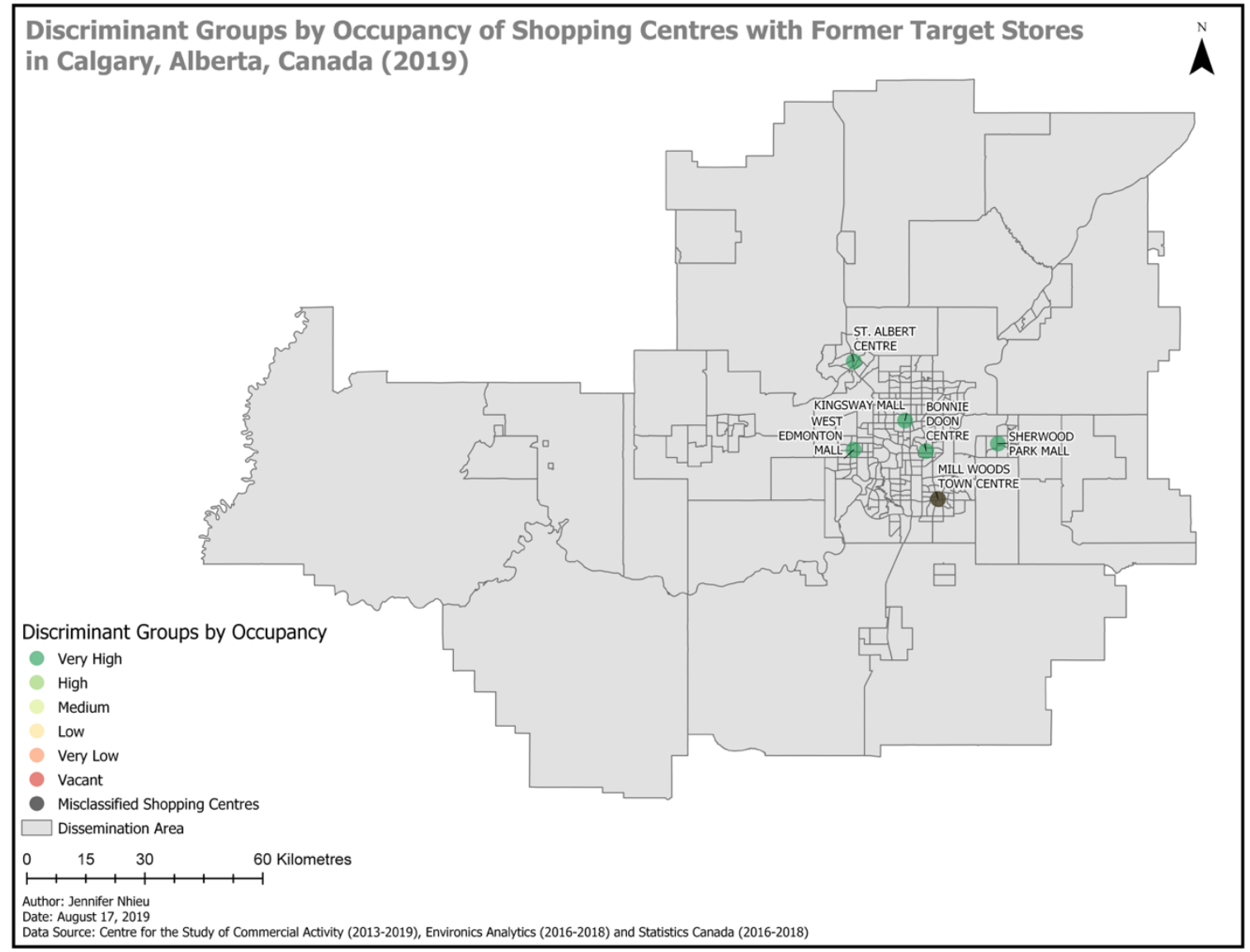

Figure 17: Target Calgary Map

Source: Centre for the Study of Commercial Activity (2013-2019), Environics Analytics (2016-2018) and Statistics Canada (2016-2018)

Six shopping centres in the Calgary market were classified as high occupancy: St. Albert Centre, West Edmonton Mall, Kingsway Mall, Bonnie Doon Centre, and Sherwood Mall (Figure 17). These shopping centres represent the majority of the Calgary market with former Target stores. Together they have an average total population of 743,747 and an average household income ranging from $\$ 85,000$ to $\$ 94,000$. These shopping centres vary in types and characteristics. Furthermore, Mill Woods Town Centre was misclassified, its actual predicted membership is vacant, as the mall is being demolished for mixed-use redevelopment. 


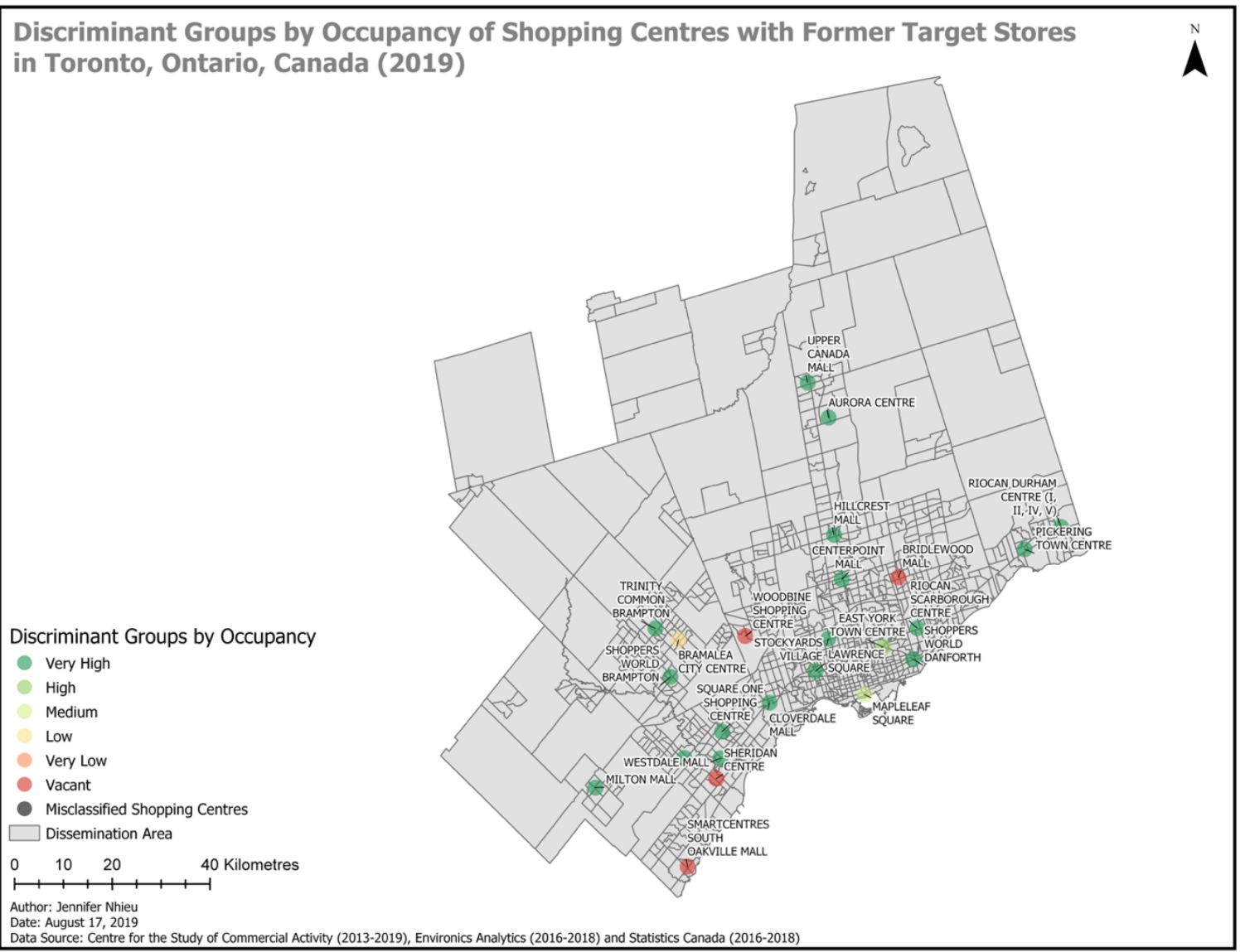

Figure 18: Target Toronto Map

Source: Centre for the Study of Commercial Activity (2013-2019), Environics Analytics (2016-2018) and Statistics Canada (2016-2018)

Twenty-three shopping centres in the Toronto market were classified as high occupancy. These shopping centres represent the majority of the Toronto market with former Target stores (Figure 18). Together they have an average total population of 1,112,686 and an average household income ranging from $\$ 69,000$ to $\$ 115,000$. These shopping centres tend to be located along major highways and intersections, and also vary in type and characteristics. The common characteristics between these shopping centres are that they were mostly located in urban and suburban markets, and eighteen of the twenty-three shopping centres did not lease to both Sears and Target. 


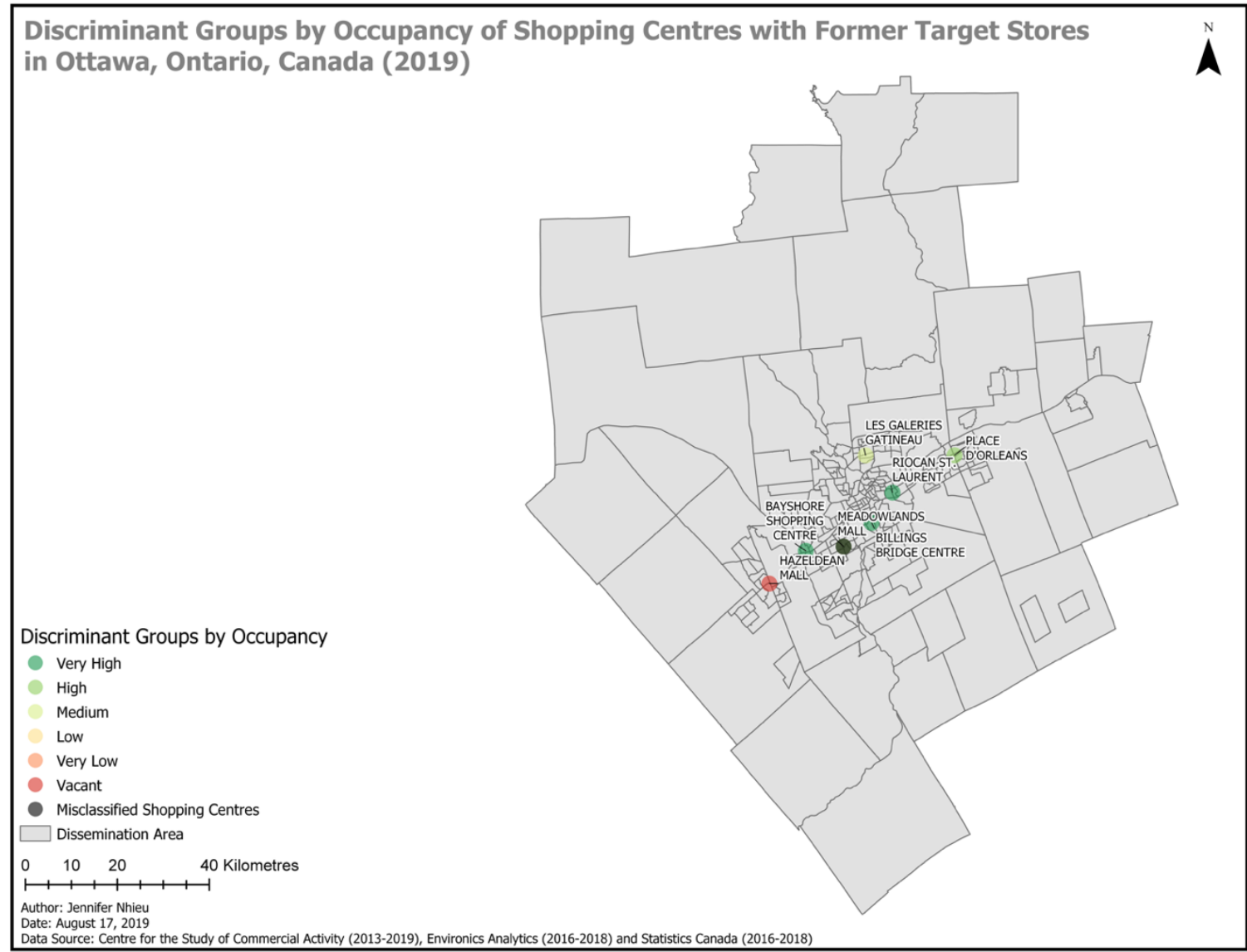

Figure 19: Target Ottawa Map

Source: Centre for the Study of Commercial Activity (2013-2019), Environics Analytics (2016-2018) and Statistics Canada (2016-2018)

Four shopping centres in the Ottawa market were classified as very high occupancy:

RioCan St. Laurent, Bayshore Shopping Centre, and Billings Bride Centre, with Meadowlands Mall, misclassified as high (Figure 19). These shopping centres have markets with an average total population of 828,767 and an average household income ranging from $\$ 78,000$ to $\$ 86,000$, which is above average compared with the other shopping centres in the market. The common characteristics are that they were in suburban markets and none of the shopping centres leased to both Sears and Target. The shopping centres that were not classified with very high occupancy had a lower total population in their respective markets. 


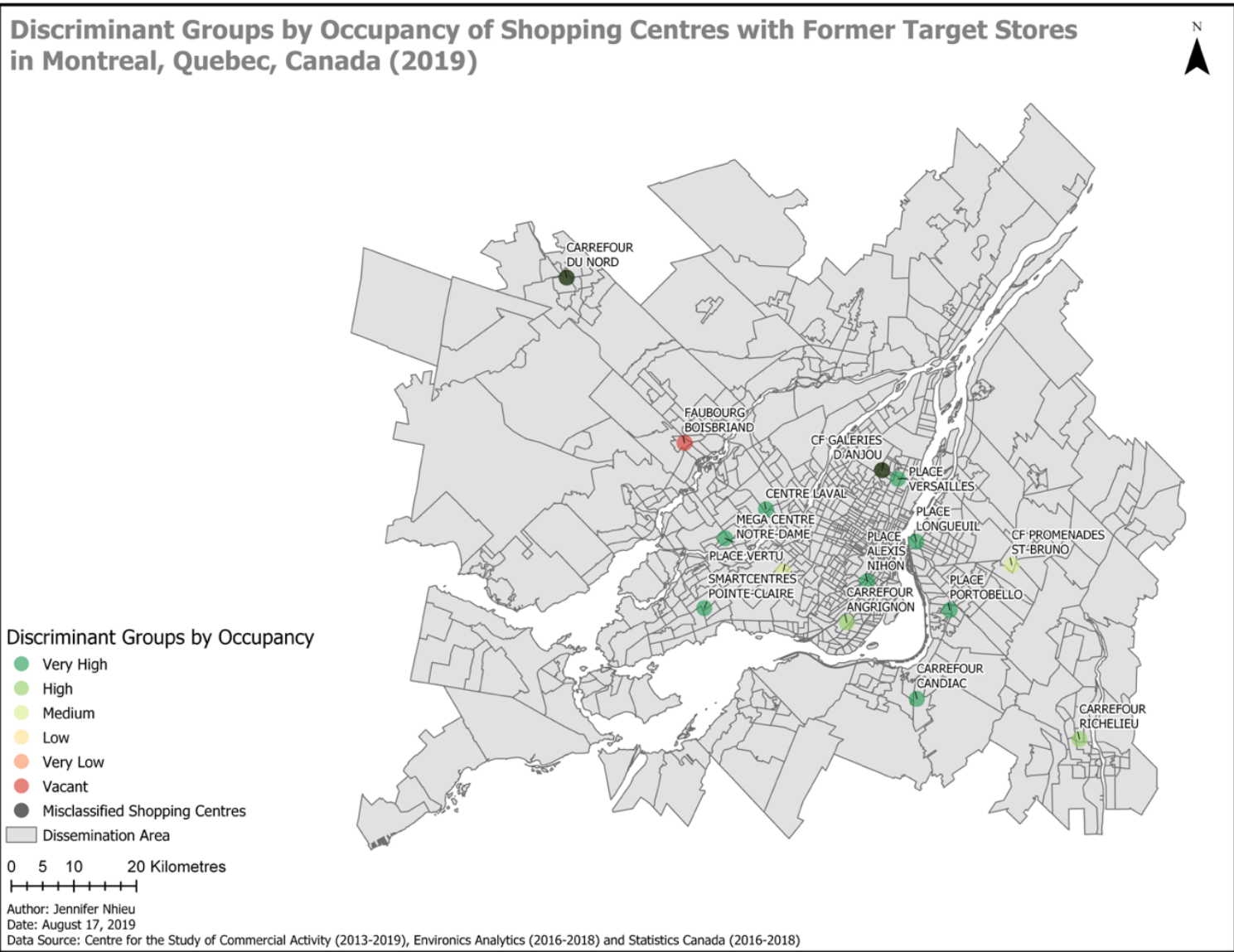

Figure 20: Target Montreal Map

Source: Centre for the Study of Commercial Activity (2013-2019), Environics Analytics (2016-2018) and Statistics Canada (2016-2018)

Ten shopping centres in the Montreal market were classified as high occupancy: Centre Laval, Mega Centre Notre-Dame, Smart Centres Pointe-Claire, Place Versailles, Place Longueuil, Place Alexis Nihon, Place Portobello, and Carrefour Candiac, with Carrefour du Nord and CF Galeries D'Anjou, misclassified as high (Figure 20). The shopping centres have an average total population of $1,508,950$ and an average household income range of $\$ 65,000$ to $\$ 81,000$. Furthermore, eight of the ten shopping centres did not lease to both Sears and Target.

\subsection{Spatial Analysis Discussion}

The number of households, total population, average household income, the size of the shopping centre and whether the shopping centre leased to both Sears and Target are important 
contributors to high occupancy. These results indicate that the analysis recognized the importance of population sizes towards a shopping centre's ability to lease former Sears or Target spaces. This finding is supported by multiple works of literatures, stating population size is important towards a shopping centre's success. Average household income was surprisingly not indicated as a good predictor in the discriminant analysis, however, when the data was spatially analyzed, shopping centres with high occupancy tend to be in the medium to highincome areas. As previously mentioned, Target is four years post-closure and is $86 \%$ partially leased across Canada. Therefore, the results may not be as representative as Sears when it comes to business decisions made immediately post-closure. For example, a year post-closure shopping centres immediately focused on leasing, redeveloping and reconfiguring their former Target properties in urban markets (Table 5). Also, smaller shopping centres were more successful in leasing their former spaces, as most of them had some of Target's smaller stores. The Big Three also played a significant role in occupying many of the large spaces in super-regional and regional shopping centres, as a single-tenant configuration which assisted in raising the lease rate in urban markets (Table 5 and 7). However, the Big Three did not have much interest in the former Sears properties. Therefore multiple-tenant configuration was a bigger contributor to higher occupancy for Sears. Overall, shopping centres in urban to suburban markets with large populations and a high average household income are more likely to have a higher occupancy rate than shopping centres in exurban with a smaller population and lower average household income.

\subsection{Limitations}

\subsection{Vacant Stores}

The Sears database contained a high number of vacant stores, while the Target database contained a high number of leased stores. As a result, the data did not have a normal distribution. with the Sears data being negatively skewed and the Target data being positively skewed. In total, the Sears database has 95 (65\%) vacant locations, while Target has 20 (14\%) (Figure 3). Removing these values of 0 would heavily influence the data as these values of 0 are not errors, but actual observed values and therefore were not removed from the analysis. Additionally, as mentioned, there was more time and opportunity to turn former Target spaces back into 
productive use, and now, leasing and investment negotiations are still ongoing, allowing shopping centres to experiment with incorporating new trends in retail into these former spaces. As such, the Target data contains a more diverse sample of changes in the absorption process.

\subsection{Misclassified Shopping Centres}

The discriminant model classified $91.8 \%$ of Sears and $96.4 \%$ of Target shopping centres correctly (Table 17 and 22). Indicating that 12 shopping centres were misclassified for Sears and 5 shopping centres were misclassified for Target. As previously mentioned, it is important to identify shopping centres that have been misclassified, as the misclassification means that the centre does not have the prototypical characteristics related to occupancy (i.e., population, average household income, shopping centre size, etc.). The model misclassified shopping centres (Table 25) with former Sears properties located in some VETCOM markets such as Vancouver, Edmonton, Calgary, and some exurban areas (Figure 7). While, the former Target properties were located in Calgary, Ottawa and Montreal, three of six VETCOM markets (Figure 14).

Table 22: Misclassified Shopping Centres

\begin{tabular}{|c|c|c|c|c|c|c|c|c|}
\hline Chain & Market & Shopping Centre Name & Type of SC & SC Sq. Ft. & Total Population & Average Household Income & Total Estimated Size of Site & Occupancy Rate \\
\hline Sears & Kingston, ON & RioCan Centre Kingston (South) & Power Centre & 514,400 & 135,017 & 78,661 & 43,290 & $100 \%$ \\
\hline Sears & Moncton, NB & Wheeler Park Power Centre & Power Centre & 648,334 & 122,951 & 69,422 & 43,163 & $100 \%$ \\
\hline Sears & Sudbury, ON & RioCan Centre Sudbury (East) & Power Centre & 366,755 & 105,397 & 78,193 & 43,000 & $100 \%$ \\
\hline Sears & Bathurst, NB & Place Bathurst Mall & Community & 216,000 & 21,928 & 67,492 & 30,000 & $100 \%$ \\
\hline Sears & Burnaby, BC & Brentwood Village Shopping Centre & Community & 286,594 & $1,001,375$ & 117,288 & 44,306 & $100 \%$ \\
\hline Sears & Drummondville, QC & Promenades Drummondville & Regional & 335,793 & 84,944 & 58,751 & 62,011 & $100 \%$ \\
\hline Sears & Edmonton, $\mathrm{AB}$ & Bonnie Doon Centre & Regional & 491,975 & 992,051 & 93,054 & 108,406 & $100 \%$ \\
\hline Sears & New Glasglow, NS & Highland Square Mall & Regional & 472,431 & 32,419 & 58,011 & 18,460 & $49 \%$ \\
\hline Sears & Surrey, BC & Guildford Town Centre & Super Regional & $1,202,667$ & $1,101,127$ & 91,470 & 140,744 & $100 \%$ \\
\hline Sears & Saint-Georges, QC & Carrefour Saint-Georges & Regional & 305,000 & 41,857 & 61,556 & 21,000 & $39 \%$ \\
\hline Sears & Thunder Bay, ON & Intercity Shopping Centre & Regional & 365,491 & 106,878 & 73,394 & 27,928 & $20 \%$ \\
\hline Sears & Truro, NS & Truro Mall & Community & 252,133 & 32,197 & 60,400 & 30,000 & $100 \%$ \\
\hline Target & Nepean, ON & Meadowlands Mall & Power Centre & 245,000 & 851,069 & 92,419 & 56,500 & $100 \%$ \\
\hline Target & Anjou, QC & CF Galeries D'Anjou & Super Regional & 940,321 & $1,923,479$ & 67,349 & 77,506 & $100 \%$ \\
\hline Target & Edmonton, $\mathrm{AB}$ & Mill Woods Town Centre & Regional & 537,160 & 721,508 & 99,063 & 0 & $0 \%$ \\
\hline Target & London, ON & CF Masonville Place & Regional & 663,977 & 407,296 & 81,694 & 87,634 & $36 \%$ \\
\hline Target & Saint-Jerome, QC & Carrefour du Nord & Regional & 617,687 & 163,434 & 65,313 & 82,208 & $88 \%$ \\
\hline
\end{tabular}

\subsection{Geographic Scale}

The trade area analysis did not account for the differing trade area size of the various shopping centre types, mall hierarchy or the retail square footage. Generally, a large shopping centre or retail space will have a large trade area size in relation. For example, a super-regional mall will have a trade area of 10 to 30 kilometre, while a community mall will have a trade area of fewer than 10 kilometres. 


\subsection{Further Research}

\subsection{Exploratory Analysis of Additional Variables}

It is important to note, the Sears and Target database constructed using the CSCA's Shopping Centre (SC) and Major Retail Chain (MRC) database does not cover all aspects that contribute to a shopping centre's ability to fill the former Sears and Target spaces. Some examples of additional variables that could be explored to strengthen the analysis include the frequency of visitors to the mall, transportation accessibility, the shopping centre's retail atmosphere, and other exogenous factors such as sales potential, crime rates, or unemployment rates. As previously mentioned, a mall cannot move from its physical location; therefore, it must bear the consequences of the occurrences in its surrounding area. For example, if the shopping centre's surrounding area has a high instance of crime, this will negatively affect the reputation of the mall. If the reputation of the mall is adversely affected, this may result in lower sales and occupancy. These theories have been proven by multiple Canadian shopping centre studies, as such, examining areas faced with declining social infrastructure, selective social policy high unemployment rates, or other social indicators may be beneficial in predicting the occupancy rate of the former spaces (Peiser and Xiong, 2003; Poyser, 2005; Parlette and Cowen, 2011).

Additionally, some variables could not be explored due to information not being publicly available. However, those variables are crucial to predicting and understanding a shopping centre's ability to fill vacant spaces. These variables include events related to legal, investment, and leasing and development decisions.

\subsection{Conclusion}

The study employs market demand, market supply, property and site variables as evaluative measures of occupancy of former Sears or Target spaces in shopping centres. A Pearson's correlation revealed significant correlations between occupancy rate and variables such as leased space (market), new tenants (market), space change, configuration, and leased space (site). The results indicate spaces that had undergone re-configuration into multiple smaller units were more likely to be leased, as more retailers operate with smaller retail footprints. Furthermore, shopping centres sharing the same trade area were more likely to have leased their 
former space as well, as shopping centres in close proximity to each other are likely to have the same or similar market demand variables.

The factor analysis identified six themes based on variable type to predict occupancy of former Sears and Target properties in 246 shopping centres across Canada. These themes include market supply (e.g., the number of households, total population, etc.), shopping centre size characteristics, site characteristics, space change characteristics, sociodemographic shifts (average household income, population change, etc.), and configuration (e.g., single, small multiple, large multiple). The issue surrounding these findings is that other than linking the themes to occupancy, there is virtually nothing ground-breaking produced from the general findings. This issue supports the need for additional analysis using different exploratory methods, as long-term vacancies are a growing topic of interest in professional and academic environments. Especially with the growing media attention towards topics such as the "retail apocalypse" and "death of the shopping mall."

Further investigation, beginning with discriminant analysis, was conducted. The model identified several strong predictors of occupancy; some were common variables between Sears and Target, while others were unique to the retailer. Strong predictors of occupancy for both Sears and Target include total population, the number of households and the size of the former space (market). The results also indicated the size of the shopping centre (market), the number of stores in the shopping centre (market), and configuration to be strong, unique predictors of occupancy for shopping centres with former Sears properties. While the total estimated size of the current space (market) was a uniquely strong predictor of occupancy for former Target stores.

As previously mentioned, average household income was surprisingly not indicated as a good predictor, however, when the data was spatially analyzed, shopping centres with high occupancy tend to be in the medium to high-income areas. The main issue surrounding these findings is that they contradict each other. While the discriminant analysis does not find average household income to be a strong predictor of occupancy, a spatial pattern is present, where shopping centres with high occupancy exist in financially stable and prosperous areas. 
This study integrates trade areas, a spatial technique into the statistical analysis alongside the endogenous and exogenous variables. Many shopping centre studies not do utilize spatial techniques in their study. Therefore, the originality of this study lies in this method. Additionally, this exploratory research on former Sears and Target properties provides the groundwork for more research on long-term vacancies and topics relating to the "retail apocalypses" and the "death of the shopping mall." Limitations of the study include the distribution of data, misclassified shopping centres and the geographic scale. Possible future directions for research include the incorporation of other data points, like social indicators, and sales figures. 

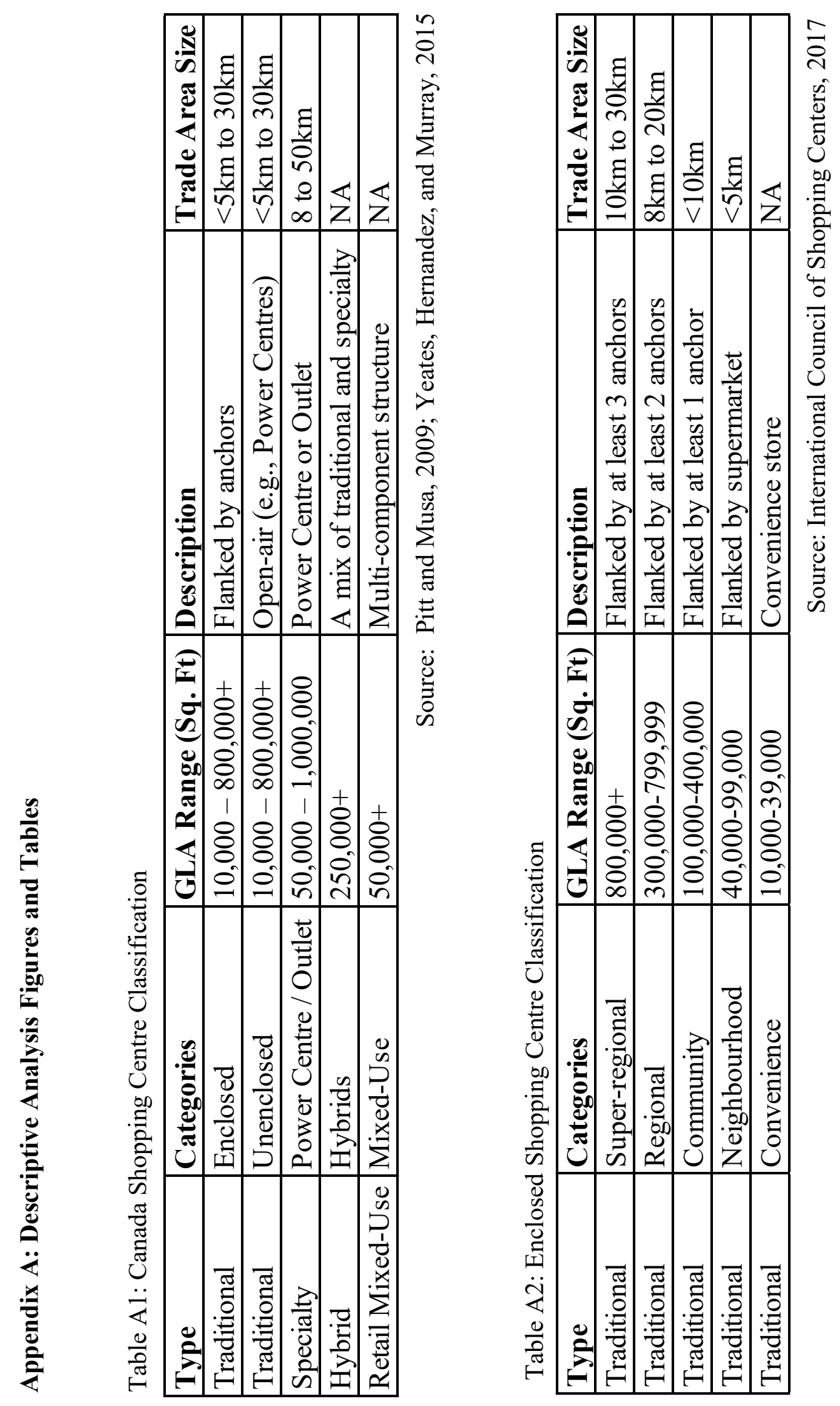
Table A3: Data Variables

\begin{tabular}{|c|c|c|c|c|c|c|}
\hline Type & Variable & Variable Name & Year & Format & Description & Source \\
\hline Market Demand & MRKTD_TOT_HH18 & $\begin{array}{l}\text { Total Household Population } 12 \text { Years } \\
\text { or Over }\end{array}$ & 2018 & Count & Total Household Population 2018 & Environics \\
\hline Market Demand & MRKTD_TOT_POP18 & Total Population & 2018 & Count & Total Population 2018 & Environics \\
\hline Market Demand & MRKTD_POPCHANGE & Population Change 2016 to 2018 & $2016-$ & Percentage & Total Population 2016 to 2018 & Environics \\
\hline Market Demand & MRKTD_AVG_HH_INC18 & $\begin{array}{l}\text { Average Household Income (Constant } \\
\text { Year 2005 \$) }\end{array}$ & 2018 & Average & Average Household Income 2018 & Environics \\
\hline Market Supply & MRKTS_FORMER_SIZE & Size of Former Sears or Target Space & $\begin{array}{l}2013 \\
2018\end{array}$ & Sq. Ft. & $\begin{array}{l}\text { Target planned opening size in } 2013 \\
\text { and Sears's closing size in } 2018 .\end{array}$ & CSCA \\
\hline Market Supply & MRKTS_EST_SIZE_STORE & $\begin{array}{l}\text { Total Estimated Size of Current } \\
\text { Configuration }\end{array}$ & 2019 & Sq. Ft. & $\begin{array}{l}\text { Total estimated size of Sears or } \\
\text { Target store in its current } \\
\text { configuration }\end{array}$ & CSCA \\
\hline Market Supply & MRKTS_LEASED_SPACE & $\begin{array}{l}\text { Leased Space of Current } \\
\text { Configuration in the Market }\end{array}$ & 2019 & Sq. Ft. & & $\mathrm{CSCA}$ \\
\hline Market Supply & MRKTS_OCCP_RATE & Market Occupancy Rate & 2019 & Percentage & $\begin{array}{l}\text { Leased Space / Total Estimated } \\
\text { Size of its Current Configuration in } \\
\text { all shopping centres in } 15 \mathrm{~km} \text { trade } \\
\text { area. }\end{array}$ & CSCA \\
\hline Market Supply & MRKTS_OCCP_CATGRY & Market Occupancy Category & 2019 & Categorical & $\begin{array}{l}0=\text { vacant } \\
1=1-20 \% \text { occupancy } \\
2=21-40 \% \text { occupancy } \\
3=41-60 \% \text { occupancy } \\
4=61-80 \% \text { occupancy } \\
5=81-100 \% \text { occupancy }\end{array}$ & CSCA \\
\hline Market Supply & MRKTS_SC_SIZES & Market Total Shopping Centre Sq. Ft. & 2018 & Sq. Ft. & $\begin{array}{l}\text { Total shopping centre sq. f.t in } 15 \mathrm{~km} \\
\text { trade area. }\end{array}$ & CSCA \\
\hline Market Supply & MRKTS_SC_STORES & $\begin{array}{l}\text { Market Total of Shopping Centre } \\
\text { Stores }\end{array}$ & 2018 & Count & $\begin{array}{l}\text { Total number of stores in } 15 \mathrm{~km} \\
\text { shopping centre trade area }\end{array}$ & $\mathrm{CSCA}$ \\
\hline Market Supply & MRKTS_NEW_TENANTS & $\begin{array}{l}\text { Market Total of New Tenants in } \\
\text { Current Space }\end{array}$ & 2019 & Count & $\begin{array}{l}\text { Number of new tenants occupying } \\
\text { the current space. }\end{array}$ & CSCA \\
\hline PROPERTY & PRPRTY_SPACE_CHANGE & $\begin{array}{l}\text { Space Change in Current } \\
\text { Configuration }\end{array}$ & 2019 & Categorical & $\begin{array}{l}0=\text { vacant } \\
1=\text { in use }\end{array}$ & CSCA \\
\hline PPROPERTY & PRPRTY_CONFIG & Configuration of Current Space & 2019 & Categorical & $\begin{array}{l}1=\text { Single Tenant } \\
2=\text { large multiple use (less than } 5 \\
\text { tenants) } \\
3=\text { small multiple use (more than } 5 \\
\text { tenants) }\end{array}$ & CSCA \\
\hline PROPERTY & PRPRTY_S_AND_T_IN_SC & $\begin{array}{l}\text { Sears and Target in the same } \\
\text { Shopping Centre }\end{array}$ & 2019 & Categorical & $\begin{array}{l}0=\text { not in same SC } \\
1=\text { in same SC }\end{array}$ & CSCA \\
\hline PROPERTY & PRRRTY_STORE_LEVELS & Store Levels in Former Space & 2019 & Count & & CSCA \\
\hline PROPERTY & PRPRTY_SC_HIERARHCY & Type Shopping Centre & 2018 & Categorical & $\begin{array}{l}5=\text { Super Regional } \\
4=\text { Regional } \\
3=\text { Power Centre } \\
2=\text { Community } \\
1=\text { Other }\end{array}$ & $\mathrm{CSCA}$ \\
\hline PROPERTY & PRPRTY_URBANITY & Shopping Centre Urbanity & 2019 & Categorical & $\begin{array}{l}1=\text { Urban } \\
2=\text { Suburban } \\
3=\text { Exurban }\end{array}$ & $\mathrm{CSCA}$ \\
\hline SITE & SITE_SC_SIZE & Size of Shopping Centre & 2018 & Sq. Ft. & & CSCA \\
\hline SITE & SITE_SC_STORES & Number of Stores in Shopping Centre & 2018 & Count & & CSCA \\
\hline SITE & SITE_FORMER_SIZE & Size of Former Sears or Target Space & 2013 & Sq. Ft. & $\begin{array}{l}\text { Target planned opening size in } 2013 \\
\text { and Sears's closing size in } 2018 .\end{array}$ & CSCA \\
\hline SITE & SITE_EST_SIZE_STORE & $\begin{array}{l}\text { Total Estimated Size of Current } \\
\text { Configuration }\end{array}$ & 2019 & Sq. Ft. & & CSCA \\
\hline SITE & SITE_LEASED_SPACE & $\begin{array}{l}\text { Total Leased Space of Current } \\
\text { Configuration }\end{array}$ & 2019 & Sq. Ft. & & $\mathrm{CSCA}$ \\
\hline SITE & SITE_OCCP_RATE & $\begin{array}{l}\text { Occupancy Rate of the Store's } \\
\text { Current Configuration }\end{array}$ & 2019 & Percentage & Leased Space / Total Estimated Size & CSCA \\
\hline SITE & SITE_OCCP_CATGRY & Occupancy Category of Current Space & 2019 & Categorical & $\begin{array}{l}0=\text { vacant } \\
1=1-20 \% \text { occupancy } \\
2=21-40 \% \text { occupancy } \\
3=41-60 \% \text { occupancy } \\
4=61-80 \% \text { occupancy } \\
5=81-100 \% \text { occupancy }\end{array}$ & CSCA \\
\hline SITE & SITE_NEW_TENANTS & $\begin{array}{l}\text { Total Number of New Tenants in } \\
\text { Current Space }\end{array}$ & 2019 & Count & & CSCA \\
\hline SITE & SITE_PER_OCCUP_OF_SC & $\begin{array}{l}\text { Percentage of Occupied Space in } \\
\text { Shopping Centre }\end{array}$ & 2019 & Percentage & $\begin{array}{l}\text { Current Total Estimated Size / Size } \\
\text { of Shopping Centre }\end{array}$ & CSCA \\
\hline
\end{tabular}

Source: Centre for the Study of Commercial Activity (2019) 

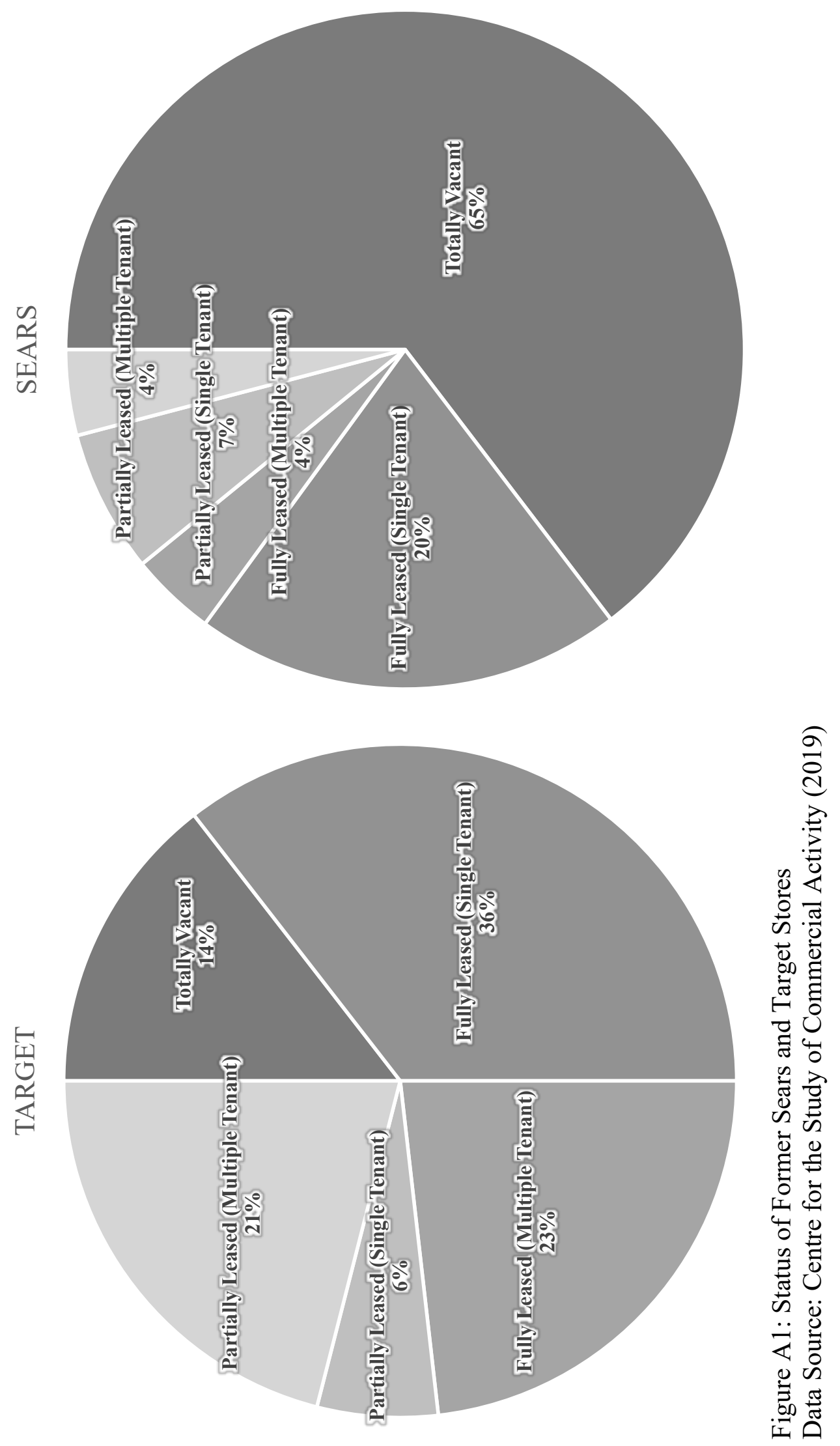


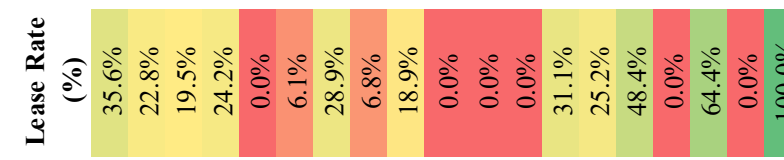

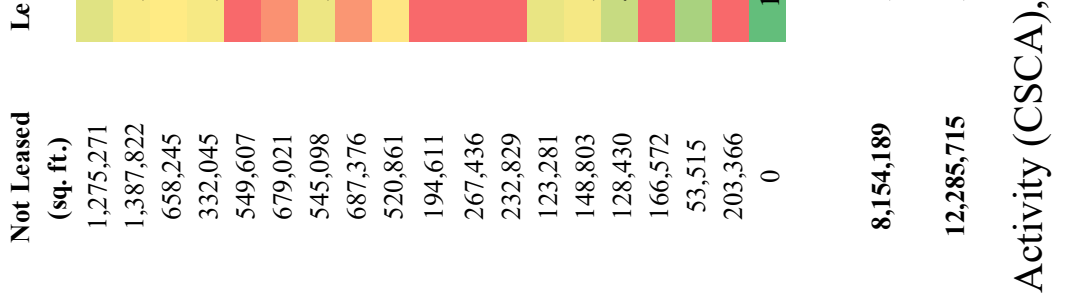

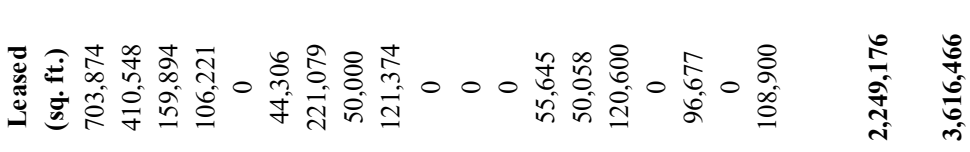
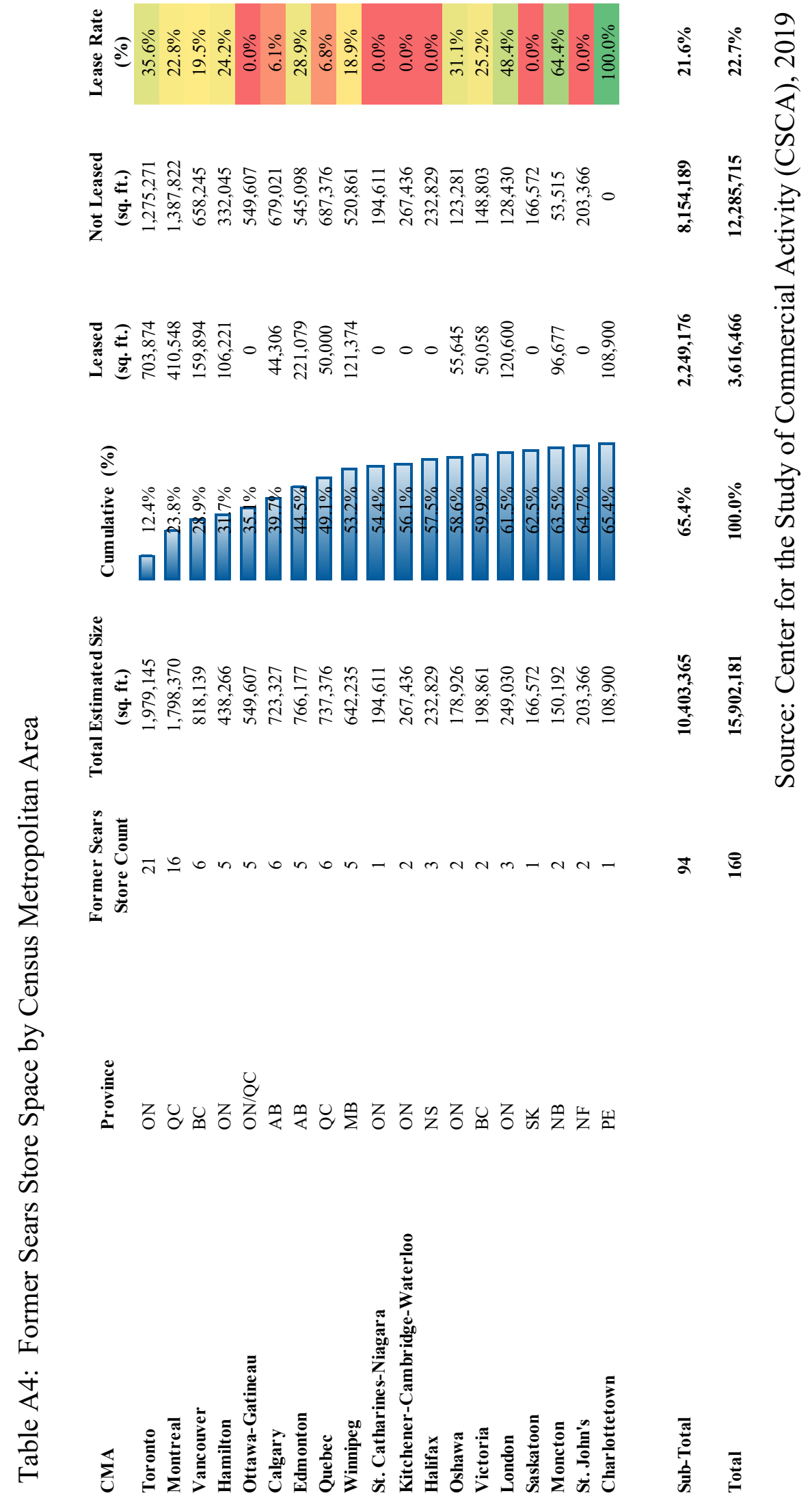


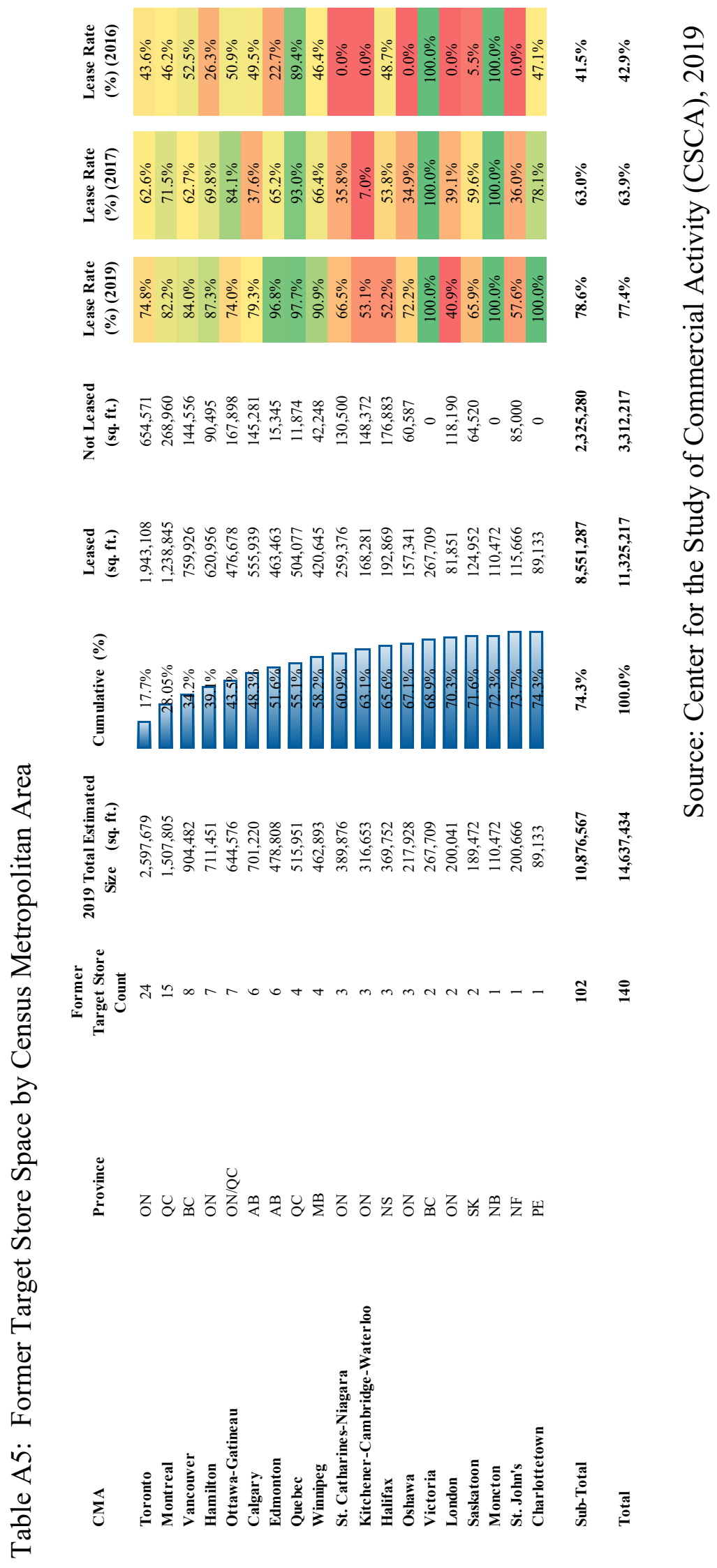




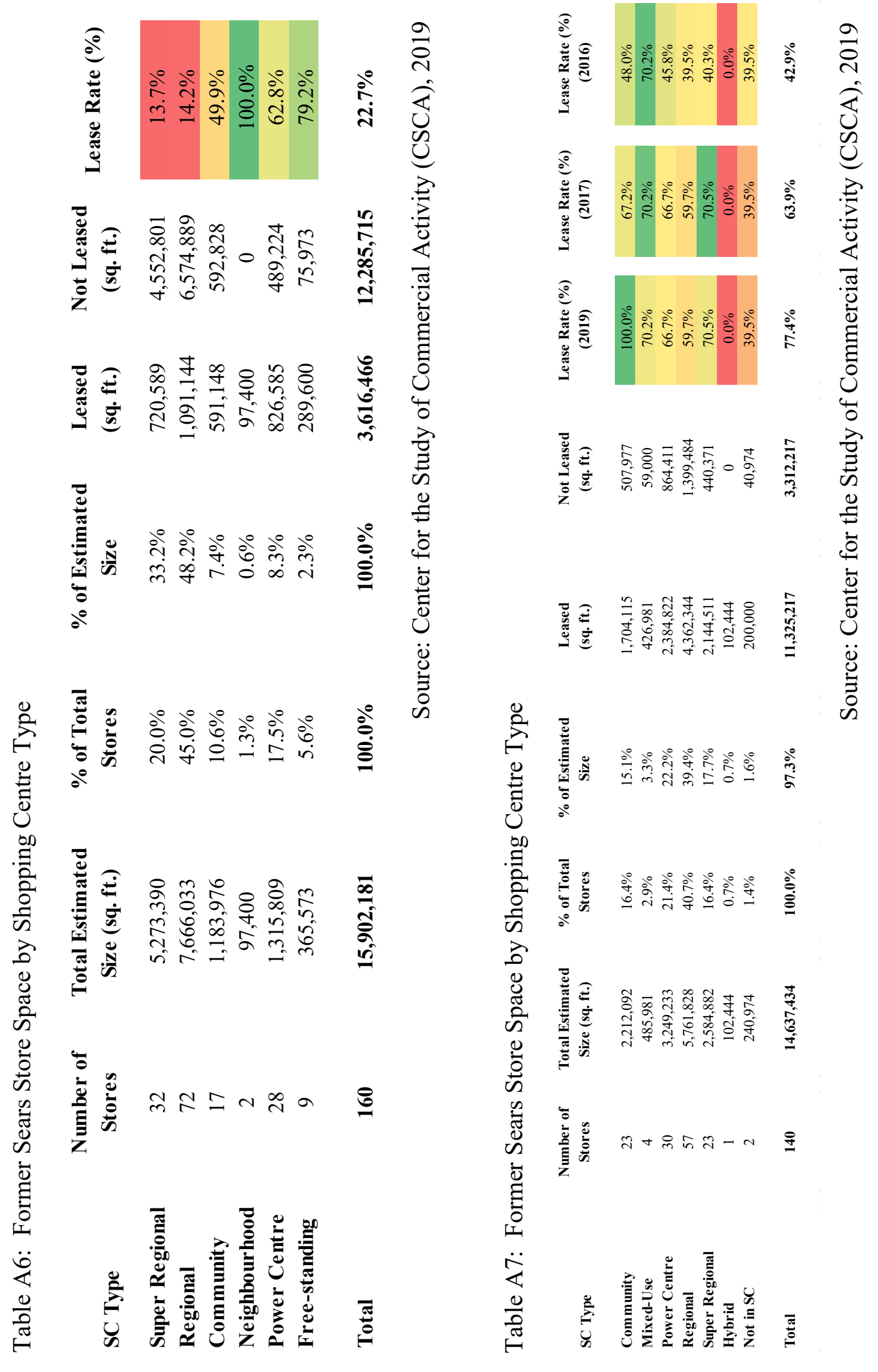



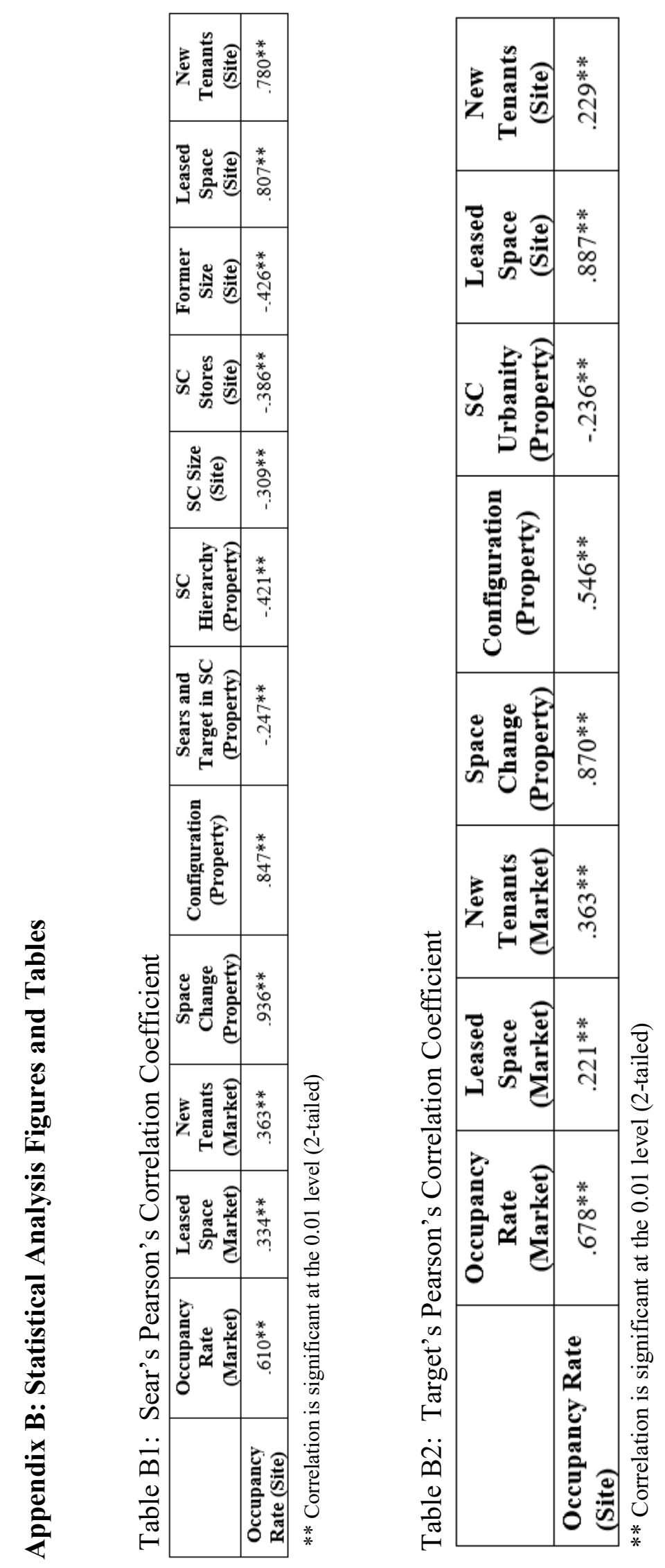

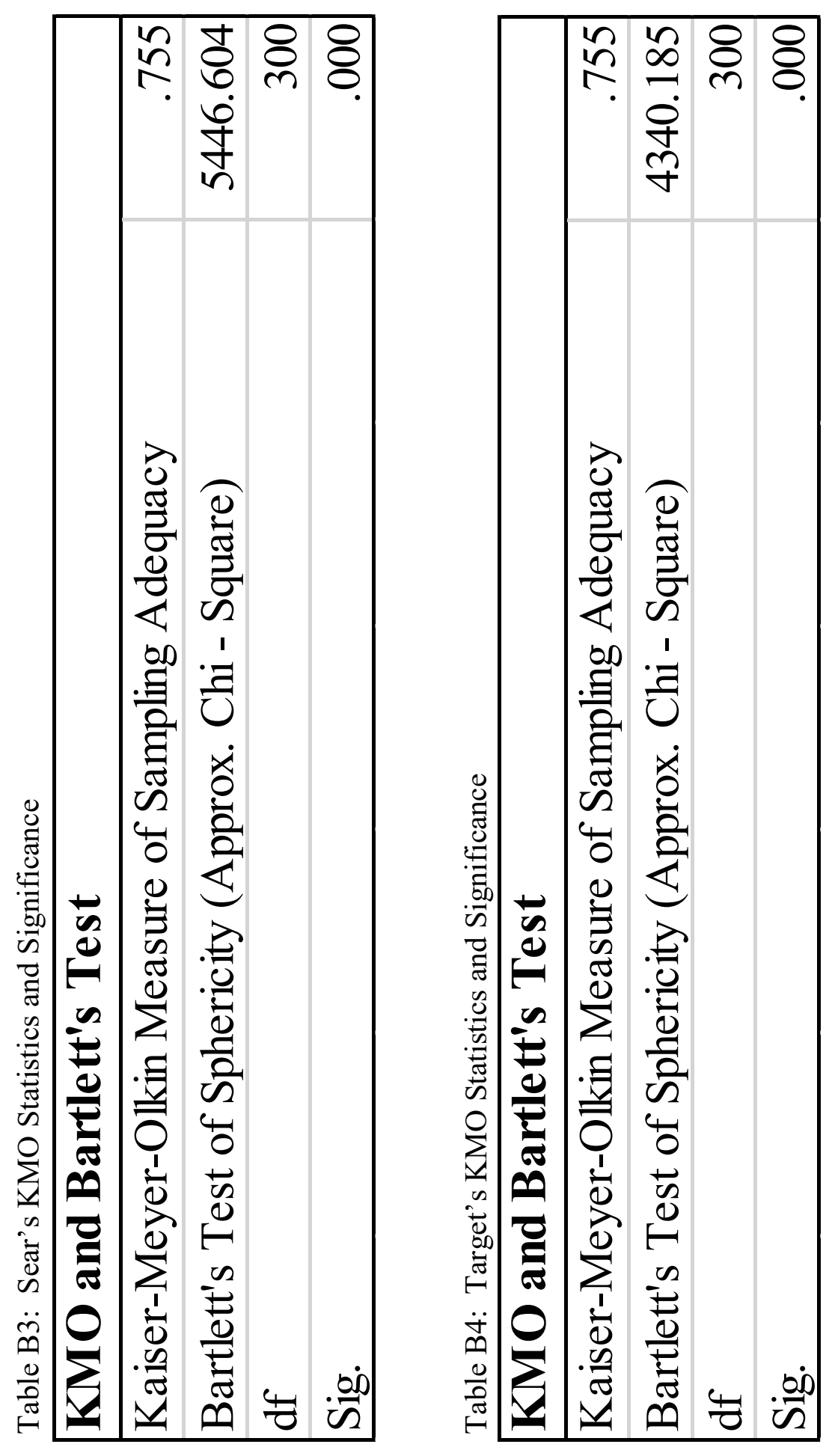

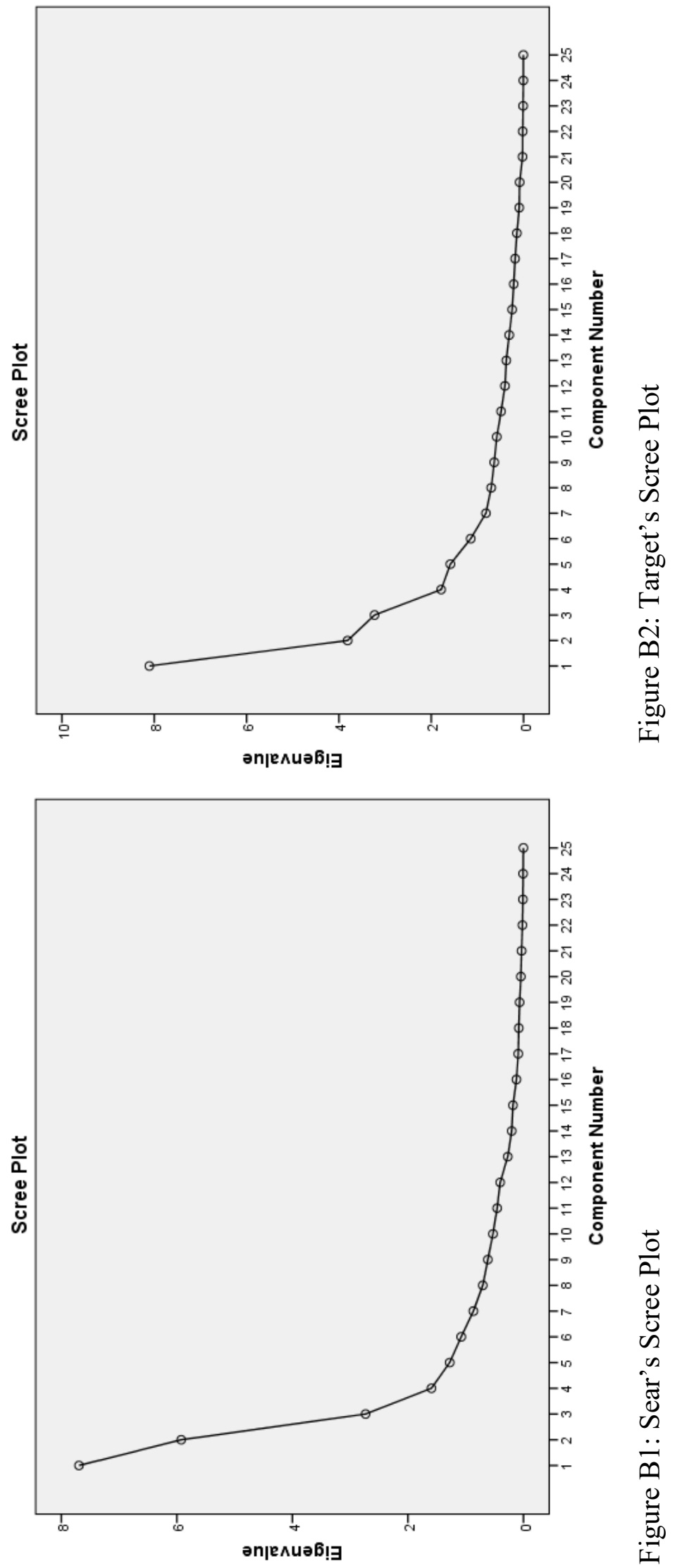

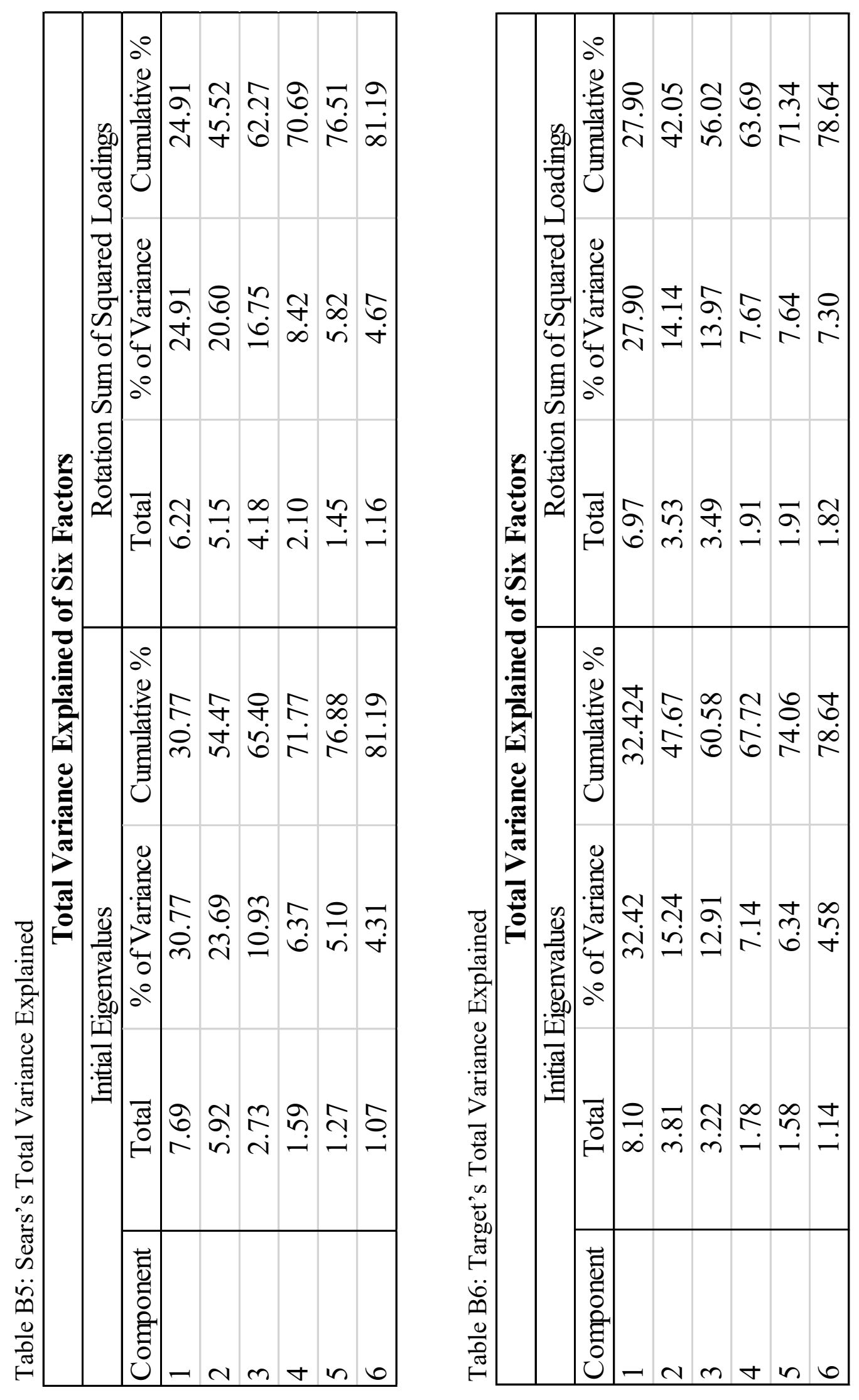


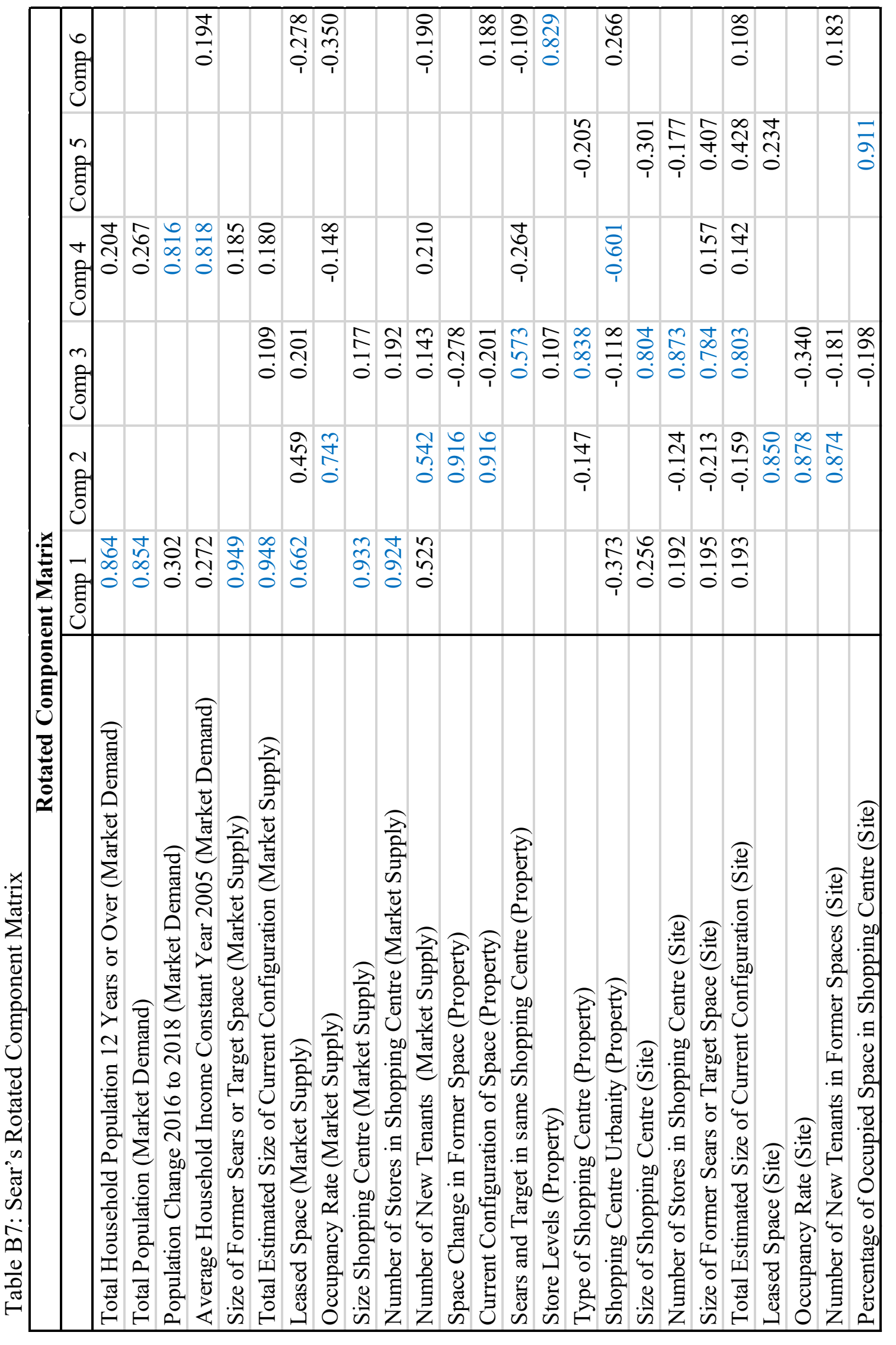




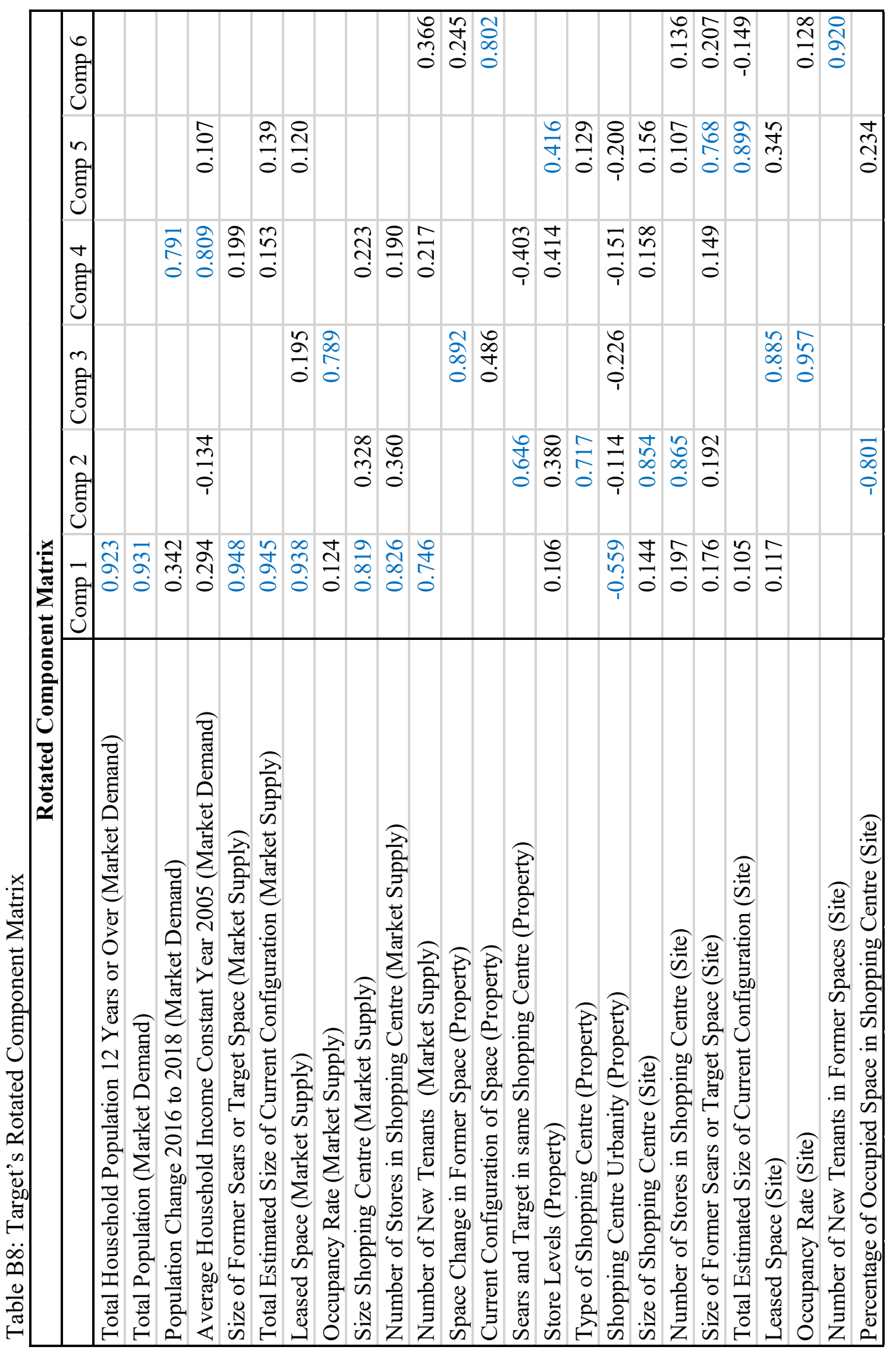




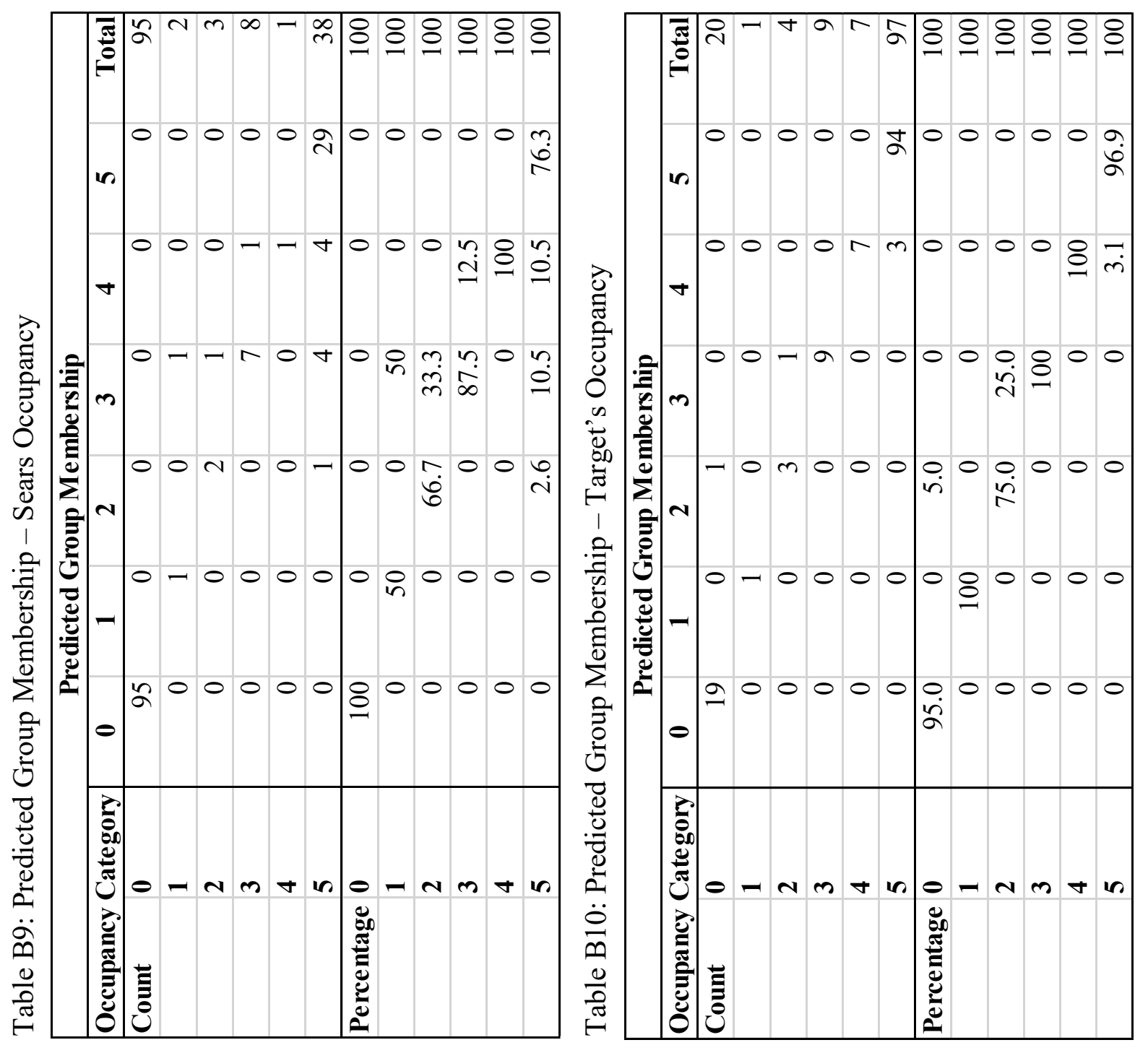



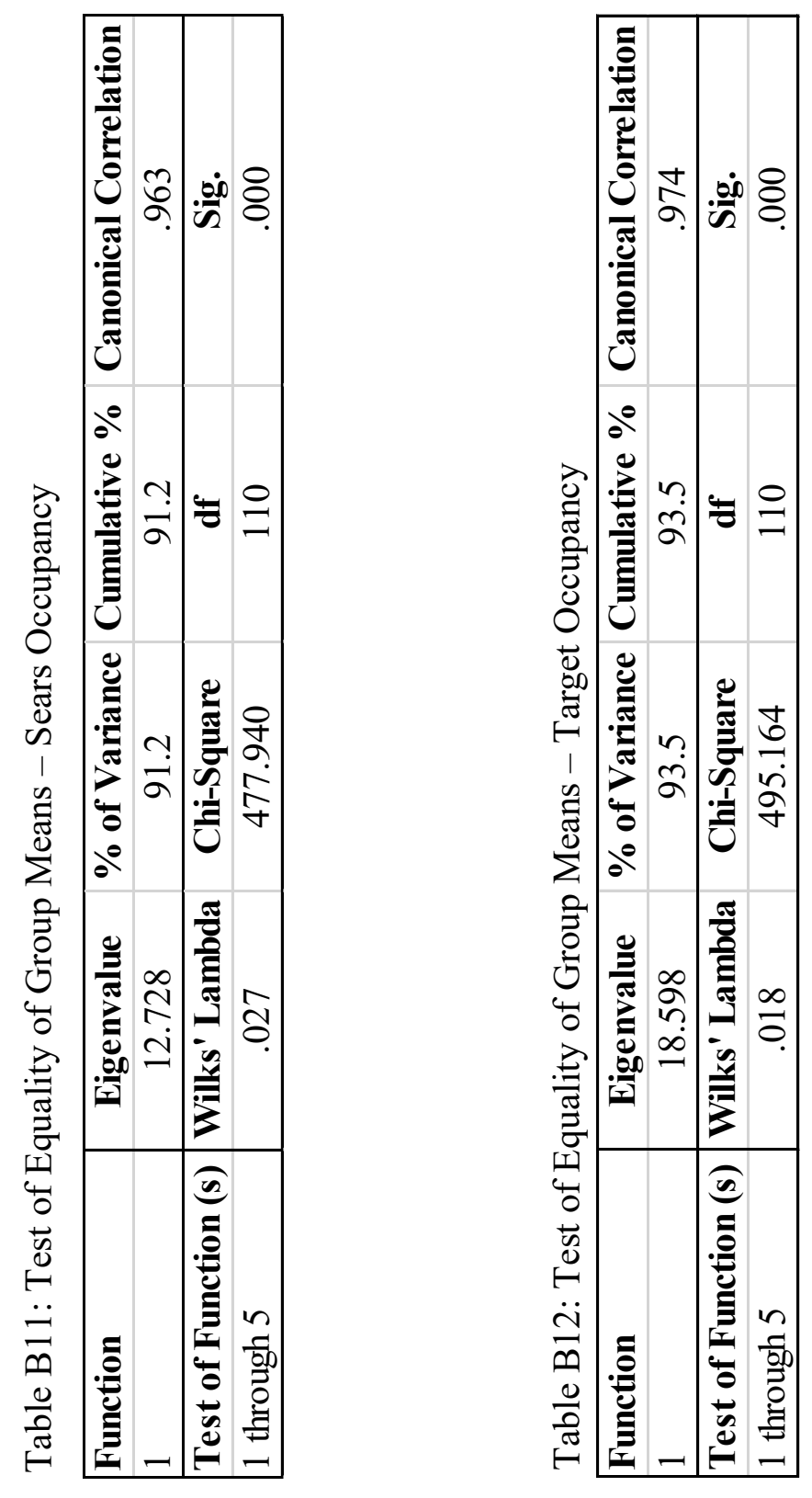


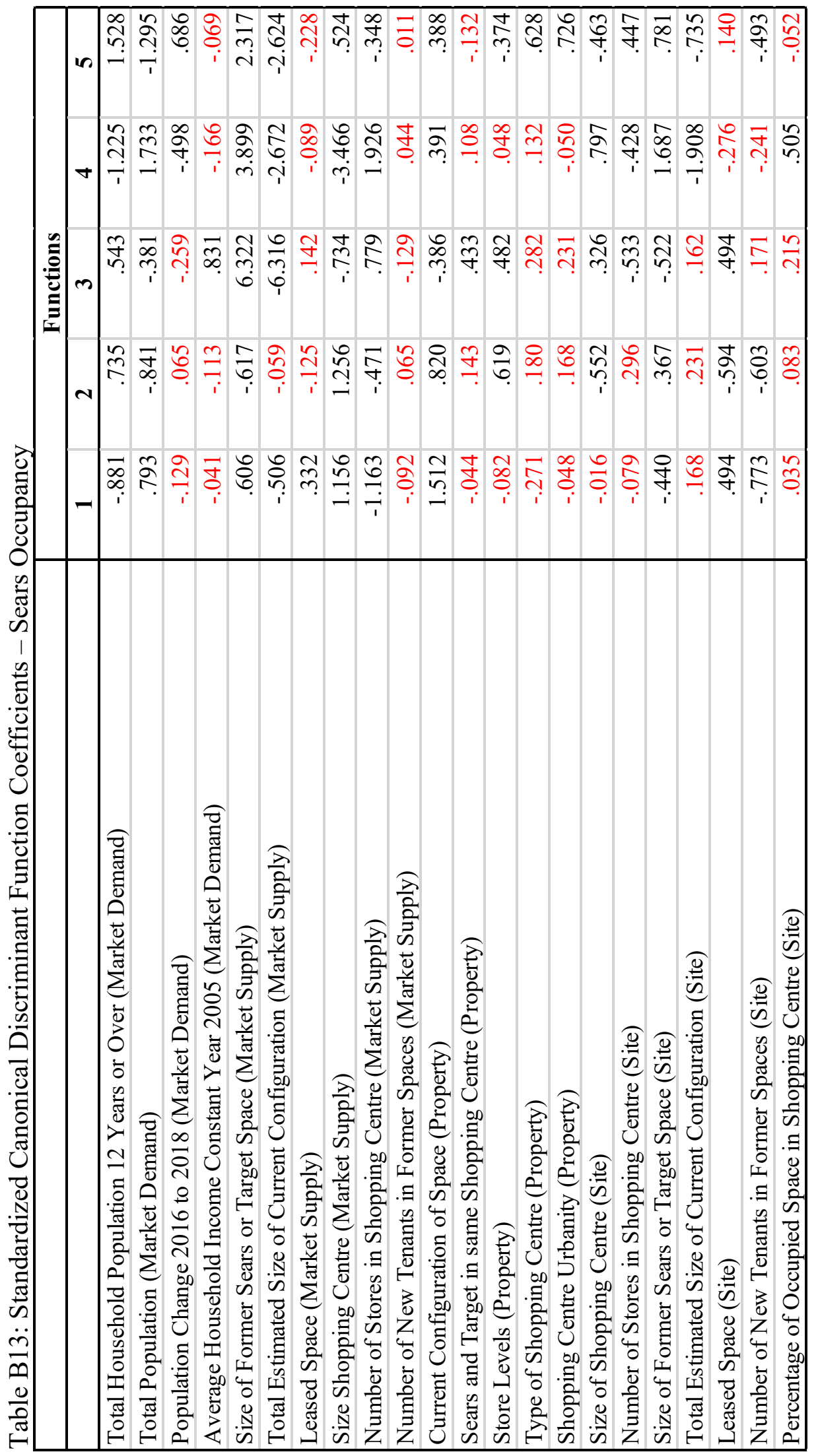




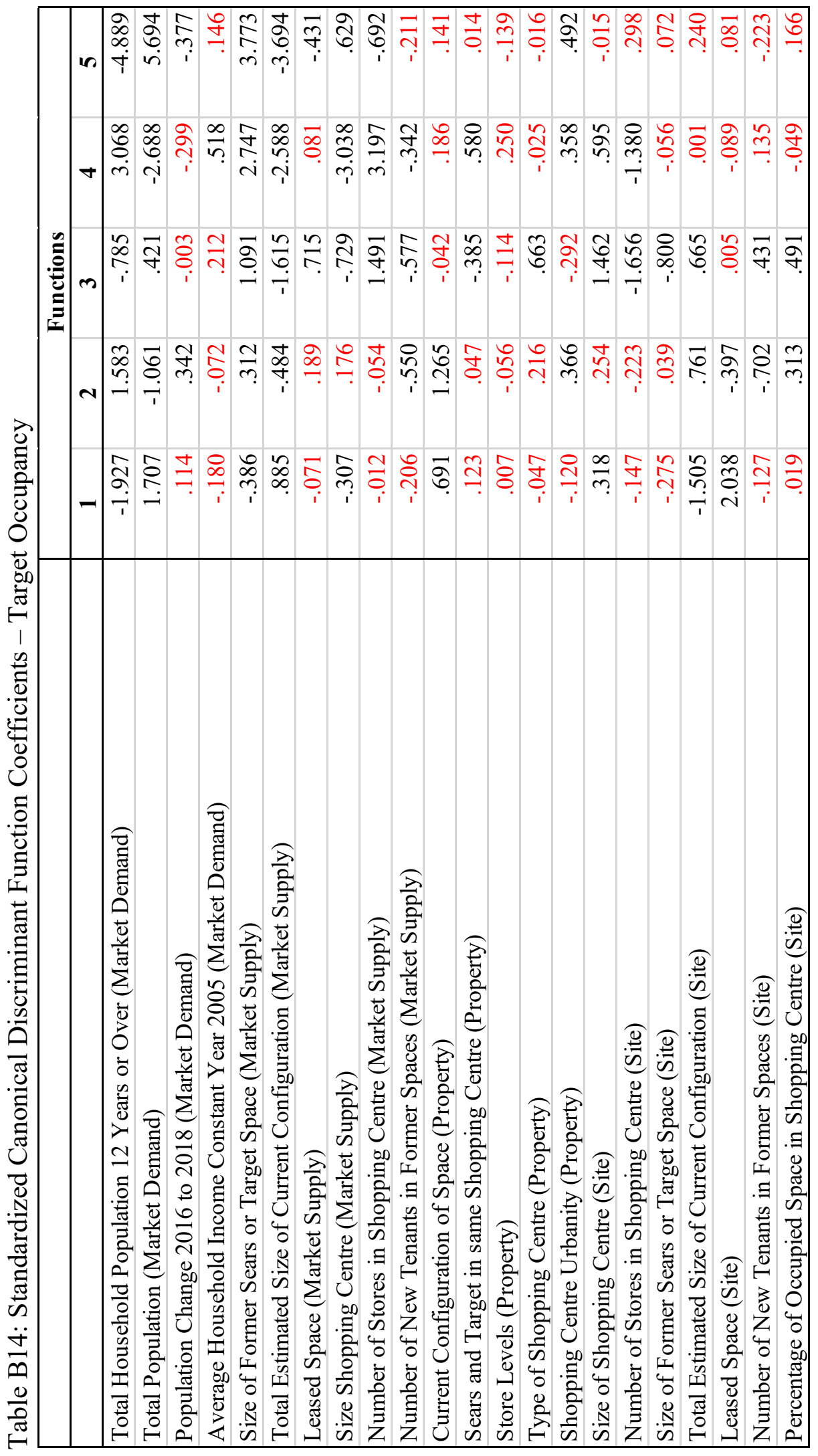




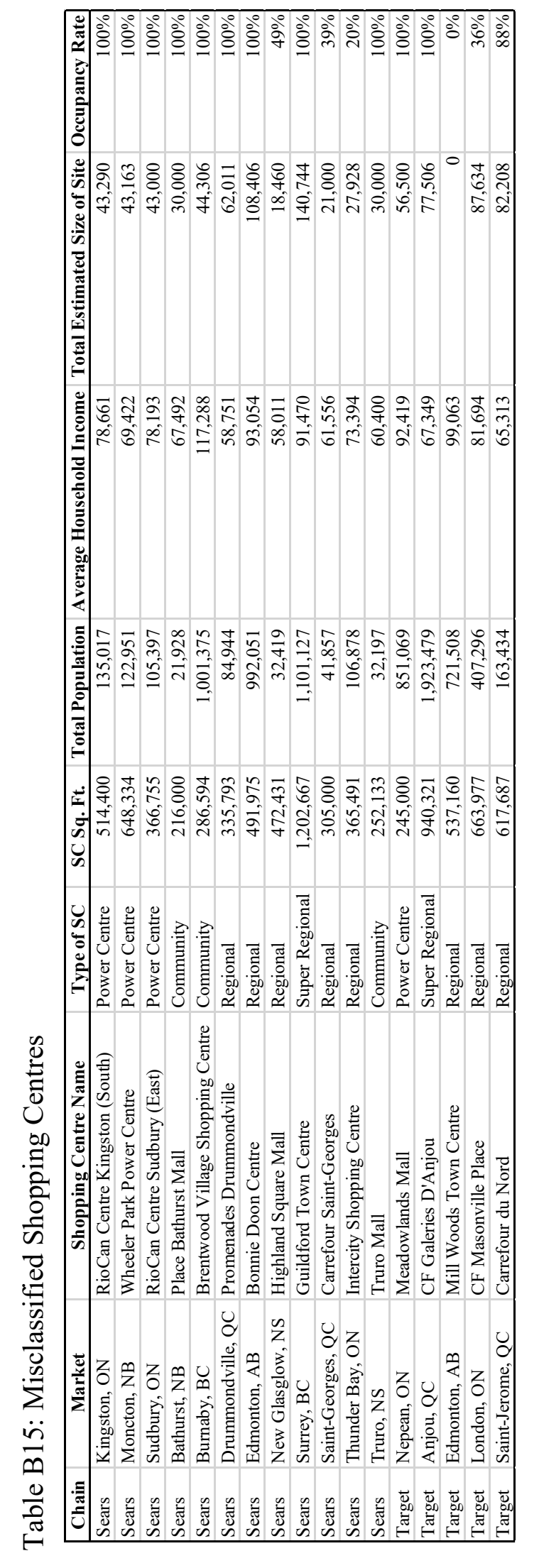




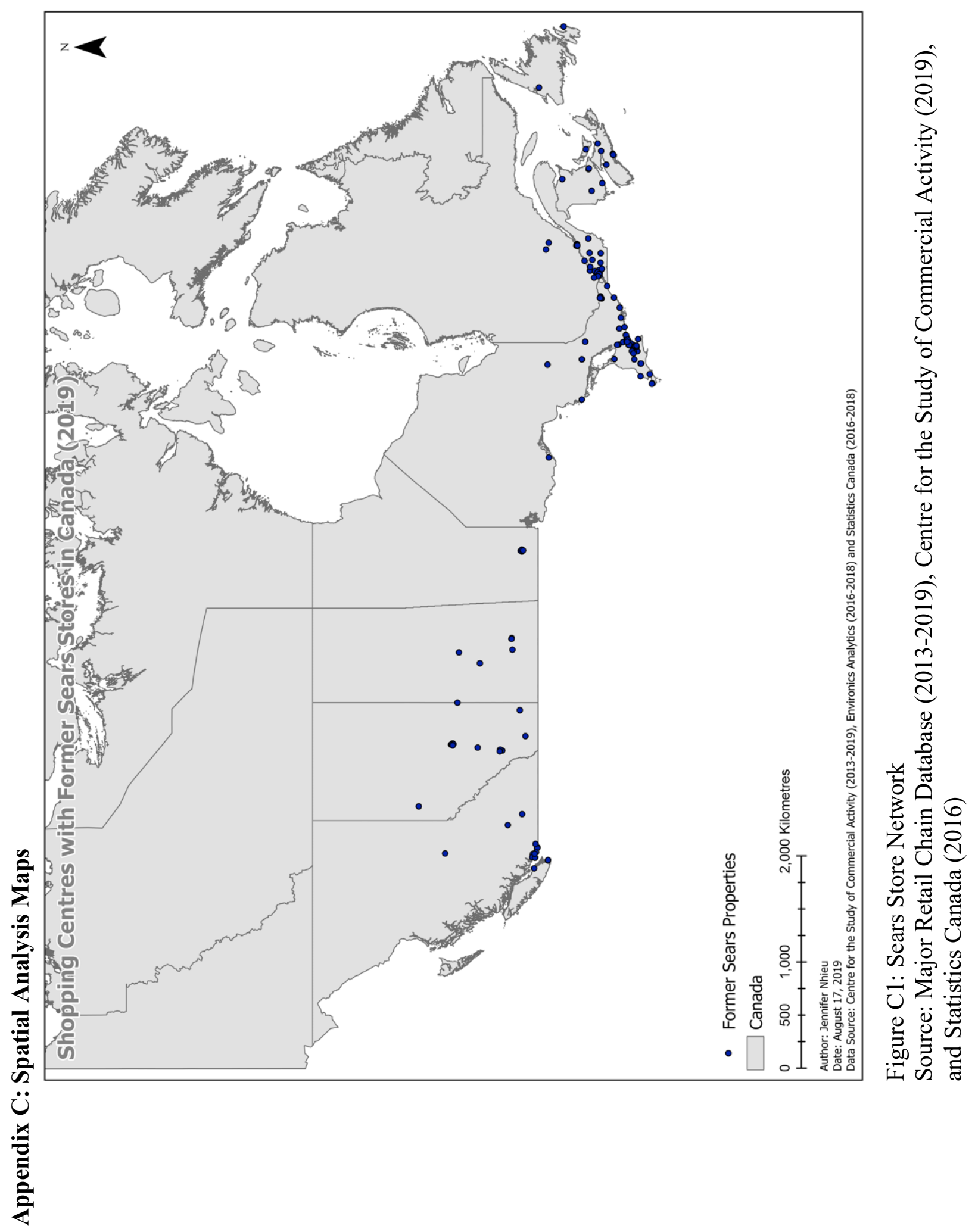




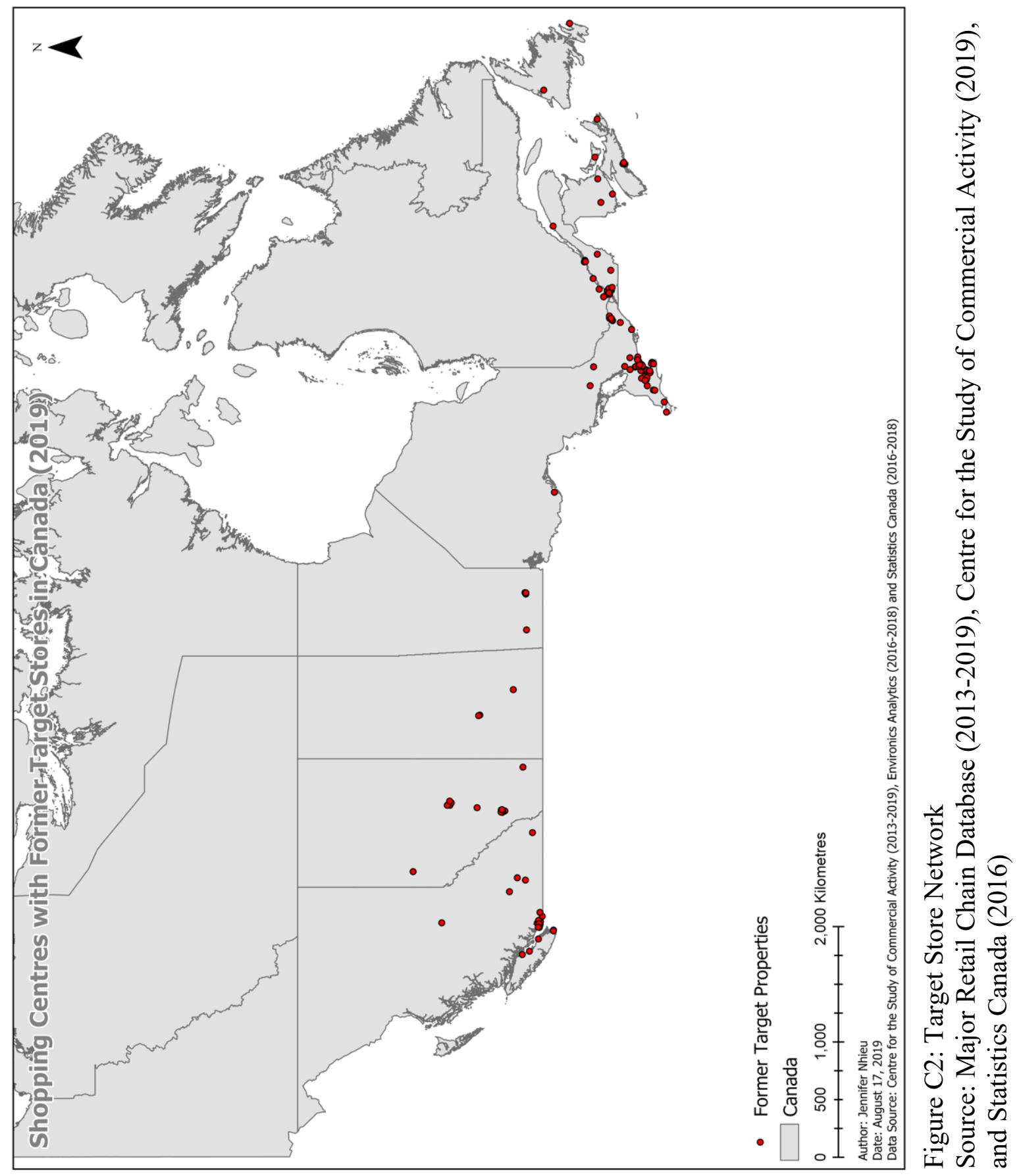




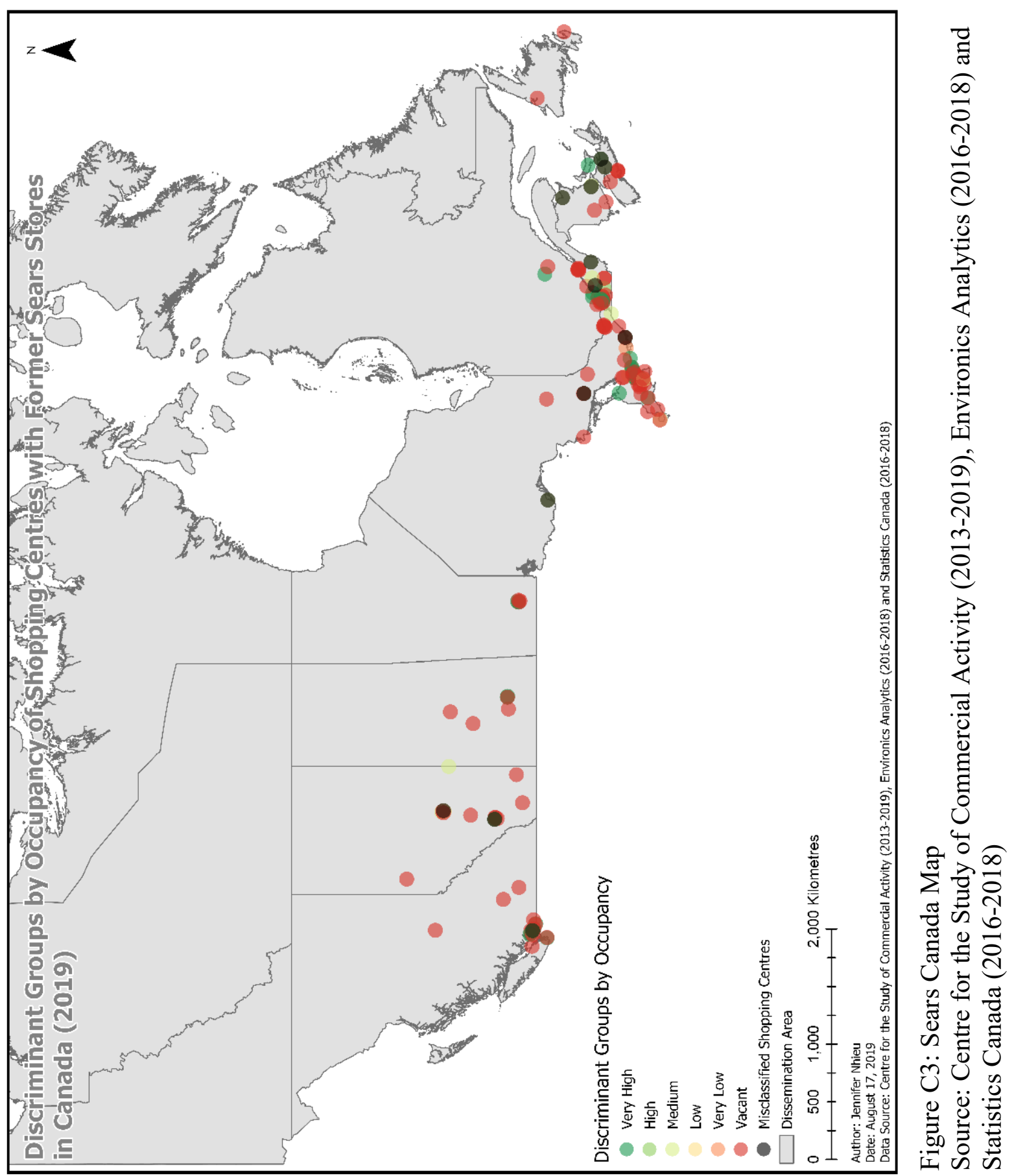




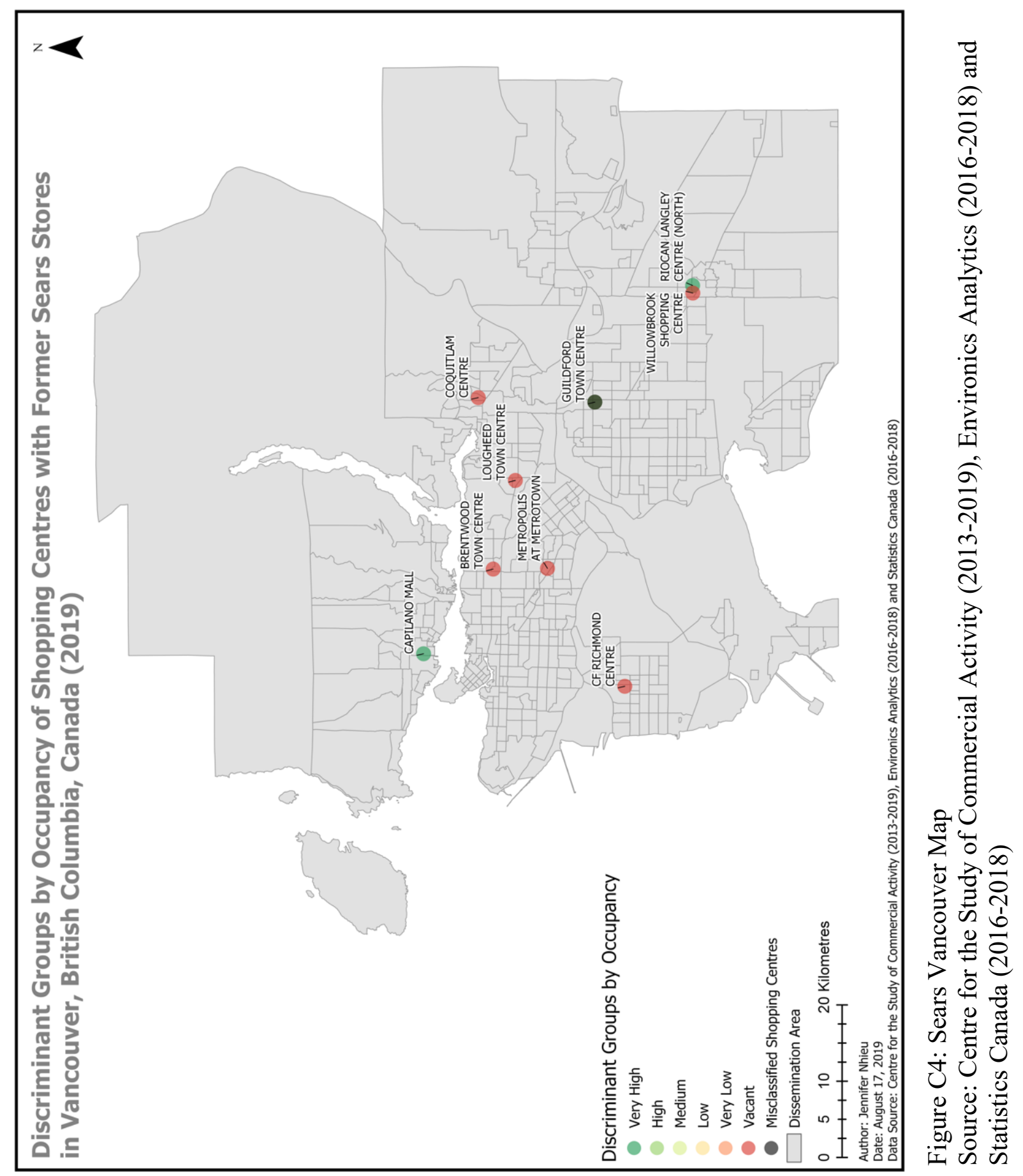




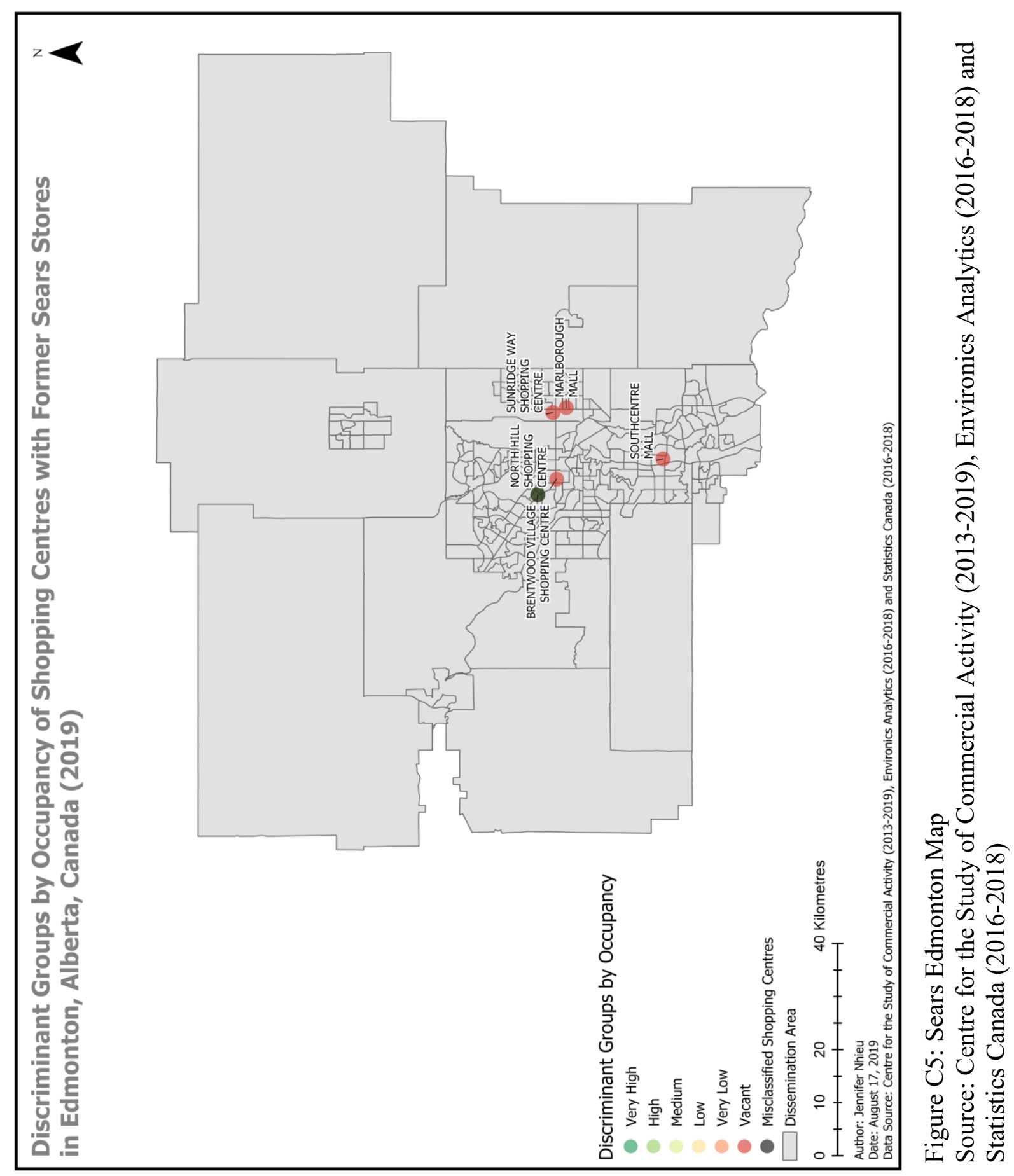




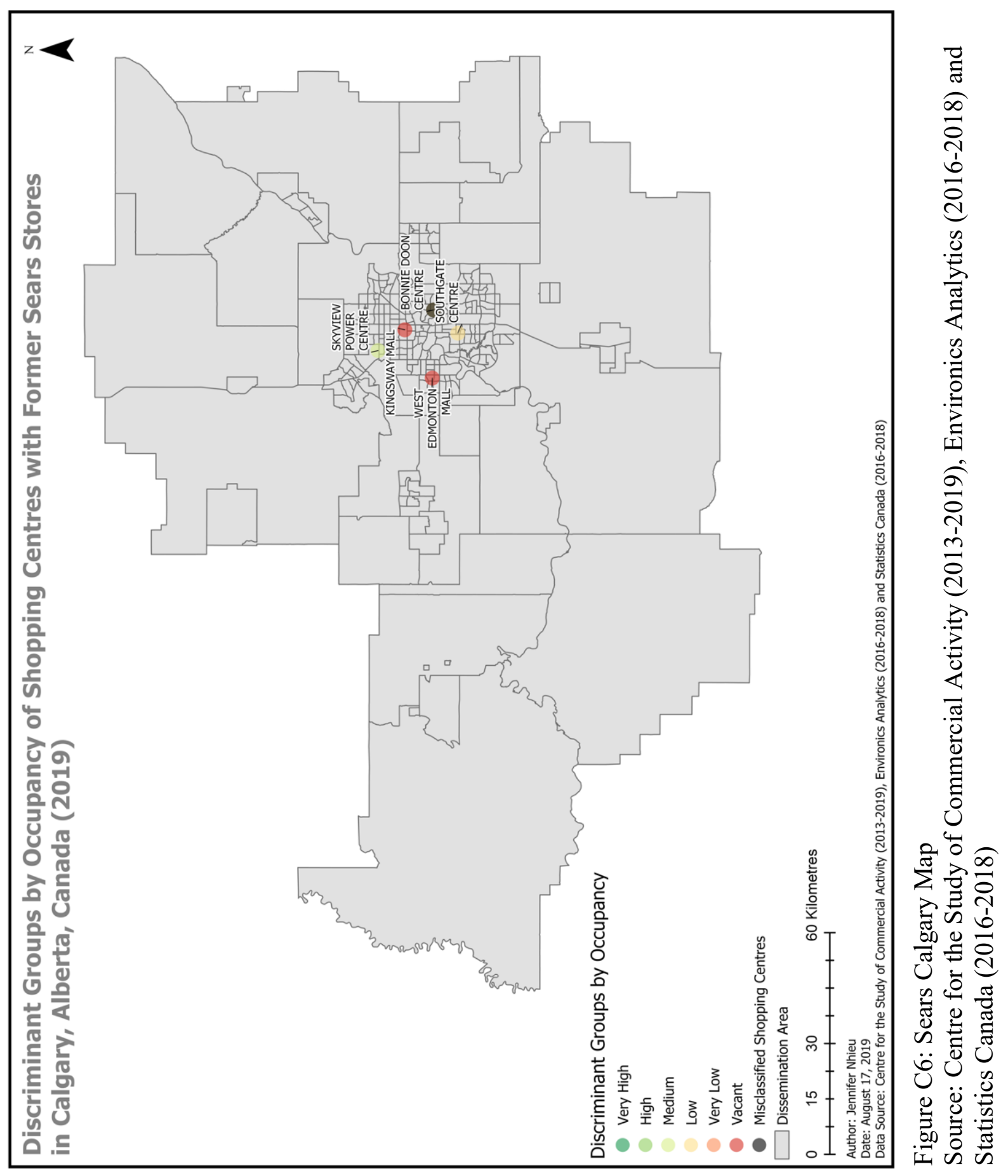




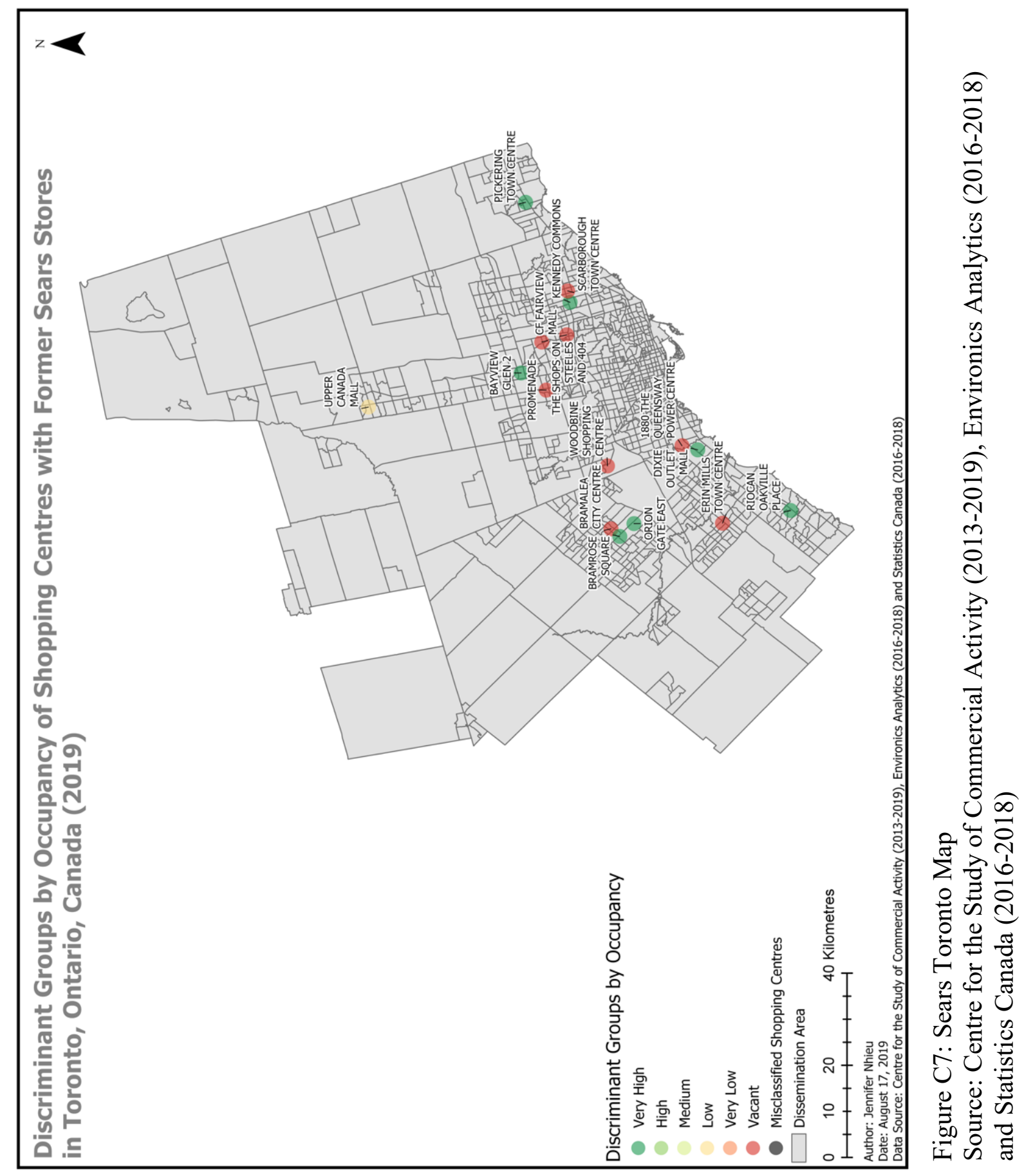




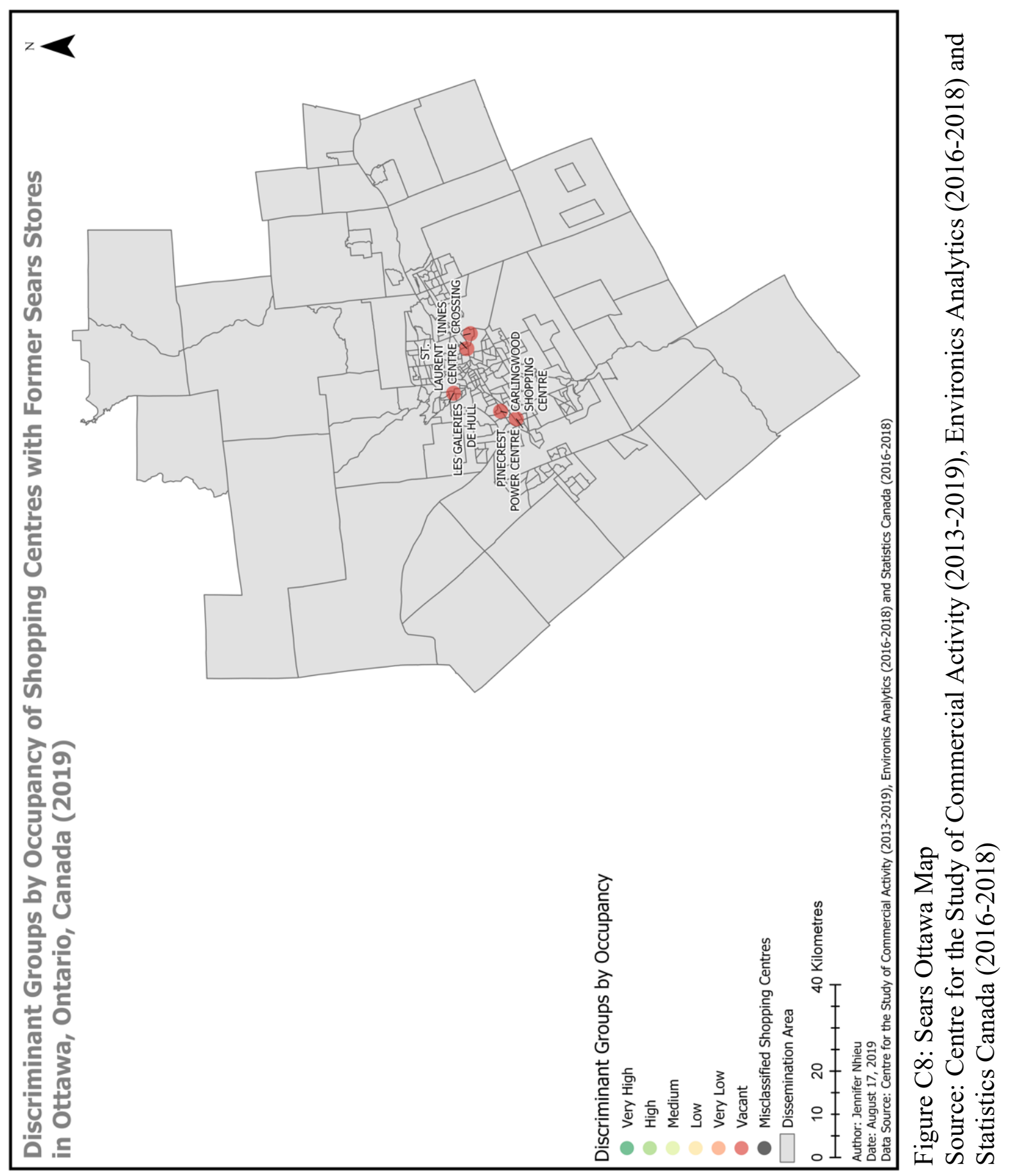




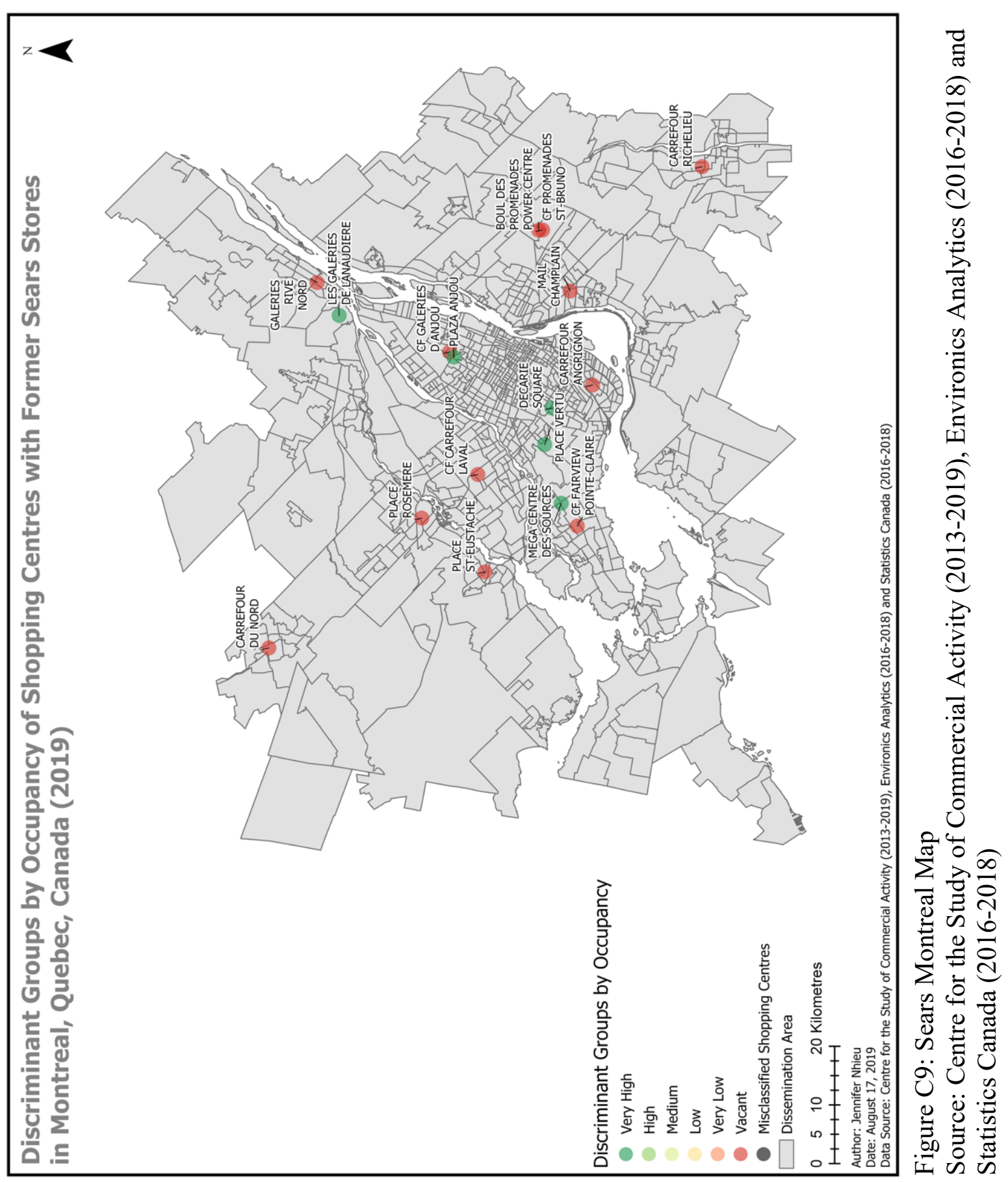




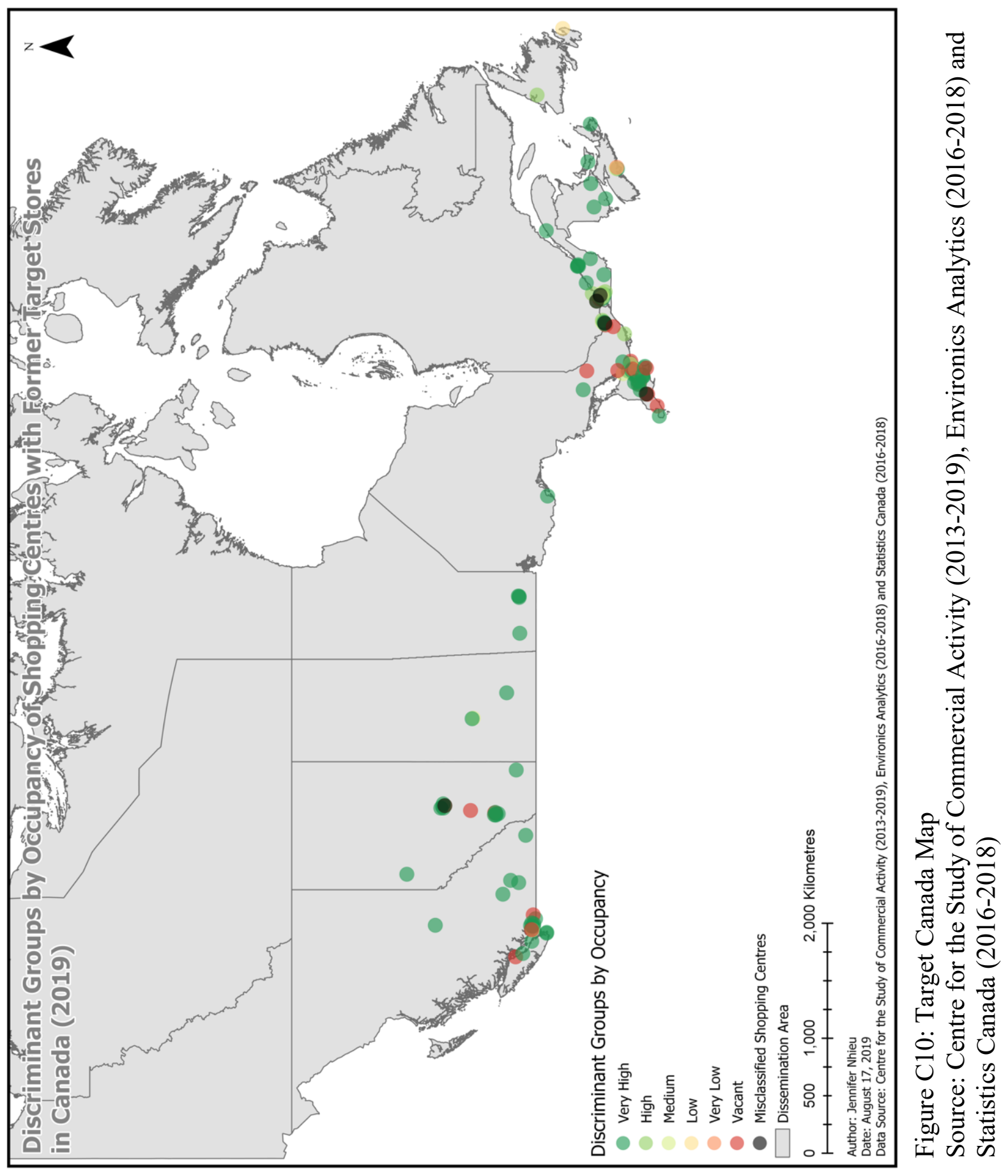




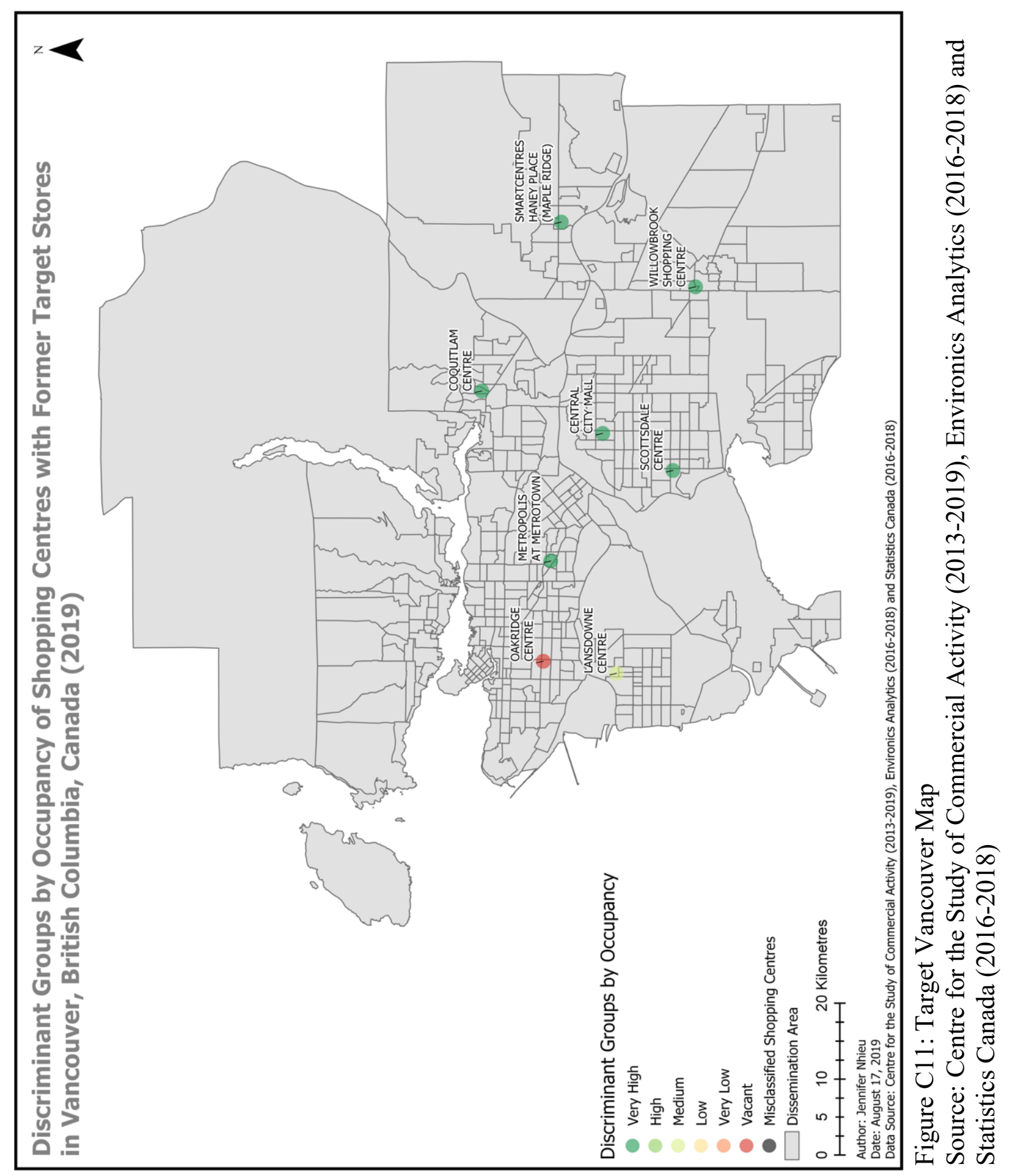




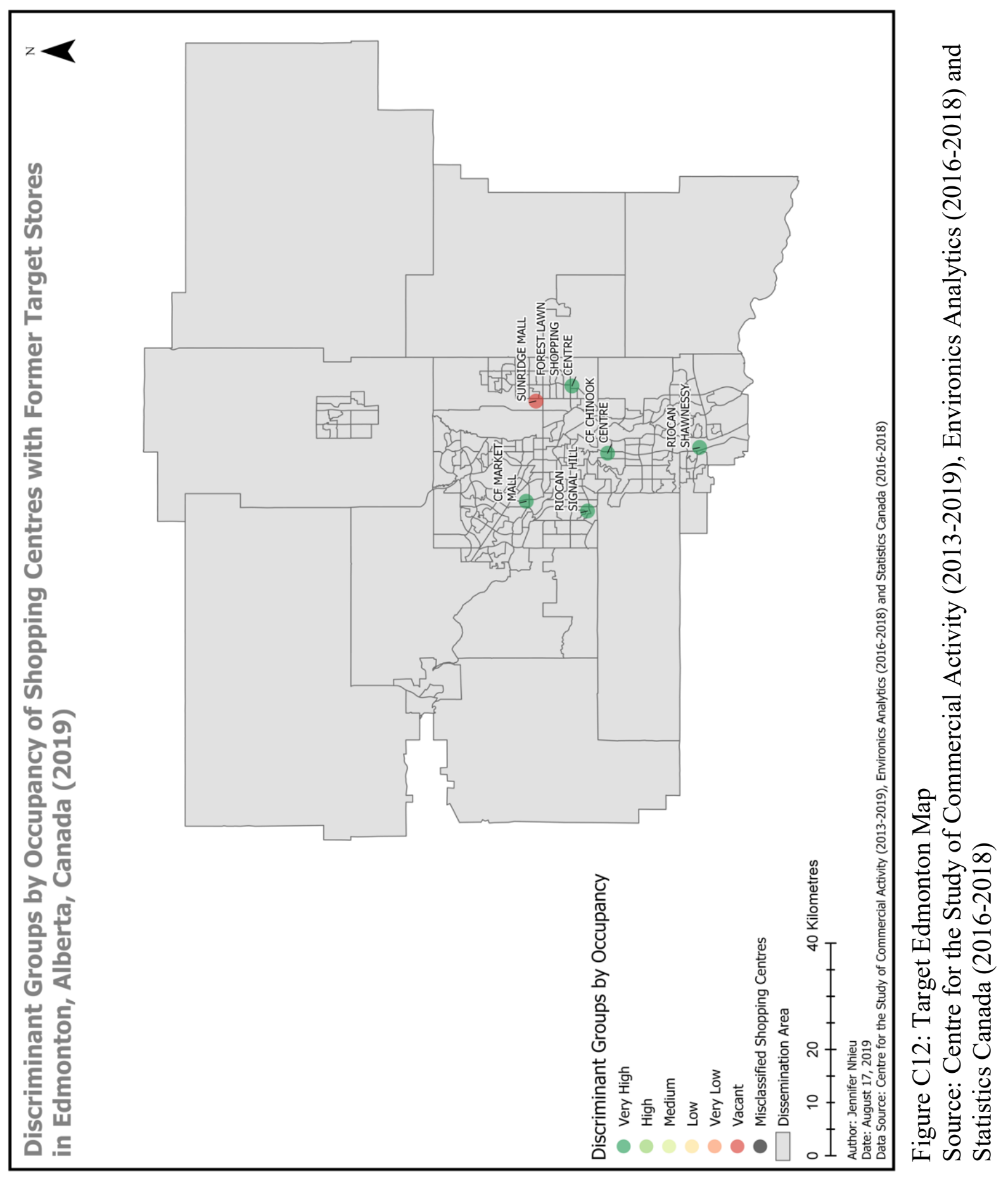




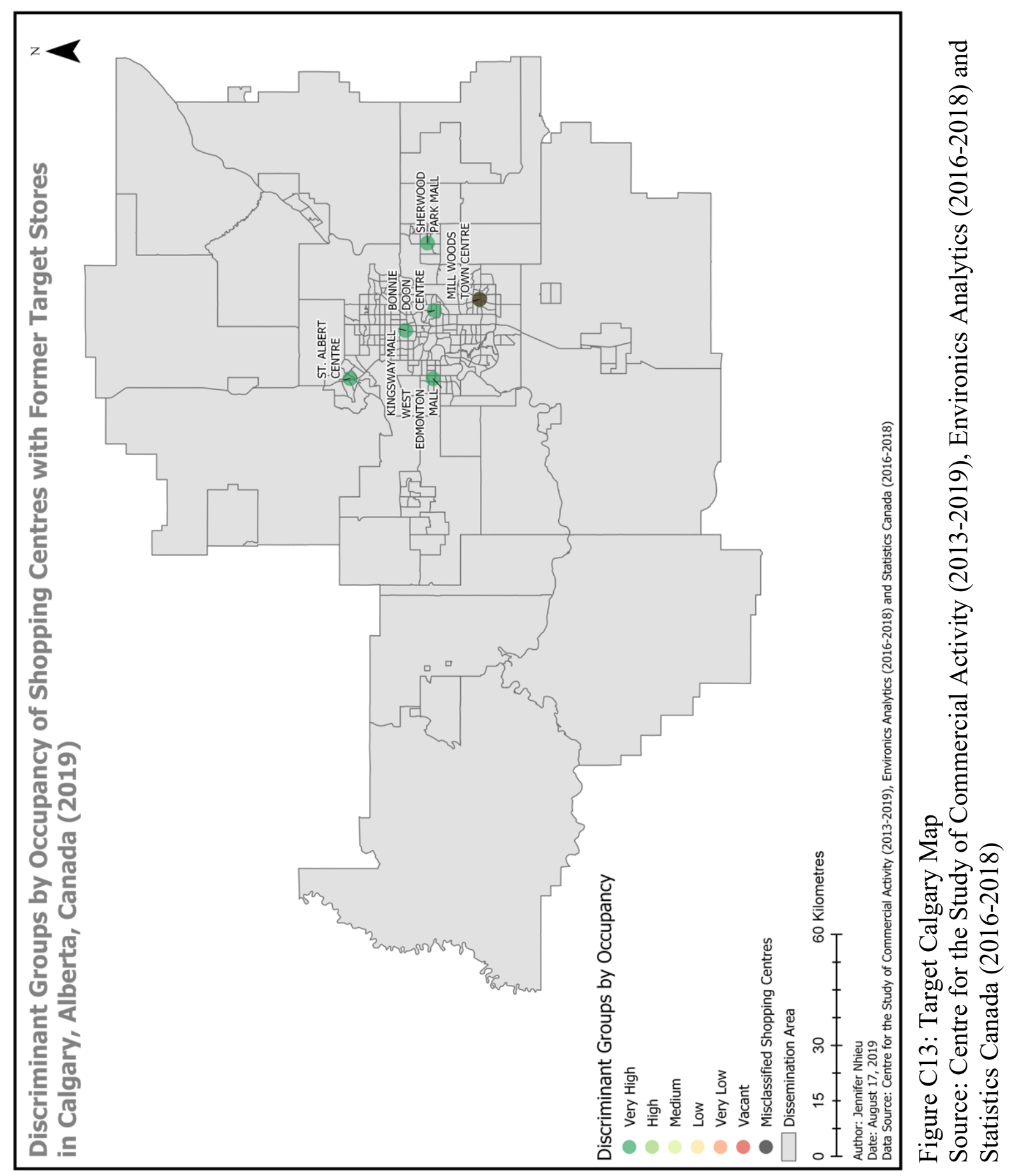




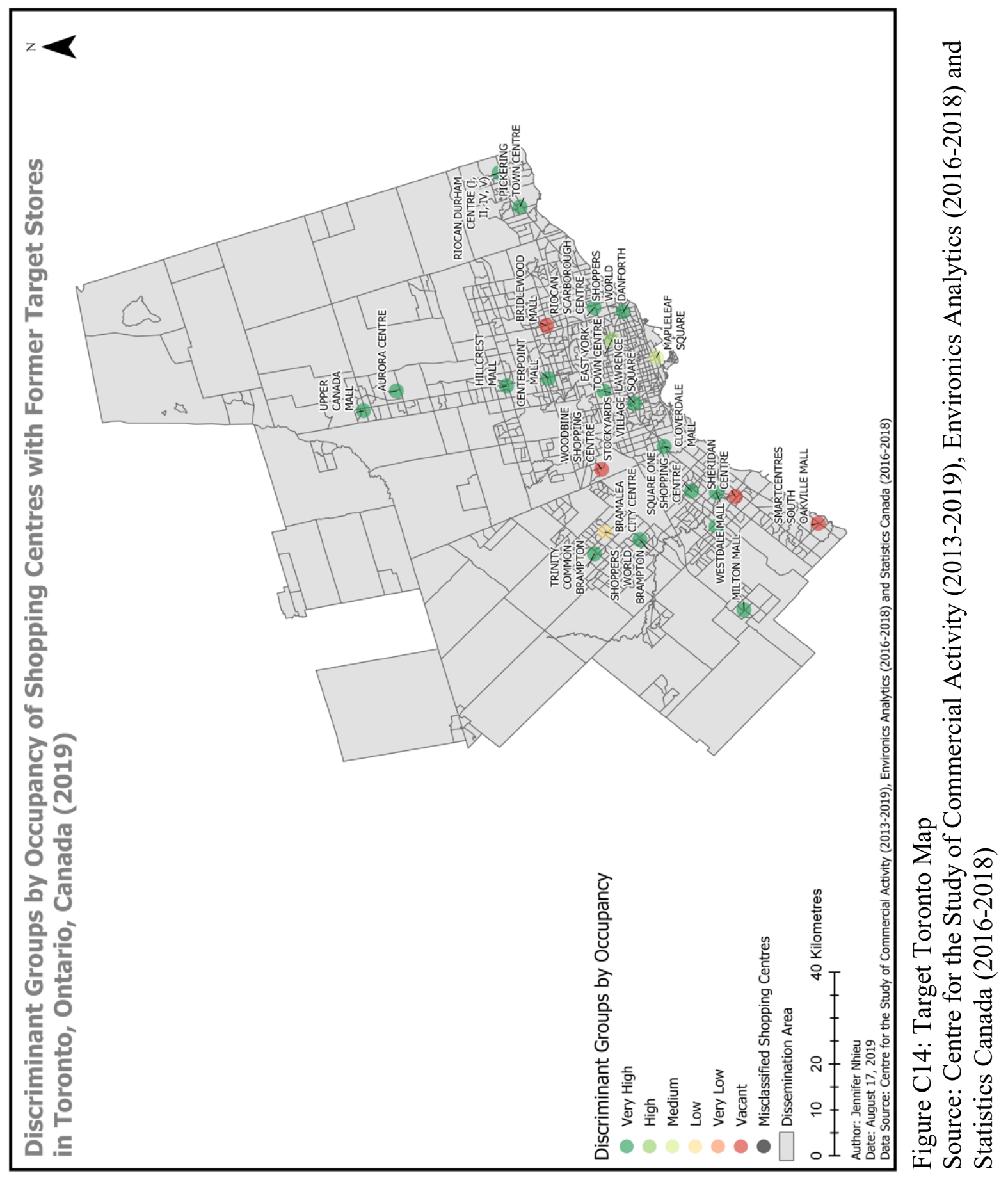




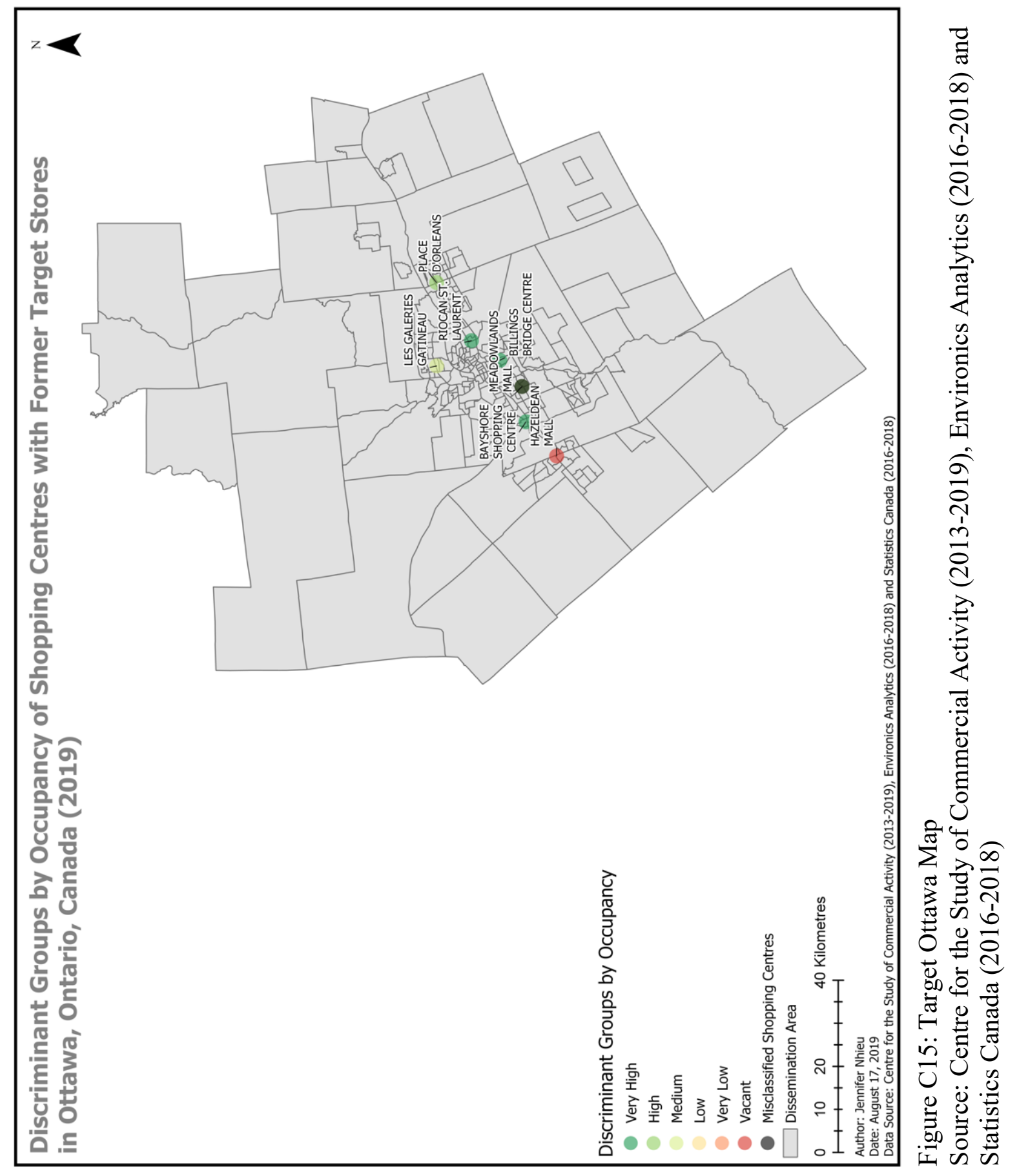




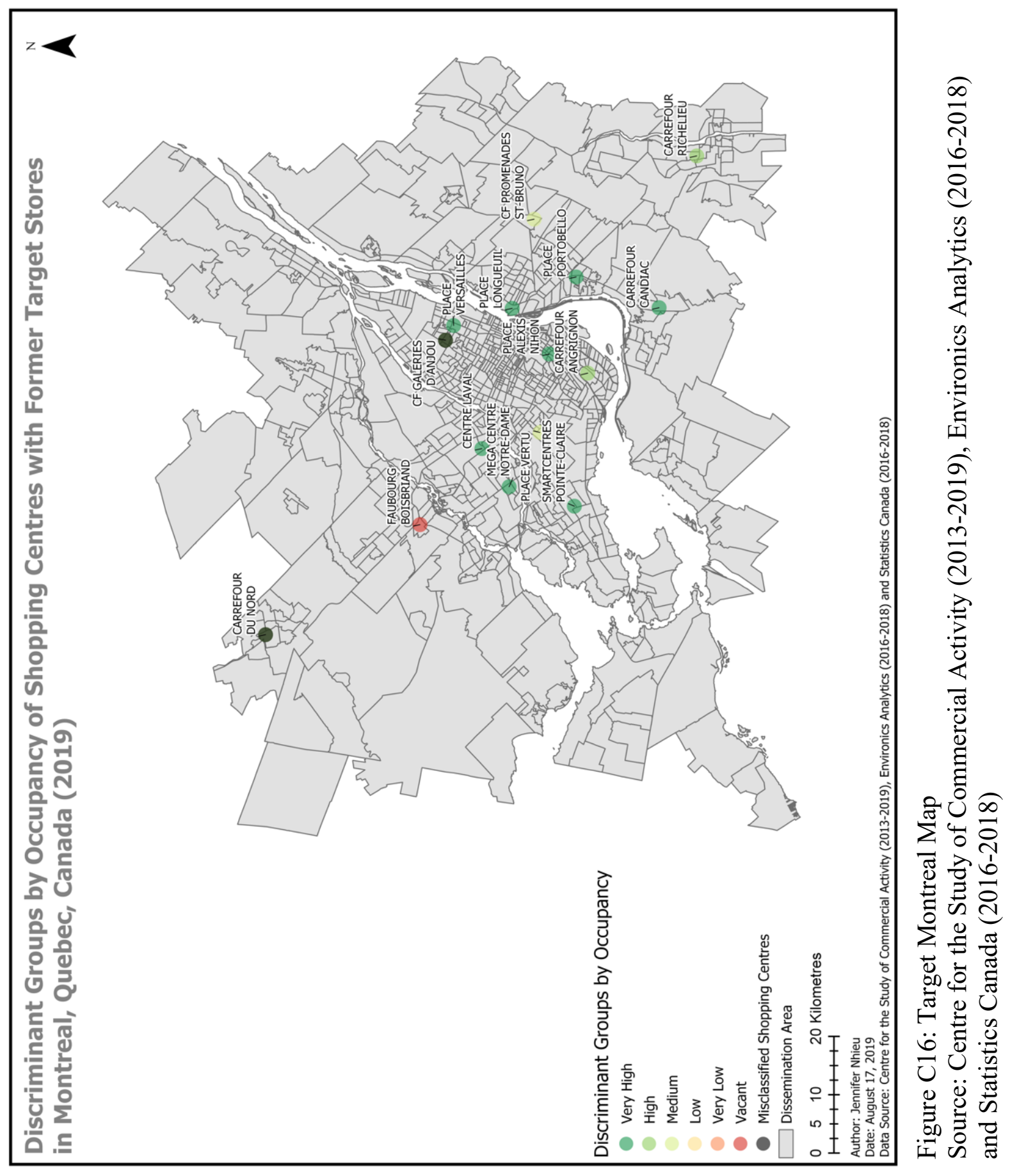




\section{References}

Applebaum, W. (1966). Methods for Determining Store Trade Areas, Market Penetration, and Potential Sales. Journal of Marketing Research, 3 (2): 127-141. DOI:10.2307/3150201.

Applebaum, W., and Cohen, S.B. (1961). The Dynamics of Store Trading Areas and Market Equilibrium 1. Annals of the Association of American Geographers, 51 (1): 73-101. DOI:10.1111/ j.1467-8306. 1961.tb00369. x.

Aoyama, Y., and Ratick, S.J. (2007). Trust, Transactions, and Information Technologies in the US Logistics Industry. Economic Geography 83 (2): 159-180. DOI:10.1111/j.1944-8287. 2007.tb00341. x.

Backstrom, K. (2006). Understanding Recreational Shopping: A New Approach. International Review of Retail, Distribution and Consumer Research. 16 (2): 143-158. DOI:10.1080/ 09593960600572167.

Bayus, B. L. (1994). Are Product Life Cycles Really Getting Shorter? Journal of Product Innovation Management, 11 (1): 300-308. DOI:10.1016/0737-6782(94)90085-X.

Bonacich, E., and Wilson, J.B. (2005). Hoisted by Its Own Petard: Organizing Wal-Mart's Logistics Workers. In New Labor Forum. 14, 67-75. New York: Queens College Labor Resource Center.

Carter, C. (2009). Review Articles: What We Know about Shopping Centers. Journal of Real Estate Literature. 17 (2): 163-180.

CBC News. (2018). Tenant found for former Sears store in Bonnie Doon mall. Retrieved from https://www.cbc.ca/news/canada/edmonton/tenant-found-for-former-sears-store-inbonnie-doon-mall-1.4665905

Chakrapani, C, Lea, T., and Hernandez, T. (2006). Market segmentation: A practitioner's guide. The Centre for the Study of Commercial Activity, Ryerson University, Toronto, Ontario.

Chebat, J. C., Michon, R., Haj-Salem, N., and Oliveira, S. (2014). The Effects of Mall Renovation on Shopping Values, Satisfaction and Spending Behaviour. Journal of Retailing and Consumer Services, 21 (4): 610-618. DOI: 10.1016/j.jretconser.2014.04.010.

Cohen, N.E. (2002). America's Marketplace: the history of shopping centers, International Council of Shopping Centers, Greenwich Publishing Group Inc., Lyme, Connecticut, United States.

Corkery, M. (2017). “Is American Retail at a Historic Tipping Point?” Retrieved from. https:// www.nytimes.com/2017/04/15/business/retail-industry.html 
Cui, C., Wang, J., Pu, J., and Chen, G. (2012). GIS-based Method of Delimitating Trade Area for Retail Chains. International Journal of Geographical Information Science, 26 (10): 1863-1879. DOI:10.1080/13658816.2012.661058.

Dramowicz, E. (2005). Retail Trade Area Analysis Using the Huff Model. Directions Magazine, $2(1): 13-14$.

Drezner, T. (2006). Derived Attractiveness of Shopping Malls. IMA Journal of Management Mathematics, 17 (4): 349-358. DOI:10.1093/imaman/dp1004.

Emmons, M. and Hernandez, T. (2017). The Absorption of Target Former Store Portfolio in Canada. Centre for the Study of Commercial Activity, Ryerson University. Toronto, ON.

ESRI. (2019). How Original Huff Model works. Retrieved from http://desktop.arcgis.com/en/arcmap/10.3/tools/business-analyst-toolbox/how-originalhuff-model-works.htm

Ferreira, D., and Paiva, D. (2017). The Death and Life of Shopping Malls: An Empirical Investigation on the Dead Malls in Greater Lisbon. The International Review of Retail, Distribution and Consumer Research 27 (4): 1-17. DOI:10.1080/09593969.2017.1309564.

Fong, P. (2003). What Makes Big Dumb Bells a Mega Shopping Mall. In Proceedings of the 4th International Space Syntax Symposium, London 10-11.

Ghosh, A., and McLafferty, S. (1987). Location Strategies for Retail and Service Firms. Lexington, MA: Lexington Books.

Hardwick, J.M., (2004). Mall maker: Victor Gruen, Architect of an American Dream. Philadelphia, PA: University of Pennsylvania

Hernandez, T., Lea, P., and Bermingham, P. (2004). What's in a Trade Area? Centre for the Study of Commercial Activity, Ryerson Polytechnic University.

Hernandez, T., Helik, J., and Moore, T. (2006). The Changing Character of Retail Strips in the City of Toronto: 1999 - 2005. Centre for the Study of Commercial Activity. Ryerson University.

Heschmeyer, M. (2017). RETAIL OUTLOOK: Shopping center owners brace for more downsizing as space rationalization still in Early Stages. CoStar.

Huff, D. L. (1963). A Probabilistic Analysis of Shopping Center Trade Areas. Land Economics, 39 (1): 81-90. DOI:10.2307/3144521. 
IBM. (2018). KMO and Bartlett's Test. Retrieved from https://www.ibm.com/support/knowledgecenter/en/SSLVMB_24.0.0/spss/tutorials/fac_te lco_kmo_01.html

International Council of Shopping Centers. (2017). Canada Shopping-Centre Classification and Typical Characteristics. Retrieved from https://www.icsc.org/uploads/t07subpage/Canada_Shopping_Center_Definition_Standard_v2.pdf

Klecka, W. R. (1980). Quantitative Applications in the Social Sciences: Discriminant analysis. Thousand Oaks, CA: SAGE Publications, Inc. DOI: 10.4135/9781412983938

Kline, D. B. (2017). Changing retail: Is everything you know about 'retail apocalypse' wrong? USA Today. Retrieved from https://www.usatoday.com/story/money/business/2017/09/21/ is-everything-you-knowabout-the-retail-apocalypse-wrong/105809518/

Konishi, H., and Sandfort, M. T. (2003). Anchor stores. Journal of Urban Economics, 53 (3): 413-435. https://DOI.org/10.1016/S0094-1190(03)00002-0

Kowinski, W.S. (1985). The Malling of America, W. Morrow Publishers, New York, United States.

Lambert. J. (2008). Healthy Growth in the Canadian Shopping Center Industry, ICSC Research Review, 15(2): 15-18., International Council of Shopping Centers, New York, United States.

LeHew, M. L., and Fairhurst, A.E. (2000). US Shopping Mall Attributes: An Exploratory Investigation of Their Relationship to Retail Productivity. International Journal of Retail \& Distribution Management, 28 (6): 261-279. DOI:10.1108/09590550010328535.

Lord, N. (2014). What is Data Integrity? Data Protection 101. Retrieved from https://digitalguardian.com/blog/what-data-integrity-data-protection-101

Lowry, J. R. (1997). The Life Cycle of Shopping Centers. Business Horizons, 40 (1): 77-86. DOI:10.1016/S0007-6813(97)90029-X.

Mejia, L.C. and Eppli, M.J. (2003). Inter-center retail externalities. Journal of Real Estate Finance and Economics, 27 (3): 321-33.

Miceli, T., Sirmans, C., and Stake, D. (1998). Optimal Competition and Allocation of Space in Shopping Centers. Journal of Real Estate Research, 16 (1): 113-126.

Miller, L. J. (2008). Reluctant Capitalists: Bookselling and the Culture of Consumption. Chicago, IL: University of Chicago Press. 
Oxford Properties. (2019a). The Food District. Retrieved from https://shopsquareone.com/thefooddistrict

Oxford Properties. (2019b). The Rec Room. Retrieved from https://shopsquareone.com/therecroom

Parlette, V., and Cowen, D. (2011). Dead Malls: Suburban Activism, Local Spaces, Global Logistics. International Journal of Urban and Regional Research, 35 (4): 794-811. DOI:10.1111/ijur.2011.35. issue 4.

Parli, R., and Miller, N. (2017). Market Equilibrium Analysis. The Appraisal Journal, 85 (4): 307-316

Peiser, R., and Xiong, J. (2003). Crime and Town Centers: Are Downtowns More Dangerous Than Suburban Shopping Nodes? Journal of Real Estate Research, 25 (4): 577-606.

Peterson, H. (2017). The retail apocalypse has officially descended on America. Business Insider. Retrieved from http://www.businessinsider.com/the-retail-apocalypse-hasofficially-descended-on-america-2017-3

Pitt, M., and Musa, Z.N. (2009). Towards Defining Shopping Centres and Their Management Systems. Journal of Retail \& Leisure Property 8 (1): 39-55. DOI:10.1057/rlp.2008.25.

Rabianski, J. S. (2002). Vacancy in market analysis and valuation. The Appraisal Journal, 70(2), 191-199.

Rajaretnam, T. (2015). Statistics for Social Sciences. Retrieved from https://bit.ly/2JvNxAv

Reimers, V., and Clulow, V. (2009). Retail Centres: It's Time to Make Them Convenient. International Journal of Retail \& Distribution Management, 37 (7): 541-562. DOI:10.1108/09590550910964594.

Remøy, H. (2010). Out of Office: A Study on the Cause of Office Vacancy and Transformation to Cope and Prevent. Retrieved from https://repository.tudelft.nl/islandora/object/uuid:9c24b779-1c61-4a88-921a$04 \mathrm{~d} 3 \mathrm{e} 12 \mathrm{a} 8 \mathrm{e} 46$ ? collection $=$ research

Retail Council of Canada. (2018). Canadian Shopping Centre Study 2018. Retrieved from https://www.retailcouncil.org/wp-content/uploads/2018/12/RCC-Canadian-ShoppingCentre-Study-2018_EN_Final-Rev1.pdf

RioCan. (2017). RioCan REIT Expects Minimal Impact from Sears Store Closures. Retrieved from https://investor.riocan.com/English/investor-relations/press-releases/press-releasedetails/2017/RioCan-REIT-Expects-Minimal-Impact-from-Sears-StoreClosures/default.aspx 
Rushe, D. (2017). Big, bold... and broken: Is the US shopping mall in a fatal decline? The Observer. Retrieved from https://www.theguardian.com/us-news/2017/jul/22/mall-ofamerica-minnesota-retail-anniversary

Sanburn, J. (2017). Why the Death of Mall Is about More than Shopping? Retrieved from http://time.com/4865957/death-and-life-shopping-mall/

Sears Canada Inc. (2016). Sears Canada Reports Second Quarter Results. Retrieved from http://collabora.wsp.com.mx

Shanmugam, R. (2013). Anchor-store quality in malls: An economic analysis. International Journal of Retail \& Distribution Management, 41(2), 90-112.

doi:10.1108/09590551311304301

Smith, H. and Hay, D. (2005). Streets, malls, and supermarkets. Journal of Economics and Management Strategy, 14 (1): 29-59.

Statistics Canada. (2019). Age of Maintainer Data Tables, 2016 Census. Retrieved from https://www12.statcan.gc.ca/census-recensement/2016/dp-pd/dt-td/Rpeng.cfm? TABID $=2 \&$ Lang $=\mathrm{E} \& \mathrm{APATH}=3 \& \mathrm{DETAIL}=0 \& \mathrm{DIM}=0 \& \mathrm{FL}=\mathrm{A} \& \mathrm{FREE}=0 \& \mathrm{GC}$ $=0 \& \mathrm{GID}=1341679 \& \mathrm{GK}=0 \& \mathrm{GRP}=1 \& \mathrm{PID}=110568 \& \mathrm{PRID}=10 \& \mathrm{PTYPE}=109445 \& \mathrm{~S}=0 \&$ SHOWALL $=0 \&$ SUB $=0 \&$ Temporal $=2017 \&$ THEME $=121 \& \mathrm{VID}=0 \& \mathrm{VNAMEE}=\& \mathrm{VNA}$ $\mathrm{MEF}=\& \mathrm{D} 1=0 \& \mathrm{D} 2=0 \& \mathrm{D} 3=0 \& \mathrm{D} 4=0 \& \mathrm{D} 5=0 \& \mathrm{D} 6=0$

Statistics How To. (2018a). Durbin Watson Test \& Test Statistic. Retrieved from https://www.statisticshowto.datasciencecentral.com/durbin-watson-test-coefficient/

Statistics How To. (2018b). What is the Kaiser-Meyer-Olkin (KMO) Test? Retrieved from https://www.statisticshowto.datasciencecentral.com/kaiser-meyer-olkin/

Statistics Solutions. (2019). Pearson's Correlation Coefficient. Retrieved from https://www.statisticssolutions.com/pearsons-correlation-coefficient/

Suhr, D. (2005). Principal Component Analysis vs. Exploratory Factor Analysis. Retrieved from http://www2.sas.com/proceedings/sugi30/203-30.pdf

The Analysis Factor. (2017). The Fundamental Difference Between Principal Component Analysis and Factor Analysis. Retrieved from https://www.theanalysisfactor.com/thefundamental-difference-between-principal-component-analysis-and-factor-analysis/

Techopedia. (2018). Data Integrity. Retrieved from https://www.techopedia.com/definition/811/data-integrity-databases 
Tokosh, J. (2018). Is the Macy's in my mall going to close? Uncovering the factors associated with the closures of Macy's, Sears, and J.C. Penney stores. Growth and

Change. 2019; 50: 403- 423. https://DOI-

org.ezproxy.lib.ryerson.ca/10.1111/grow.12269

Turley, L. W., and Chebat, J.C. (2002). Linking Retail Strategy, Atmospheric Design and Shopping Behaviour. Journal of Marketing Management, 18 (1-2): 125-144. DOI:10.1362/0267257022775891.

Wilhelm, W. B., and Mottner, S. (2005). Teens and Shopping Mall Preferences: A Conjoint Analysis Approach to Understanding the Generation Shift toward an Experience Economy. Journal of Shopping Center Research 12 (1): 23-52.

Yeates, M., Hernandez, T., and Murray, A. (2015). Shopping Centres in Canada in a Time of Uncertainty. Centre for the Study of Commercial Activity. Ryerson University. 